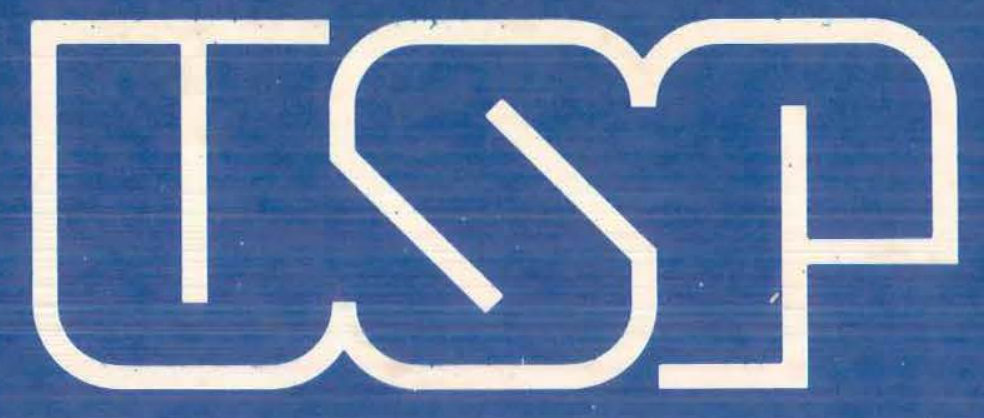

Campus de São Carlos

ESTUDO E APLICAÇÃO DE MODELOS CONSTITUTIVOS PARA O CONCRETO FUNDAMENTADOS NA MECÂNICA DO DANO CONTÍNUO

AUTOR: JOSÉ JULIO DE CERQUEIRA PITUBA ORIENTADOR: PROF. DR. SÉRGIO P.B. PROENÇA

UNIVERSIDADE DE SÃO PAULO

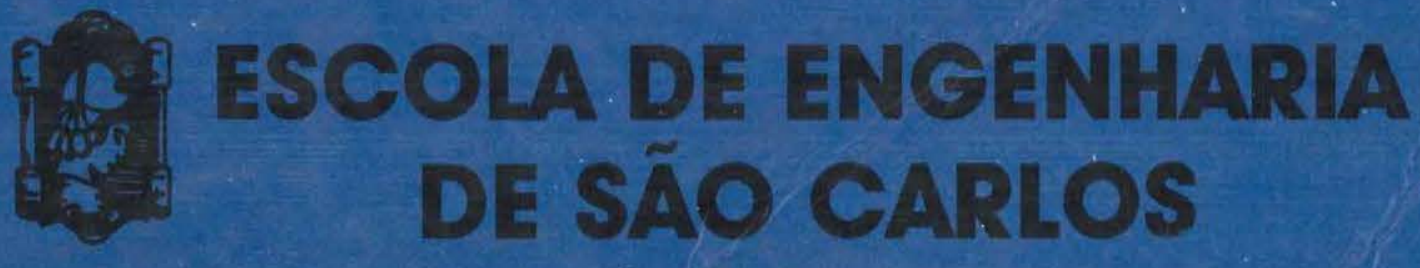




\section{ESTUDO E APLICAÇÃO DE MODELOS CONSTITUTIVOS PARA O CONCRETO FUNDAMENTADOS NA MECÂNICA DO DANO CONTÍNUO}
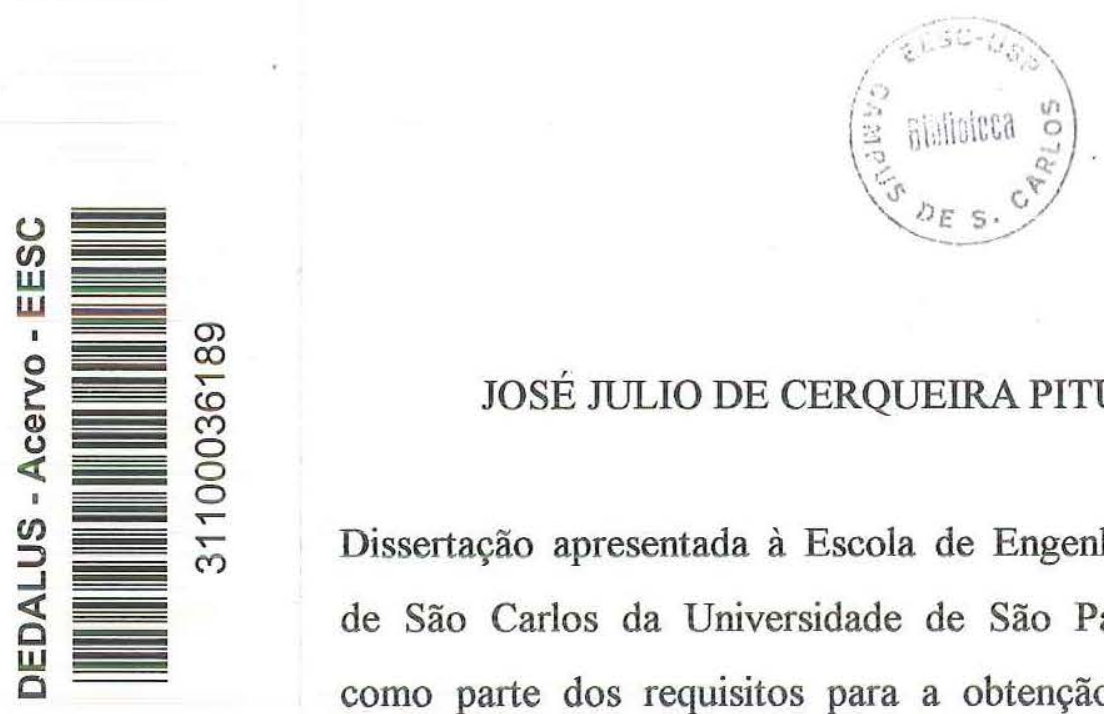

JOSÉ JULIO DE CERQUEIRA PITUBA

Dissertação apresentada à Escola de Engenharia de São Carlos da Universidade de São Paulo, como parte dos requisitos para a obtenção do título de Mestre em Engenharia de Estruturas

ORIENTADOR: PROF. DR. SÉRGIO PERSIVAL BARONCINI PROENÇA 


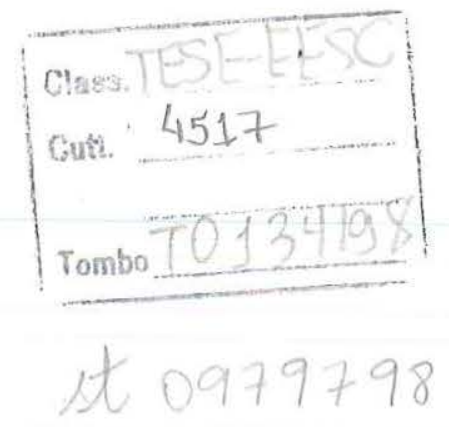

Ficha catalográfica preparada pela Seção de Tratamento da Informação do Serviço de Biblioteca - EESC-USP

Pituba, José Julio de Cerqueira
P692e Estudo e aplicação de modelos constitutivos para o concreto fundamentados na mecânica do dano contínuo / José Julio de Cerqueira Pituba. -São Carlos, 1998.

Dissertação (Mestrado) -- Escola de Engenharia de São Carlos-Universidade de São Paulo, 1998.

Área: Engenharia de Estruturas.

Orientador: Prof. Dr. Sérgio Persival Baroncini Proença.

1. Concreto. 2. Modelos constitutivos.

3. Mecânica do dano. I. Título. 
Aos que considero como meus pais:

Giovane, Márcia, Gérdson e Gláucia, minhas irmãs Márcia Thaysa e Juliana,

Camila. 


\section{AGRADECIMENTOS}

Ao Prof. Dr. Sérgio Persival Baroncini Proença, pela grande orientação, paciência, apoio e amizade demonstrados durante a realização deste trabalho.

A Manoel da Silva Álvares pela importante contribuição para o desenvolvimento deste trabalho.

Aos amigos Luciano, Luciano Jorge, Prof. Abel Galindo, Alexandre, Romel e Arthur entre outros, pela ajuda e amizade nas horas alegres e dificeis.

Ao LMT (Laboratoire de Mécanique et Technologie - Université Paris VI) pela utilização do programa EFICoS.

Ao $\mathrm{CNPq}$ e FAPESP, pelo apoio financeiro que possibilitou a realização deste trabalho.

A DEUS, por tudo. 
LISTA DE FIGURAS

LISTA DE TABELAS iv

LISTA DE SÍMBOLOS V

RESUMO Xi

ABSTRACT xii

1 INTRODUÇÃO

1.1 CONSIDERAÇÕES PRELIMINARES E SÍNTESE DO CONTEÚDO 1

1.2 COMENTÁRIOS SOBRE MODELOS CONSTITUTIVOS PARA O

CONCRETO 3

1.2.1 Introdução 3

1.2.2 Formulação Secante 4

1.2.3 Formulação Tangente 5

1.2.4 Modelo Físico da Microestrutura 6

1.2.5 Formulação com Plasticidade e Dano 6

$\begin{array}{ll}\text { 1.2.6 Modelo Constitutivo com Dano } & 7\end{array}$

1.3 ALGUNS ASPECTOS DO COMPORTAMENTO MECÂNICO DO

CONCRETO 9

1.3.1 Introdução 9

1.3.2 Aspectos da Anisotropia do Dano 10

1.3.3 Deformações Permanentes 14

1.3.4 Aspecto Unilateral no Comportamento Mecânico do Concreto 15

$\begin{array}{ll}\text { 1.3.5 Evidências Experimentais de Dano no Concreto } & 17\end{array}$

2 COMENTÁRIOS SOBRE A MECÂNICA DO DANO CONTÍNUO 25

2.1 INTRODUÇÃO 25

2.1.2 Generalidades 26

2.1.3 Definição da Variável de Dano 
2.1.4 Definição da Tensão Efetiva 31

2.2 FUNDAMENTOS DA TERMODINÂMICA 35

2.2.1 Considerações Gerais 35

2.2.2 Primeira Lei da Termodinâmica 36

2.2.3 Segunda Lei da Termodinâmica 40

2.2.4 A desigualdade de Clausius-Duhem 41

2.2.5 Método do Estado Local 43

2.2.5.1 Potencial de Estado Termodinâmico 44

2.2.5.2 Potenciais de Dissipação 47

2.3 FORMALISMO DA MECÂNICA DO DANO CONTÍNUO 48

3 MODELOS CONSTITUTIVYOS PARA O CONCRETO 56

3.1 INTRODUÇÃO 56

3.2 MODELO CONSTITUTIVO DE MAZARS (1984) 57

3.2.1 Modelo Constitutivo com Variável Escalar de Dano e Carregamento

$\begin{array}{ll}\text { Proporcionalmente Crescente } & 57\end{array}$

3.2.2 Modelo de Dano Unilateral de Mazars 66

3.3 MODELO CONSTITUTIVO DE LA BORDERIE, MAZARS \& PIJAUDIER-CABOT (1991) 72

3.4 MODELO CONSTITUTIVO DE FLOREZ-LÓPEZ 80

3.4.1 Modelo Constitutivo de ÁLVARES (1998) 91

4 EXEMPLOS DE APLICAÇÃO E ANÁLISE DE RESULTADOS 98

4.1 INTRODUÇÃO 98

4.2 VIGAS EM CONCRETO ARMADO 99

4.2.1 Características das Vigas Ensaiadas 99

$\begin{array}{ll}\text { 4.2.2 Análise Numérica } & 100\end{array}$

4.3 PÓRTICO EM CONCRETO ARMADO 107

$\begin{array}{ll}\text { 4.3.1 Características do Pórtico Ensaiado } & 107\end{array}$

$\begin{array}{ll}\text { 4.3.2 Análise Numérica } & 109\end{array}$ 
5 CONSIDERAÇÕES FINAIS, CONCLUSÕES E PERSPECTIVAS

6 REFERÊNCIAS BIBLIOGRÁFICAS

APÊNDICE

A-1 


\section{LISTA DE FIGURAS}

1.1 Síntese dos modelos constitutivos 04

1.2 a) Influência da anisotropia inicial em testes uniaxiais 11

b) Influência da anisotropia inicial em testes triaxiais 11

1.3 Processo de dano em rochas e concretos sob compressão e tração uniaxial.

Relação tensão-deformação

1.4 Representação esquemática de fissuração típica de rochas e concretos em tensão plana

1.5 Espécime para teste uniaxial 15

1.6 Curva tensão $\mathrm{x}$ deformação obtida do ensaio 16

1.7 a) Diagrama esquemático do teste e geometria do espécime. 16

b) Curva carga total $\mathrm{x}$ deslocamento 17

1.8 Configurações de fissuras em diferentes níveis de deformação

1.9 Locais de emissão acústica (AE) no espécime de concreto com agregados graúdos

1.10 Locais de emissão acústica (AE) no espécime de concreto simples

1.11 a) Estágios de carregamento e pontos onde os deslocamentos foram medidos

1.11 b) Razão entre deslocamentos verticais e horizontais entre os pontos A-B e C-D

1.12 Desenvolvimento de modelos de fissuras em vários estágios de carregamento

1.13 Redução progressiva da rigidez inicial

1.14 a) Energia dissipada por um material ideal

b) Energia dissipada por um espécime de concreto 
2.3 Hipótese de deformação equivalente 32

2.4 Curva $\sigma-\varepsilon$ do comportamento à compressão do concreto

3.1 a) Comportamento experimental

b) Modelo constitutivo

3.3 a) Curva experimental para o comportamento à tração do concreto

b) Curva ajustada para o comportamento à tração do concreto 60

c) Curva experimental para o comportamento à compressão do concreto 60

d) Curva ajustada para o comportamento à compressão do concreto 60

3.4 a) Influência do parâmetro $\varepsilon_{\mathrm{d} 0}$

b) Influência do parâmetro $A_{T}$

c) Influência do parâmetro $\mathrm{B}_{\mathrm{T}}$ 63

3.5 a) Influência do parâmetro $\mathrm{B}_{\mathrm{C}}$ 64

b) Influência dos parâmetros $\mathrm{A}_{\mathrm{C}}$ e $\mathrm{B}_{\mathrm{C}} \quad 65$

3.6 Variação do coeficiente $h \quad 69$

3.7 a) Influência de $Y_{01}$ sobre o comportamento em tração 77

b) Influência de $A_{1}$ sobre o comportamento em tração 77

c) Influência de $B_{1}$ sobre o comportamento em tração 78

3.8 a) Influência de $Y_{02}$ sobre o comportamento em compressão 79

b) Influência de $A_{2}$ sobre o comportamento em compressão 79

c) Influência de $B_{2}$ sobre o comportamento em compressão 80

3.9 Deformações, forças internas, tensões generalizadas e elemento finito empregado

3.10 Ensaio para identificação paramétrica: espécime e história de carregamento

3.11 Modelo de dissipação concentrada do ensaio

3.12 Tensões generalizadas do modelo de ÁLVARES (1998) 94

3.13 Influência da constante c na curva Força x Deslocamento 95 
3.14 Influência da constante $M_{y}$ na curva Força x Deslocamento 95

3.15 Influência da constante Q na curva Força x Deslocamento 96

3.16 Dano como função do seu momento termodinâmico associado 97

4.1 Geometria e armação das vigas $\quad 99$

4.2 Discretização em elementos finitos bidimensionais 101

$\begin{array}{ll}4.3 \text { Elemento finito empregado } & 102\end{array}$

$\begin{array}{ll}4.4 \text { Resultados numéricos - viga } 3 \$ 10.0 \mathrm{~mm} & 105\end{array}$

$\begin{array}{ll}4.5 \text { Resultados numéricos - viga } 5 \phi 10.0 \mathrm{~mm} & 105\end{array}$

4.6 Resultados numéricos - viga $7 \$ 10.0 \mathrm{~mm} \quad 106$

4.7 Detalhes do pórtico em concreto armado 108

$\begin{array}{ll}\text { 4.8 Seções Transversais A e B } & 108\end{array}$

$\begin{array}{ll}4.9 \text { Resultados numéricos do pórtico em concreto armado } & 111\end{array}$

4.10 Discretização adotada na simulação numérica com o modelo de $\begin{array}{ll}\text { ÁLVARES (1998) } & 112\end{array}$

4.11 Estado do pórtico na carga última

a) Rótulas plásticas e de dano $\quad 113$

b) Diagrama de momentos fletores em kN.mm $\quad 113$

APÊNDICE

1 Fluxo através de dô $\Omega$ A-2

2 Volume $\Omega$ no espaço $\quad$ A-4 


\section{LISTA DE TABELAS}

3.1 Variáveis de estado e variáveis associadas no modelo de dano

4.1 Propriedades dos materiais empregados

4.2 Parâmetros do modelo constitutivo de MAZARS (1984) empregados na análise numérica das vigas

4.3 Parâmetros do modelo constitutivo de LA BORDERIE, MAZARS \& PIJAUDIER-CABOT empregados na análise numérica das vigas

4.4 Parâmetros do modelo constitutivo de ÁLVARES (1998) empregados na análise numérica das vigas

4.5 Propriedades dos materiais empregados na confeç̧ão do pórtico em concreto armado

4.6 Parâmetros do modelo constitutivo LA BORDERIE, MAZARS \& PIJAUDIER-CABOT empregados na análise numérica do pórtico

4.7 Parâmetros do modelo constitutivo de ÁLVARES (1998) empregados na análise numérica do pórtico 


\section{LISTA DE SÍMBOLOS}

\section{GREGOS}

$\alpha$

$\alpha_{1}$ e $\alpha_{c}$

$\{\alpha\}$

$\beta_{1}$ e $\beta_{2}$

$\{\beta\}$

$\chi$

$\delta$

$\delta^{\mathrm{P}}$

$\delta^{\mathrm{d}}$

$\varepsilon_{\mathrm{i}}$

$\varepsilon_{\mathrm{e}}$

$\varepsilon$

$\varepsilon_{\mathrm{d} 0}$

$\varepsilon_{\text {an }}$

$\widetilde{\varepsilon}$

$<\varepsilon_{\mathrm{i}}>$

$\varepsilon_{\mathrm{V}}^{+}$

$\varepsilon_{\mathrm{Ti},} \varepsilon_{\mathrm{Ci}}$

$\dot{\varepsilon}^{\mathrm{e}}$

$\dot{\varepsilon}^{\mathrm{p}}$
Ângulo entre o eixo do elemento e o sistema de referência da estrutura

Componentes de combinação linear $\left(0 \leq \alpha_{T}, \alpha_{C} \leq 1\right)$

Vetor de variáveis internas devido ao efeito de plasticidade

Parâmetros anelásticos do modelo em tração e compressão

Vetor de forças termodinâmicas conjugadas aos parâmetros de encruamento plástico

Potencial de energia livre de Gibbs

Alongamento de um membro

Alongamento de um membro devido ao efeito de plasticidade Alongamento de um membro devido ao efeito de dano

Deformação segundo a direção i

Deformação elástica

Tensor de deformações

Deformação correspondente ao esforço máximo em uma prova de tração uniaxial

Deformação anelástica

Deformação equivalente

Componente positiva da deformação principal na direção i

Variável cinemática representativa do estado local de extensão

Componentes de tração e compressão da deformação principal

Taxa de deformação elástica

Taxa de deformação plástica 
$\phi$

$\{\phi\}$

$\left\{\phi^{\mathrm{r}}\right\}$

$\left\{\phi^{\mathrm{p}}\right\}$

$\left\{\phi^{\mathrm{d}}\right\}$

$\phi_{\mathrm{u}}^{\mathrm{p}}$

$\Phi$

$\gamma$

$\dot{\lambda}^{\mathrm{d}}$

$\dot{\lambda}^{p}$

$v$

$\underline{v}$

$v_{\mathrm{n}}$

$\rho$

$\sigma_{\mathrm{i}}$

$\underline{\sigma}$

$\tilde{\sigma}$

$\langle\underline{\sigma}\rangle_{+},\langle\underline{\sigma}\rangle$

$\left\langle\sigma_{\mathrm{i}}\right\rangle_{+}, \bar{\sigma}_{\mathrm{i}}>$

$\underline{\widetilde{\sigma}}$

$\sigma_{0 \mathrm{~T}}, \sigma_{0 \mathrm{C}}$

$\sigma_{\mathrm{f}}$

(1)

$\hat{\partial} \Omega$

$\Omega$

$\xi$
Diâmetro da barra de aço

Vetor de deformações

Vetor de deformações das rótulas

Vetor de deformações plásticas

Vetor de deformações devido ao dano

Deformação plástica no momento último

Potencial de dissipação

Vetor aceleração de um corpo

Multiplicador de dano

Multiplicador plástico

Coeficiente de Poisson

Vetor velocidade

Velocidade na direção do vetor $\underline{\underline{n}}$

Densidade do corpo estudado

Tensão normal segundo a direção i

Tensor de tensões

Esforço efetivo

Componentes positiva e negativa de $\underline{\sigma}$

Partes positiva e negativa da tensão principal $\sigma_{\mathrm{i}}$

Tensor de tensões efetivas

Tensões de início de dano em tração e compressão

Tensão de fechamento de fissura

Parte simétrica do tensor de deformações associada à taxa de deformação

Área de um elemento de superficie

Volume arbitrário do corpo estudado

Potencial de dissipação devido ao dano e plasticidade 
$\psi$

$\psi$

\section{ROMANOS}

$a^{T}$

A

$A_{1}, B_{1}, Y_{01}$

$A_{2}, B_{2}, Y_{02}$

$\mathrm{A}_{\mathrm{T}}, \mathrm{B}_{\mathrm{T}}$

$\mathrm{A}_{\mathrm{C}}, \mathrm{B}_{\mathrm{C}}$

c, $M_{y}, G_{c r}, q$

[C(D)]

D

$\mathrm{D}_{\mathrm{n}}$

$\underline{\underline{\mathrm{D}}}$

$\underline{\underline{D}}_{0}$

$\underline{\mathrm{D}}$

$\mathrm{D}_{\mathrm{T}}, \mathrm{D}_{\mathrm{C}}$

$\mathrm{D}_{1}, \mathrm{D}_{2}$

$\mathrm{d}_{\mathrm{i}}, \mathrm{d}_{\mathrm{j}}$

$\mathrm{d}_{\mathrm{n}}$

$\mathrm{dH}, \mathrm{dV}$

E

$\widetilde{\mathrm{E}}_{1}, \widetilde{\mathrm{E}}_{\mathrm{C}}$

$\widetilde{\mathrm{E}}$
Variável que quantifica a ausência de deterioração do material

Potencial de energia livre
Vetor de variáveis internas

Vetor das variáveis termodinâmicas associadas ao vetor $\underline{a}^{\mathrm{T}}$

Parâmetros do modelo relativos à tração

Parâmetros do modelo relativos à compressão

Parâmetros do modelo relativos à tração

Parâmetros do modelo relativos à compressão

Constantes características de um elemento

Matriz de flexibilidade das duas rótulas de um membro

Variável escalar de dano

Dano local

Tensor constitutivo elástico de quarta ordem com dano anisótropo

Tensor constitutivo elástico de quarta ordem do material íntegro

Tensor simétrico de quarta ordem

Componentes da variável de dano em tração e compressão

Componentes da variável de dano em tração e compressão

Dano devido a flexão nas rótulas i e j

Dano devido ao esforço axial na barra

Diferenças entre os deslocamentos horizontais e verticais entre dois pontos

Módulo de elasticidade do material íntegro

Módulos de elasticidade do material com dano em tração e compressão

Módulo de elasticidade do material com dano 
$\dot{\mathrm{E}}_{\mathrm{c}}$

$\mathrm{E}_{\mathrm{T}}$

$\dot{\mathrm{E}}_{\mathrm{D}}$

$\mathrm{E}_{\mathrm{C}}$

$\mathrm{E}_{\mathrm{S}}$

f

$\mathrm{F}$

$\mathrm{f}(\widetilde{\varepsilon}, D)$

$\mathrm{F}(\widetilde{\varepsilon})$

$\mathrm{F}_{\mathrm{T}}, \mathrm{F}_{\mathrm{C}}$

$f(\sigma)$

$\left[\mathrm{F}^{0}\right]$

$\left[\mathrm{F}^{\mathrm{e}}\right]$

$\left[\mathrm{F}^{\mathrm{d}}\right]$

g

$\{\mathrm{G}\}$

$\mathrm{G}_{1}, \mathrm{G}_{2}$

$\mathrm{h}$

h

I

K

$\mathrm{m}$

M

$\{\mathrm{M}\}$

$\mathrm{M}_{\mathrm{cr}}$

$\mathrm{M}_{\mathrm{p}}$

$\mathrm{M}_{\mathrm{u}}$
Taxa de energia cinética

Energia total do sistema

Taxa de energia dissipada

Módulo de elasticidade do concreto

Módulo de elasticidade do aço

função de plasticidade

Força sobre a superficie de área $\mathrm{S}$ e normal $\underline{\mathrm{n}}$

Função de dano

Função contínua e positiva da deformação equivalente

Funções contínuas e positivas de $\mathrm{Y}_{\mathrm{T}}$ e $\mathrm{Y}_{\mathrm{C}}$

Função que controla as condições de abertura e de fechamento da fissura

Matriz de flexibilidade

Matriz de flexibilidade de um membro elástico

Matriz de flexibilidade de uma barra com dano

função de dano

Vetor de forças termodinâmicas conjugadas ao dano

Funções de encruamento relativas à tração e compressão

coeficiente que caracteriza o fechamento de microfissuras

Vetor fluxo de calor através da unidade de superficie

Tensor identidade

Matriz de rigidez global da estrutura

Massa total no volume $\Omega$

Fluxo de massa por unidade de área

Matriz das tensões generalizadas

Momento de fissuração

Momento de plastificação ou de escoamento

Momento último 
$\mathrm{n}$

$\mathrm{N}$

$\underline{\mathrm{n}}$

$P_{e}$

p

Q

$\mathrm{Q}_{\mathrm{e}}$

q

$\{\mathrm{Q}\}$

s

S

$\mathrm{S}_{\mathrm{i}}$

$\mathrm{S}$

$\mathrm{S}_{\mathrm{f}}$

$\mathrm{S}_{0}$

$\widetilde{\mathrm{S}}$

$\left[\mathrm{S}^{0}\right]$

[S $\left.\mathrm{S}^{\mathrm{d}}(\mathrm{D})\right]$

$\mathrm{T}$

T

u

U்

U*

$U^{\mathrm{P}}\{\alpha\}$

V

$\mathrm{W}^{*}$

$\mathrm{y}_{\mathrm{k}}$

Relação entre os módulos de elasticidade do aço e do concreto esforço normal à seção transversal

normal que individualiza a seção do sólido

Potência externa introduzida ao sistema

Forças de corpo por unidade de volume

Quantyidade ou taxa de calor (condução) que passa pela superfície

Taxa de calor introduzida ao sistema

Fluxo de calor

Vetor de forças internas

Entropia específica por unidade de massa

Entropia do domínio $\Omega$

Área da seção ideal (homogeneizada)

Área de toda seção transversal (concreto + aço)

Área de aço

Área total de defeitos

Área resistente efetiva

Matriz de rigidez

Matriz de rigidez de uma barra com dano

Temperatura local absoluta

Forças de superficie

Energia específica interna

Taxa de energia interna

Energia potencial complementar de um membro com dano

Potencial elástico

Fluxo total de volume através de uma superficie finita

Energia potencial complementar de um membro elástico

Distância do eixo médio da camada $\mathrm{k}$ ao eixo neutro da seção transversal 
$\mathrm{Y}_{1}, \mathrm{Y}_{2}$

Taxa de energia liberada durante o processo de evolução de dano em tração e compressão

$\mathrm{Y}_{\mathrm{T}}, \mathrm{Y}_{\mathrm{C}}$

Variáveis termodinamicamente conjugadas, respectivamente, às variáveis internas $\mathrm{D}_{\mathrm{T}}$ e $\mathrm{D}_{\mathrm{C}}$

$\mathrm{Y}_{\mathrm{T}}^{0}$ e $\mathrm{Y}_{\mathrm{C}}^{0}$ energia de início de dano em tração e compressão

$\mathrm{Z}$ Rigidez elástica

$Z_{1}$ e $Z_{2}$ Funções que controlam a evolução das funções representativas dos critérios de danificação em tração e compressão 


\section{RESUMO}

PITUBA, J. J. C. Estudo e Aplicação de Modelos Constitutivos para o Concreto Fundamentados na Mecânica do Dano Contínuo. São Carlos, 130 p. Dissertação (Mestrado) - Escola de Engenharia de São Carlos, Universidade de São Paulo.

No trabalho estudam-se alguns aspectos relativos à formulação teórica e à simulação numérica de modelos constitutivos para o concreto fundamentados na Mecânica do Dano Contínuo, incluindo-se os chamados métodos simplificados de análise estrutural.

Inicialmente apresenta-se uma discussão sobre deformações permanentes e anisotropia induzidas pela evolução do dano. A resposta unilateral do concreto submetido a solicitações com inversão de sinal, também é comentada. Cada um dos fenômenos é ilustrado por respostas observadas experimentalmente.

O modelo de dano proposto por Mazars para o concreto submetido a carregamento proporcionalmente crescente é então analisado. Em seguida, apresentase uma extensão do modelo considerando-se o aspecto unilateral no comportamento do concreto

Na sequência, analisa-se o modelo constitutivo proposto por La Borderie em seus aspectos de formulação e resposta numérica. O modelo é mais completo permitindo levar em conta todos os fenômenos discutidos anteriormente.

Um outro aspecto considerado no trabalho é relativo à aplicação dos modelos estudados à análise de estruturas aporticadas. Em termos de discretização destacamse a técnica de divisão dos elementos estruturais em estratos e os chamados modelos simplificados. Neste último caso, o modelo de Flórez-López é analisado e a simplificação consiste na definição prévia, sobre a estrutura discretizada através de elementos de viga e de coluna, de zonas de localização da plastificação e do dano; no limite com a evolução do processo de carregamento, aquelas zonas passam a se constituir em rótulas. Por último uma generalização do modelo anterior proposta por Álvares é estudada.

Os resultados numéricos fornecidos pelos modelos são confrontados com os experimentais de vigas em concreto armado (biapoiadas e com diferentes taxas de armadura) e de um pórtico em concreto armado.

Palavras-chave: concreto, modelos constitutivos, mecânica do dano. 


\begin{abstract}
PITUBA, J. J. C. Study and Application of the Constitutive Models for the Concrete Based on the Continuum Damage Mechanics. São Carlos, 130 p. Dissertação (Mestrado) - Escola de Engenharia de São Carlos, Universidade de São Paulo.
\end{abstract}

In this work some aspects related to the theoretical formulation and numerical simulation of constitutive models for the concrete based on the Continuum Damage Mechanics are studied, including simplified methods of structural analysis.

Initially a discussion about permanent strains and anisotropy induced by the evolution of the damage is presented. The unilateral response of the concrete submitted to loadings with signal inversion is commented as well. Each one of the phenomena is illustrated by experimental tests.

The damage model proposed by Mazars for the concrete under proportional increasing load is then analysed. Afterwards, it is shown an extension of the model considering the unilateral aspect of the concrete behaviour.

In the sequence the constitutive model proposed by La Borderie is presented in its aspects of formulation and numerical response. This model is more complete, allowing to take in to account all the phenomena discussed previously.

Another aspect considered in the work is related to the application of the models studied to the analysis of framed structures. Regarding the discretization, the technique of division of the structural elements in layers and the so called simplified models are enhanced. In this last case, the model proposed by Flórez-López is analysed and the simplification consists on previous definition of yielding and damage zones over the assembly of beam and column elements, which compose the discretized structure; in the limit evolution of the loading process, these zones become hinges. Finally, a generalization of the previous model proposed by Álvares is studied.

The numerical results supplied by the models are compared with the experimental results of reinforced concrete beams (simply supported and with different reinforced rates) and of a reinforced concrete frame.

Keywords: concrete, constitutive models, damage mechanics. 


\section{INTRODUÇÃO}

\subsection{CONSIDERAÇÕES PRELIMINARES E SÍNTESE DO CONTEÚDO}

Neste trabalho são tratados modelos constitutivos para o concreto formulados pela Mecânica do Dano Contínuo, que é uma ferramenta de grande importância na modelagem macroscópica da resposta de materiais que apresentam o processo de microfissuração como fenômeno mais importante no seu comportamento, sendo este o caso do concreto.

O objetivo do trabalho é o estudo dos aspectos relativos à formulação teórica de alguns modelos constitutivos e sua aplicação na simulação numérica do comportamento de estruturas com destaque para os chamados métodos simplificados de análise estrutural.

Também inserem-se no trabalho estudos sobre fenômenos inerentes ao comportamento mecânico do concreto, sendo abordados a anisotropia elástica e as deformações permanentes induzidas pelo dano, além da consideração do fechamento das fissuras na recuperação da resistência do material (comportamento unilateral).

Com relação ao conteúdo desta dissertação, a disposição de assuntos é descrita a seguir de forma resumida.

No capítulo 1, introdução da dissertação, mostra-se um resumo sobre as diversas formulações empregadas para a modelagem do comportamento do concreto. Alguns aspectos sobre o comportamento mecânico do concreto são tratados em seguida, sendo discutidas de forma individual as deformações permanentes, a resposta 
unilateral e a anisotropia do material. Por último fazem-se alguns comentários sobre evidências experimentais de dano no concreto.

O capítulo 2 trata de alguns fundamentos da Mecânica do Dano Contínuo, dando uma base teórica para um melhor entendimento do trabalho. Em seguida, apresentam-se os princípios da termodinâmica e do método do estado local além de uma formalização da Mecânica do Dano em forma resumida com base nos princípios da termodinâmica.

O capítulo 3 trata das formulações teóricas dos modelos constitutivos para o concreto estudados neste trabalho. São eles: modelo constitutivo de MAZARS (1984), modelo constitutivo de LA BORDERIE, MAZARS \& PIJAUDIER-CABOT (1991) e o modelo constitutivo de FLÓREZ-LÓPEZ (1993).

No capítulo 4 sã̃o apresentados resuitados relativos à aplicação dos modelos no estudo do comportamento de estruturas em concreto armado, destacando-se as respostas fornecias pelos chamados métodos simplificados de análise estrutural.

No quinto capítulo faz-se um relato das conclusões observadas neste trabalho, além das perspectivas de novos trabalhos a partir deste.

No capítulo 6 apresentam-se as referências bibliográficas para o desenvolvimento do estudo proposto neste trabalho.

Finalmente, apresentam-se alguns conceitos de interesse num apêndice que acompanha o trabalho para servir de base na exposição dos princípios da termodinâmica e do método do estado local. 


\subsection{COMENTÁRIOS SOBRE MODELOS CONSTITUTIVOS PARA O} CONCRETO

\subsubsection{Introdução}

Uma lei constitutiva ou modelo constitutivo é um modelo mecânicomatemático que descreve uma idéia do comportamento tensão-deformação do material, LUCCIONI (1993).

Em geral, é bastante dificil encontrar uma lei constitutiva que reproduza o comportamento de um material em função de um tipo qualquer de solicitação. Devese restringir os modelos aos campos de interesse específico.

Muitos são os trabalhos que abordam diferentes leis constitutivas para o concreto. A título de orientação pode-se citar entre os mais difundidos, ASCE (1982), CEDOLIN (1982), CHEN \& SALEEB (1982) e XIAOQING et al. (1989).

Devido à sua complexidade de comportamento, a formulação de um modelo constitutivo completo para o concreto se torna algo dificil. Modelos têm sido formulados com base na teoria da plasticidade, na elasticidade, e mais recentemente na mecânica do dano, cada qual fornecendo boas respostas desde que a situação estudada proporcione um comportamento do concreto coerente com a teoria proposta.

Na figura 1.1 (PEREGO(1989)) apresenta-se um diagrama esquemático das teorias nas quais os modelos constitutivos estão fundamentados. 


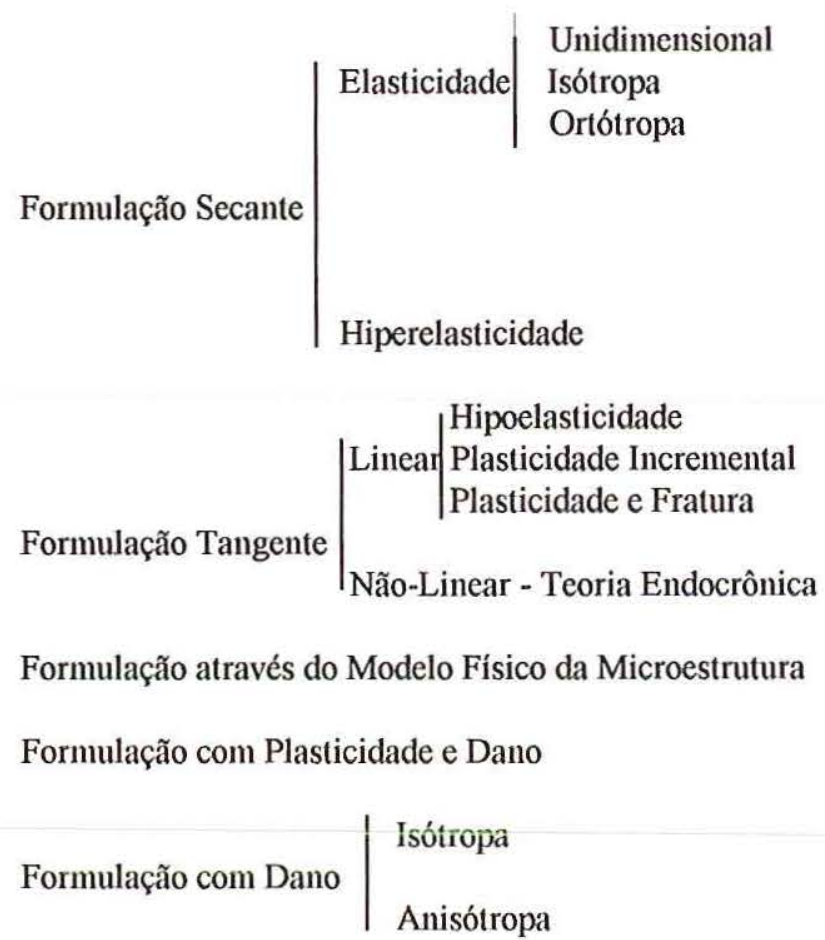

Figura 1.1 - Síntese dos modelos constitutivos

\subsubsection{Formulação Secante}

Estes modelos tem origem na simples generalização da teoria clássica da elasticidade linear, e na hipótese da existência de uma relação não-linear entre o estado de tensão e de deformação.

Por exemplo, no caso de compressão unidimensional, a proposta mais conhecida é a da parábola-retângulo, função de apenas um parâmetro experimental: a resistência máxima. Ainda no caso unidimensional, uma formulação mais perto da realidade experimental é a de SAENS (1965), que faz referência a quatro parâmetros: a resistência máxima e correspondente deformação, o módulo de elasticidade e a deformação última. Na sua extensão para o caso de estado multiaxial as propriedades de isotropia e ortotropia podem ser consideradas.

Com relação a aplicação de um modelo deste tipo, em particular CEDOLIN, CRUTZEN \& POLI (1977) obtiveram bons resultados, bastante de acordo com resultados experimentais, com um modelo isótropo para análises multiaxiais. 
Por outro lado, uma lei constitutiva ortótropa é proposta por LIU, NILSON \& SLATE (1972), sendo derivada diretamente de uma prova de compressão biaxial do concreto. Esta lei pode ser entendida como uma extensão de SAENS (1965) para o estado biaxial.

\subsubsection{Formulação Tangente}

A formulação Hipoelástica, de tipo incremental, supõe uma relação linear entre o incremento do estado de tensão e o incremento do estado de deformação, onde o coeficiente de proporcionalidade é função do estado de tensão. Deste modo o material é sensível à história de carregamento.

A Plasticidade incremental leva a um outro tipo de formulação tangente onde deformações permanentes são incluídas. Alguns modelos foram propostos, entre eles ARGYRIS et al. (1974) e CHEN \& CHEN (1975). A proposta "pioneira" de ARGYRIS et al. (1974), consiste em considerar o concreto como um material perfeitamente elastoplástico. No trabalho de CHEN \& CHEN (1975) tem-se a introdução do encruamento positivo do material.

É importante observar que a formulação elastoplástica não leva em conta fenômenos muito importantes e característicos do concreto como a variação do módulo de elasticidade devido a uma progressiva microfissuração do material.

BAZANT \& KIM (1978) propõem uma teoria incremental denominada "plastic-fracturing", que combina a plasticidade convencional com a teoria da fratura descrito no trabalho de DOUGILL (1976). Este modelo é baseado na hipótese que a deformação anelástica do concreto é devida ao fenômeno de microfissuração e de escoamento plástico.

Uma formulação tangente não-linear é constituída pela "teoria endocrônica" proposta por Bazant. Nesta teoria a deformação anelástica é caracterizada por uma variável escalar não decrescente cujos incrementos dependem dos incrementos da deformação. Este modelo é capaz de representar fenômenos de encruamento, contrações de ciclos de histerese em presença de carregamentos cíclicos e resposta ao 
longo do tempo. Se por uma parte esta teoria consegue descrever bem o comportamento do concreto, por outro apresenta o inconveniente de definir um elevado número de parâmetros, o que dificulta a identificação experimental.

\subsubsection{Modelo Físico da Microestrutura}

A complexidade de formular, para o concreto, uma lei constitutiva macroscópica coerente com a realidade física, deriva do fato que esta lei deve levar em conta um elevado número de fenômenos que acontecem ao nível microestrutural.

O chamado modelo da microestrutura tem o objetivo de prever a resposta macroscópica através de um arranjo de elementos que simulam a microestrutura do material. Em particular BUYUKOZTURK, NILSON \& SLATE (1972) estudaram, experimentalmente e analiticamente, um modelo no qual a estrutura interna é idealizada mediante um conjunto de agregados de forma circular inclusos numa matriz de argamassa. A análise numérica é feita com o emprego de elementos finitos, incluindo-se aí os de junta, especiais para modelar o comportamento na interface argamassa-agregado.

Na proposta de GAMBAROVA \& FLORIS (1986) o material é modelado através de um sistema de planos de orientações aleatórias. O comportamento macroscópico à tração é simulado pela superposição dos comportamentos anelásticos nos planos individuais.

\subsubsection{Formulação com Plasticidade e Dano}

Esta formulação supõe que o comportamento não-linear do concreto é causado por um processo de microfissuração, responsável pela redução de rigidez, e pela plastificação, de modo que a deformação total é dada pela soma de uma componente recuperável e uma irreversível. 
Nestes modelos cada um dos fenômenos responsáveis pela resposta não-linear vêm representados por adequadas variáveis internas, cujas leis de evolução seguem os princípios da termodinâmica.

Entre as publicações relativas a estes modelos, é possível citar os trabalhos de HAN \& CHEN (1986) e OLLER et al. (1988). Nestes últimos, em particular, associase a evolução da superficie de escoamento plástico, definida no espaço das tensões, com a evolução de três variáveis internas: coesão, ângulo de atrito interno e ângulo de dilatação. O modelo aborda também a questão numérica da "objetividade" de resposta, conseqüência da localização do dano, introduzindo uma medida que depende da relação entre volume da zona com dano e a área da fissura. Esta medida, na prática, serve como um parâmetro de controle da rede de elementos finitos e permite uma correta avaliação da energia dissipada no processo de dano.

\subsubsection{Modelo Constitutivo com Dano}

Segundo DRIEMEIER(1995), o conceito de dano foi inicialmente utilizado para análise e descrição, em regime de ruptura, do comportamento de metais sob carregamentos monotônicos ou cíclicos. Nos metais em regime de ruptura, aparecem microfissuras após o desenvolvimento de uma pronunciada plastificação. O conceito de dano aplica-se bem ao concreto uma vez que:

- o desenvolvimento da microfissuração, pode ser considerado contínuo e se inicia com baixas tensões ou deformações;

- as deformações permanentes são também devidas ao processo de evolução de microfissuras.

Os modelos de dano admitem que a perda progressiva de rigidez e de resistência (ramo 'softening') do material são devidos exclusivamente ao processo de microfissuração. Neste últimos anos diversos modelos foram formulados podendo classificá-los em escalares ou anisótropos segundo a variável representativa de dano 
seja de natureza escalar ou tensorial. A formulação de um modelo mecânico de dano distribuído que contempla as perdas de rigidez e de resistência admite a presença, no comportamento do material, de um ramo 'softening' ou de encruamento negativo onde se manifesta de modo evidente a degradação das características mecânicas.

Entre os numerosos trabalhos voltados para a determinação do ramo 'softening' da curva tensão-deformação pode-se citar HSU et al. (1963), DIAZ \& HILSDORF (1971) e VAN MIER (1984). Entretanto é conveniente observar-se que este ramo decorre de uma localização do processo de microfissuração, a qual, via de regra, não é considerada nos modelos propostos. De fato, em HSU et al. (1963) vem referenciada a existência de um trecho descendente da lei constitutiva em compressão axial ao longo do qual se verifica a ruptura do material. No trabalho de DIAZ \& HILSDORF (1971) é também confirmado que a ruptura vem em forma localizada ao longo deste ramo. Também os resultados experimentais do tipo triaxial (VAN MIER (1984)) têm caracterizado um ramo descendente.

Nos modelos constitutivos escalares (RESENDE (1984) e MAZARS (1984)) supõe-se que a degradação do material ocorre de tal modo a manter invariante a propriedade de isotropia inicial. Entre os modelos anisótropos, ORTIZ (1985) tem como hipótese que o processo de microfissuração conduz a uma anisotropia do material.

Também foram propostos modelos constitutivos aplicáveis a situações de carregamento repetido, de 'fadiga' (MARIGO (1985) e PAPA (1990)) e modelos que consideram a deformação permanente conseqüente do dano (PAPA(1990)).

Além disso, é possível levar em conta o dano inicial existente na forma de defeitos (microfissuras ou vazios) que precedem a deterioração mecânica causada por carregamentos externos.

Concluindo, pode-se observar que no âmbito da análise não-linear, os modelos de dano para o concreto constituem uma interessante alternativa aos modelos elastoplásticos. 


\subsection{ALGUNS ASPECTOS DO COMPORTAMENTO MECÂNICO DO} CONCRETO

\subsubsection{Introdução}

O concreto mesmo antes da aplicação de qualquer carga já apresenta um estágio de microfissuração resultante do fenômeno de retração, mais liberação de calor, que se desenvolve na fase inicial da cura.

O comportamento não-linear do concreto, que se dá mesmo em baixos níveis de tensão, é influenciado pela microfissuração inicial e pela sua propagação durante o processo de carregamento. Também a microfissuração justifica, ainda na fase da resposta elástica, a consideração da anisotropia do material para fins de modelagem macroscópica.

É importante notar que, a propagação das fissuras basicamente passa a se desenvolver na fase de carregamento devida às diferentes características de resistência e propriedades elásticas entre os agregados graúdos e a argamassa. Tais diferenças e o comportamento na interface entre os elementos citados são responsáveis pela baixa resistência à tração do concreto.

Um outro fenômeno também decorrente da evolução de microfíssuras no concreto é o aparecimento de deformações permanentes. A relação entre evolução de microfissuras e deformações permanentes pode ser interpretada como uma consequência da heterogeneidade do material e do atrito entre as faces das fissuras, que impede, em caso de descarregamento, um fechamento total das mesmas.

Um último fenômeno característico do concreto, e materiais granulares em geral, é a chamada resposta unilateral ou recuperação da rigidez do material quando da inversão do carregamento.

Nota-se que o comportamento mecânico global do concreto também é diretamente influenciado por fatores tais como textura e tamanho dos agregados, índice de vazios, relação água-cimento, etc. Tais fatores são, de certa maneira, 
considerados nas leis de evolução das variáveis que descrevem o dano quando da formulação de modelos constitutivos.

\subsubsection{Aspectos da Anisotropia do Dano}

A mecânica do dano contínuo propõe uma abordagem racional para o fenômeno de danificação distribuída em meios contínuos, valendo até os limites da mecânica da fratura. A danificação inclui o processo de nucleação e aumento de cavidades microscópicas distribuídas em meios submetidos a diferentes tipos de carregamentos tendo efeito direto sobre as propriedades mecânicas do material Localmente a distribuição de defeitos e microfissuras iniciais localmente varia significativamente com a direção considerada, sendo intrinsecamente anisótropa. Muitos pesquisadores concordam em escrever que as microfissuras são responsáveis pela anisotropia elástica do concreto, BERTHAUD, LA BORDERIE \& RAMTANI (1990). Assim, a anisotropia induzida no material com dano é um aspecto importante a ser considerado na elaboração de modelos constitutivos, especialmente se as condições forem de carregamento não-proporcional.

Na figura 1.2a (VAN MIER (1985)) é ilustrado o efeito de anisotropia inicial $\mathrm{em}$ dois testes uniaxiais, sendo um paralelo e outro perpendicular a direção de moldagem, onde a deformação $\varepsilon_{1}$ é a variável independente nos testes de deformação controlada. Pode-se observar que no ramo ascendente das curvas, a inclinação inicial é diferente nos dois casos; já nos testes triaxiais (figura 1.2b (VAN MIER (1985)), efeitos similares são observados, porém com maior intensidade. Observa-se, portanto, que a resposta tensão-deformação na fase 'pré-pico' é consideravelmente afetada pela orientação do campo inicial de dano com respeito ao estado de tensões governante. 
3.:

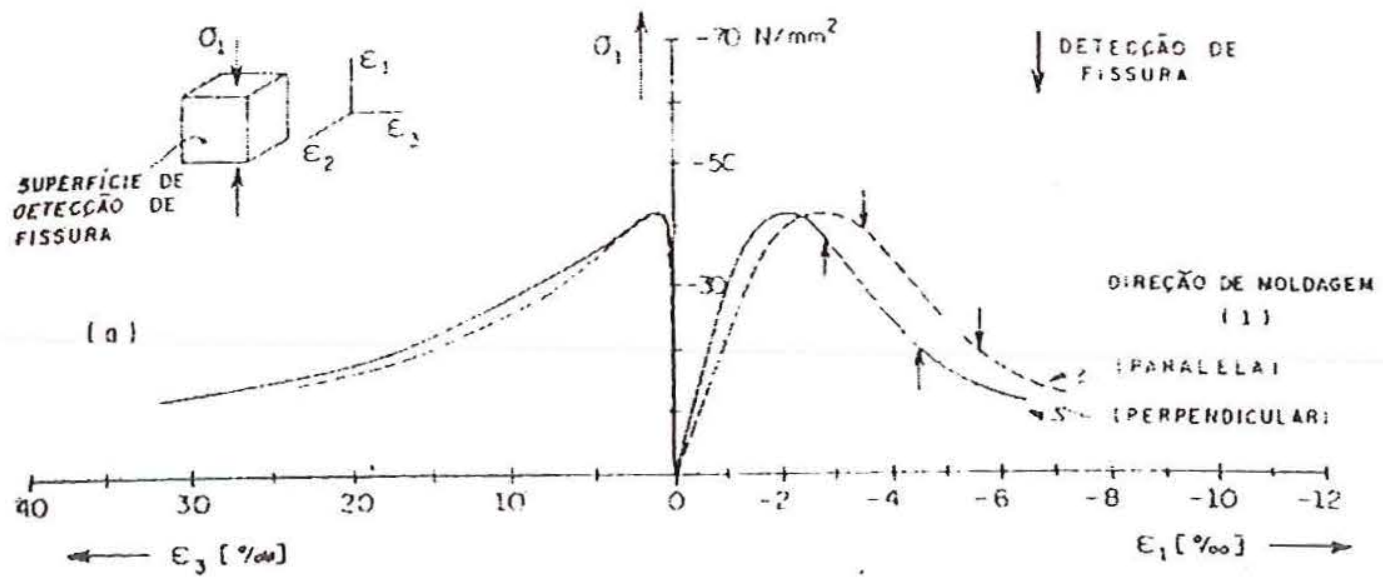

$\sigma_{2}=\sigma_{3}=0$

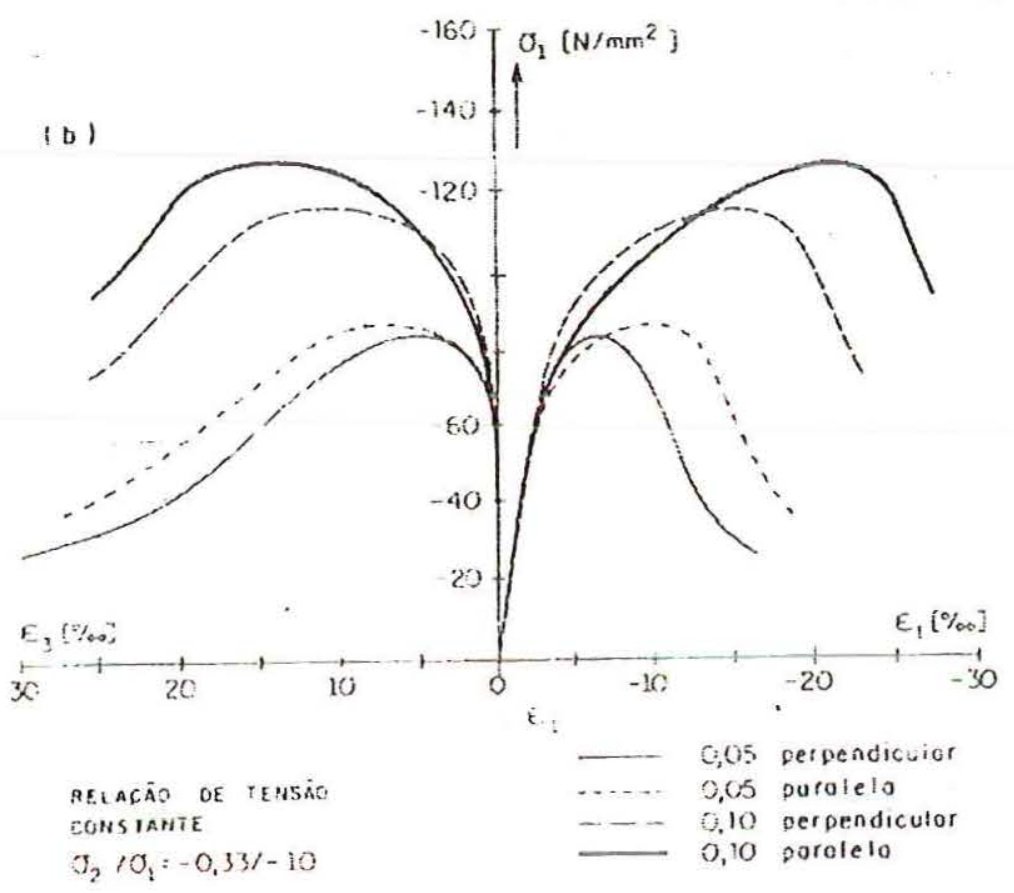

Figura 1.2a) Influência da anisotropia inicial em testes uniaxiais;

b) Influência da anisotropia inicial em testes triaxiais.

O dano em materiais granulares como rochas e concretos, é caracterizado pelo crescimento de microfissuras em planos geralmente perpendiculares à direção da tensão principal máxima. A figura 1.3 ilustra o processo de dano de testes uniaxiais de materiais frágeis (DRAGON \& MROZ (1979)). No caso de testes de compressão, 
quando a tensão supera o limite de proporcionalidade do ponto $\mathrm{A}$, microfissuras aparecem progressivamente em pontos distribuídos aleatoriamente no corpo ensaiado. $\mathrm{Na}$ região de deformação estável $\mathrm{AD}$, as microfissuras desenvolvem-se principalmente em planos paralelos à direção da tensão principal compressiva máxima. Na região de deformação instável $\mathrm{DE}$, por outro lado, as microfissuras concentram-se e confundem-se com fissuras macroscópicas. De um modo geral, o desenvolvimento das microfissuras é acompanhado por um decréscimo gradual na rigidez elástica como também pela dilatação macroscópica do material. A fratura final, neste caso, resulta em fissuras macroscópicas paralelas à carga de compressão, ou na formação de uma 'banda inclinada de cisalhamento' concentrada no material (LEMAITRE \& CHABOCHE (1985), JAEGER \& COOK (1979)). Em testes de tração axial, em contrapartida, materiais fraturam de modo frágil devido a formação de fissuras no plano perpendicular à direção da tensão aplicada.

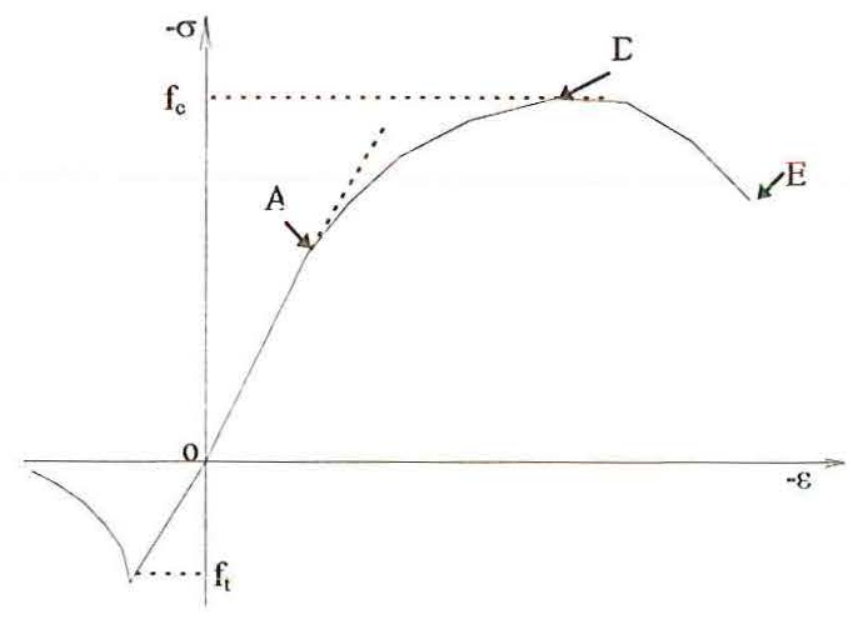

Figura 1.3 - Processo de dano em rochas e concretos sob compressão e tração uniaxial. Relação tensão-deformação.

A figura 1.4 (DRAGON (1976)) mostra os modelos esquemáticos de fissuras observadas em concretos sob vários estados planos de tensão. Contudo a densidade, configuração e o modelo de aumento de fissura dependem largamente da razão de tensão, todas as fissuras desenvolvem-se principalmente em planos perpendiculares à 
direção da tensão principal máxima ou então segundo planos perpendiculares à direção de maior alongamento; o dano mostra evidente anisotropia.

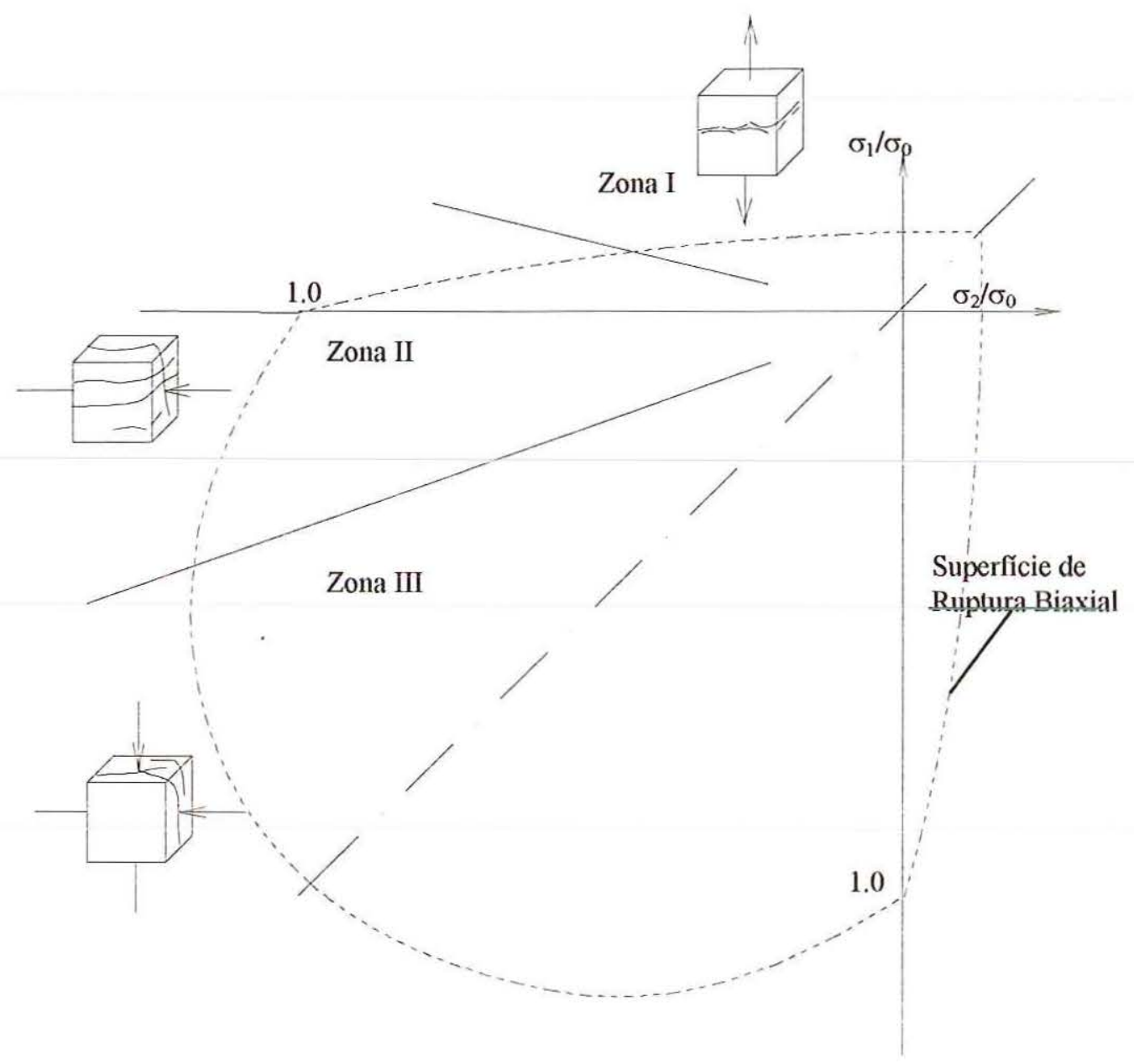

Figura 1.4 - Representação esquemática de fissuração típica de rochas e concretos em tensão plana. 


\subsubsection{Deformações Permanentes}

O fenômeno de deformação permanente não é significativo em níveis baixos de solicitação. A deformação nesses níveis pode ser considerada como o resultado de movimentos quase reversíveis de átomos sendo, portanto, elástica, com uma baixa viscosidade.

Para valores de carga que são maiores do que aquele que corresponde ao limite elástico, microfissuras na interface entre a pasta e os agregados maiores começam a se propagar de forma quase irreversível ao longo dos contornos dos agregados gerando, assim, a nível macroscópico, deformações permanentes em conjunto com as deformações elásticas. Numa fase seguinte as microfissuras se propagam na pasta e no caso de carregamento de compressão tendem a se alinhar numa direção paralela à tensão. $\mathrm{O}$ dano torna-se fortemente anisótropo. $\mathrm{O}$ estágio final é o de fratura: fissuras macroscópicas aparecem pela união de microfissuras, a tensão necessária para produzir mais deformação diminui, o volume específico aumenta e a fratura final consiste na formação de uma descontinuidade da superficie.

Segundo BERTHAUD, LA BORDERIE \& RAMTANI (1990), várias explicações podem ser dadas para interpretar a evolução das deformações permanentes em correspondência a diferentes níveis de solicitação. De um lado, tensões iniciais devidas à hidratação são relaxadas durante o carregamento mecânico e produzem apenas deformações permanentes evidenciadas num caminho de descarregamento. Esta explicação física é provavelmente válida apenas na fase inicial de carregamento porque as tensões iniciais desaparecem rapidamente. Por outro lado, com o crescimento da fissura aumenta a possibilidade de friç̧ão entre as suas faces. Algumas das fissuras, então, mantém-se abertas mesmo para um estado nulo de tensões. As deformações permanentes são, neste caso, induzidas diretamente pela danificação. 


\subsubsection{Aspecto Unilateral no Comportamento Mecânico do Concreto}

Um último fenômeno com relação ao concreto, a ser abordado neste trabalho, é o efeito de recuperação de rigidez por fechamento de fissura. Como será visto a seguir, uma série de testes foi proposta para ilustrar as consequências do fechamento de fissuras (MAZARS, BERTHAUD \& RAMTANI (1990)). Em particular, nestes testes, o concreto sofre primeiro dano em tração, havendo, uma redução do módulo de elasticidade. Em seguida opera-se um descarregamento passando-se a uma inversão do sinal da carga; observa-se nesta fase que o módulo de elasticidade inicial é recuperado.

Do ponto de vista experimental, o comportamento unilateral do concreto com dano está, portanto, relacionado com a mudança de sinal da carga. Em MAZARS, BERTHAUD \& RAMTANI (1990) são apresentados dois ensaios, o primeiro uniaxial e o segundo multiaxial.

No primeiro nota-se a influência de microfissuras previamente criadas na resposta do concreto com dano. Quando se inverte o sinal do carregamento, o módulo de elasticidade e a tensão de pico iniciais não são modificados pelo dano criado previamente. O modelo ensaiado e os resultados obtidos estão descritos a seguir:

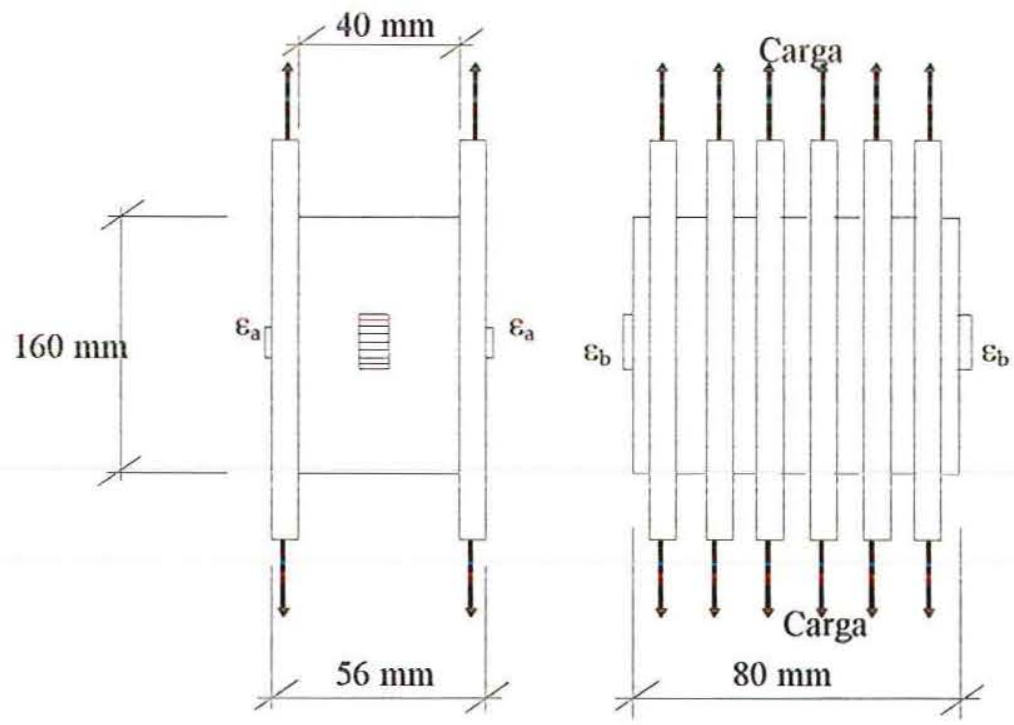

Figura 1.5 - Espécime para teste uniaxial.

MAZARS, BERTHAUD \& RAMTANI (1990) 


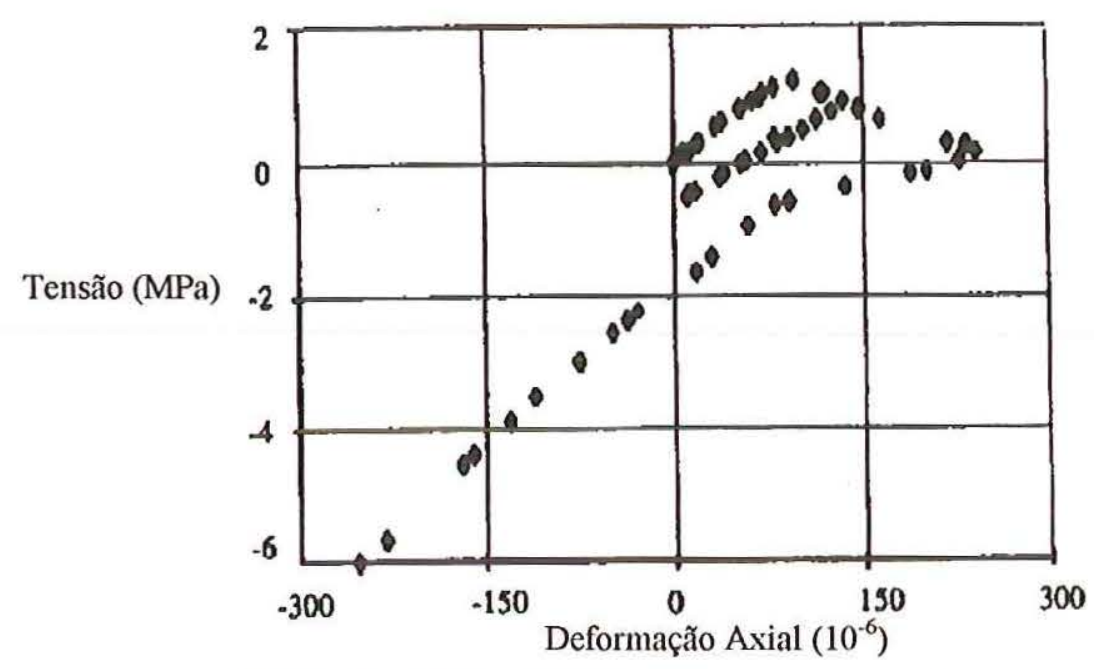

Figura 1.6 - Curva Tensão x Deformação obtida do ensaio. MAZ,ARS, BERTHAUD \& RAMTANI (1990)

No segundo ensaio uma viga de concreto (Figura 1.7a) é submetida a um teste de fadiga de baixo ciclo afim de analisar a evolução da rigidez global. Conclui-se que uma estrutura que é previamente danificada devido a um carregamento aplicado num certo sentido poderá suportar cargas no sentido oposto se todas as microfissuras se fecham ao mesmo tempo (isto acontece em situações de carregamento proporcional ou radial). A curva de carga $\mathrm{x}$ deslocamento obtida é dada na figura 1.7b.

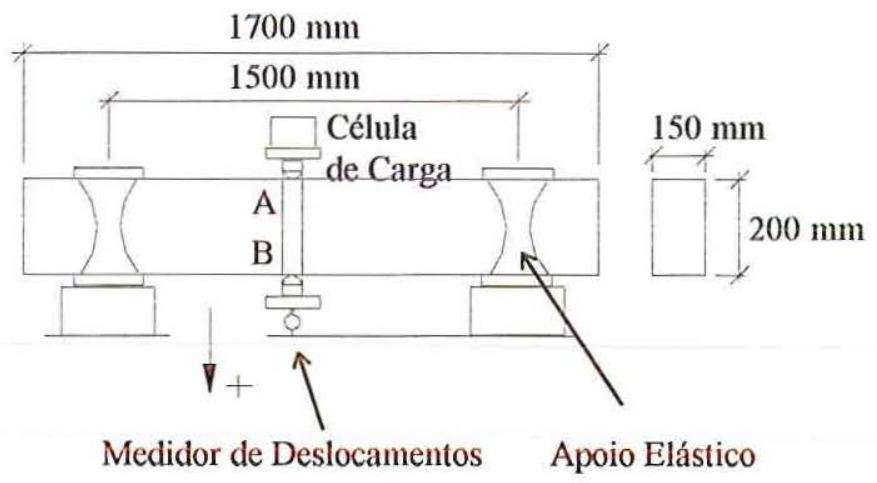

Figura 1.7a - Diagrama esquemático do teste e geometria do espécime. MAZARS, BERTHAUD \& RAMTANI (1990) 


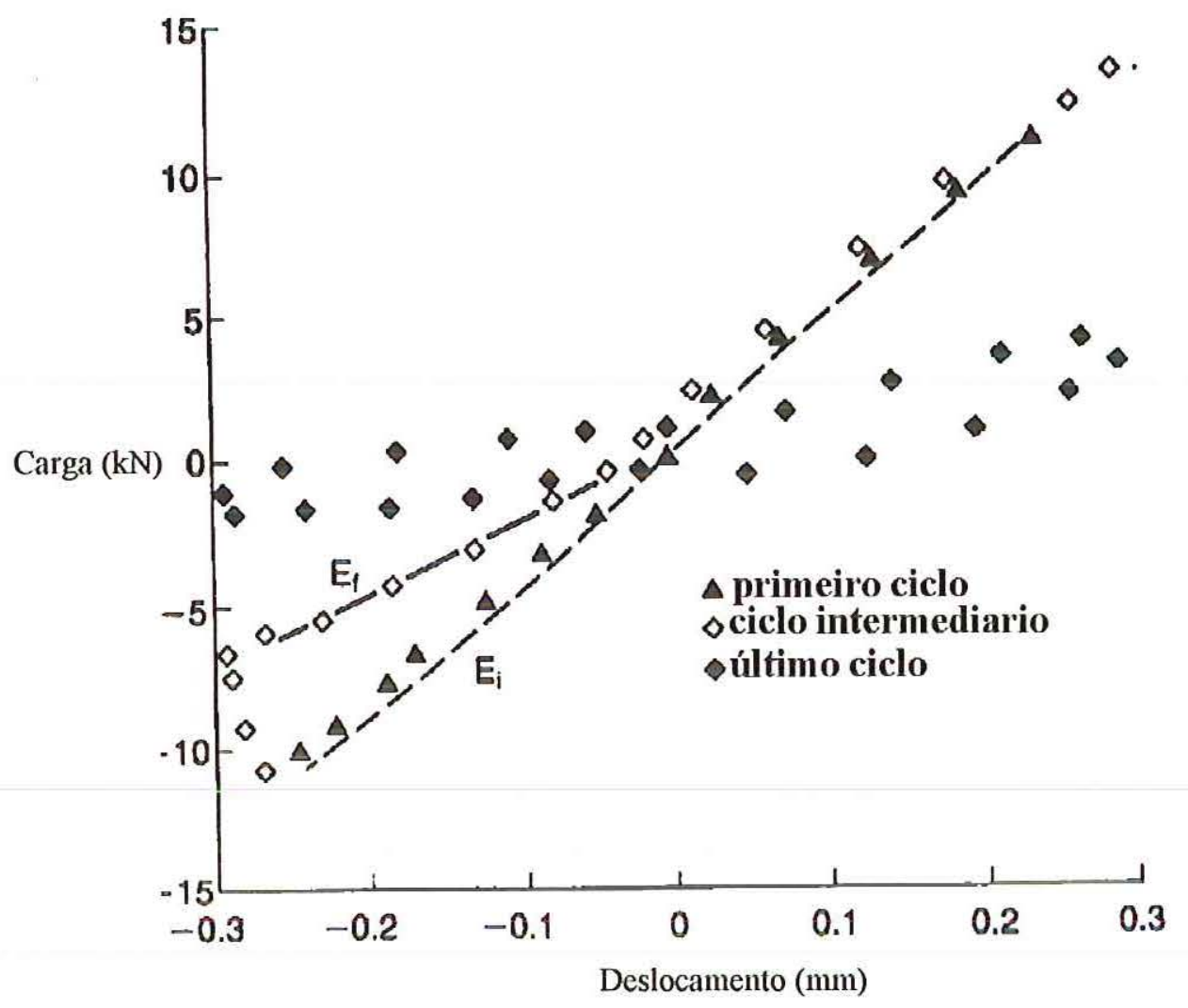

Figura 1.7b - Curva carga total x deslocamento.

MAZARS, BERTHAUD \& RAMTANI (1990)

\subsubsection{Evidências Experimentais de Dano no Concreto}

Faz-se neste item o relato de algumas evidências experimentais de ocortência de dano no concreto, com base em trabalhos contidos na bibliografia consultada.

Os métodos de ensaio para o estudo do processo de fissuração estão classificados da seguinte forma; métodos diretos e métodos indiretos. Os métodos diretos estudam visualmente a formação e propagação de fissuras, tais métodos podem ser aplicados com o uso da petrografia e do microscópio ótico. Os métodos indiretos estudam a formação e propagação de fissuras através do relacionamento entre estas e o registro de um fenômeno particular, por exemplo, a ocorrência de emissão acústica.

A figura 1.8 (VAN MIER (1985)) mostra uma das primeiras aplicações dos métodos diretos através das observações das mudanças macroscópicas 
(comportamento tensão-deformação) em corpos de prova cilíndricos sob compressão uniaxial, HSU et al. (1963). Observa-se na figura que somente fissuras de interface existem em um nível zero de deformações. Estas fissuras começam a crescer aproximadamente no nível de tensão de $30 \%$ do valor de pico ou último. A curva tensão-deformação começa a ter um desvio na sua linearidade quando as fissuras de interface começam a aumentar em comprimento e número. Entre o nível de $30 \%$ e $70 \%$ da carga máxima as fissuras aumentam em quantidade. Entre $70 \%$ e $90 \%$ da carga máxima, fissuras da argamassa começam a se propagar e também pontes são formadas unindo-as. A partir de um nível de deformação de $3,0 \%$ (figura $1.8 \mathrm{~d}$ ) as fissuras permanecem estáveis somente quando um aumento de deformação for acompanhado por uma diminuição de tensão, isto é, sob condições de ensaio com controle de deslocamento.

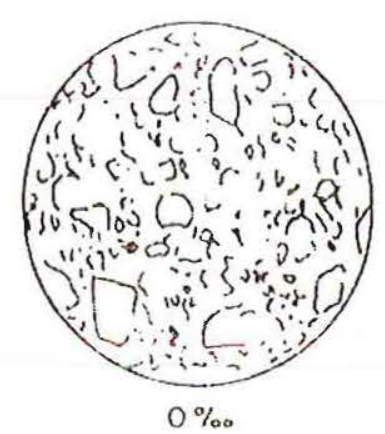

a)

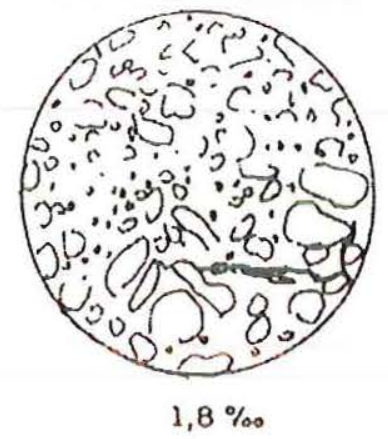

b)

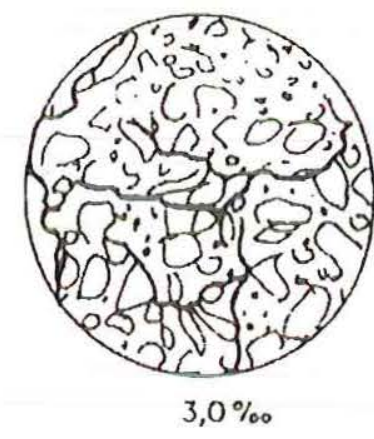

c)

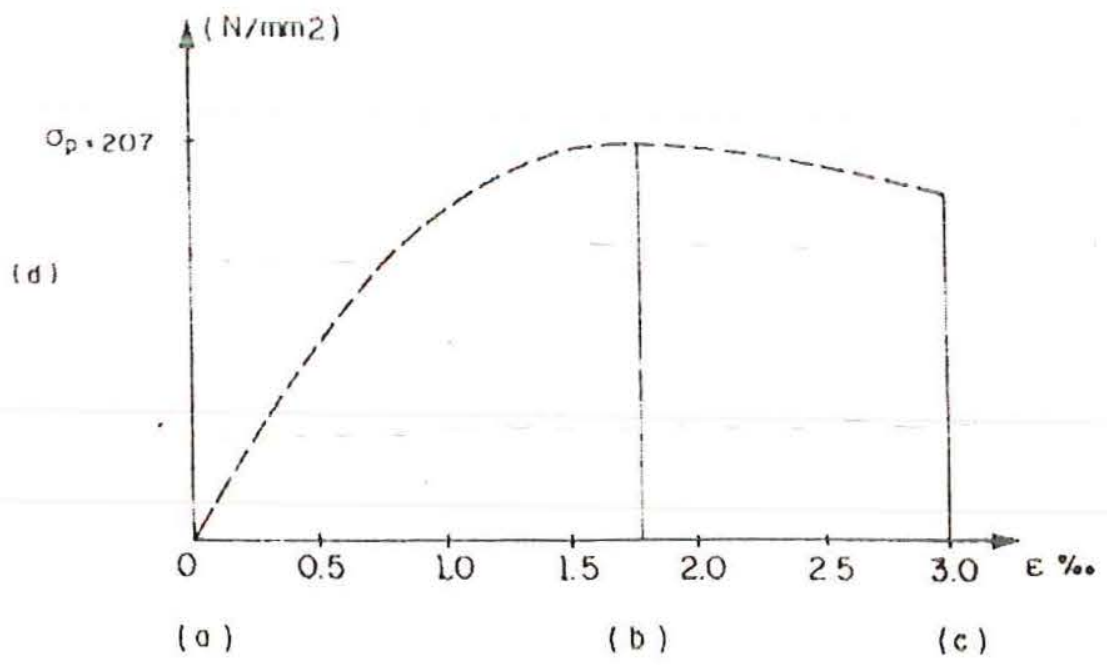

Figura 1.8 - Configurações de fissuras em diferentes níveis de deformação. 
Resultados através de observações diretas também foram obtidos por HILSDORF (1969) e MAJI \& SHAH (1988). Ambos, de forma geral e resumida, detectaram que em cargas correspondentes a $85 \%$ do valor máximo, o estado de fissuração é semelhante ao do estado com carga nula no sentido que as fissuras desenvolveram-se ao longo da interface e que existe um pequeno número delas na argamassa. Já no trecho descendente do diagrama tensão-deformação, o crescimento das fissuras foi mais rápido.

O método indireto da emissão acústica foi estudado por SPOONER et al. (1976) e MAJI \& SHAH (1988). O primeiro autor estudou a emissão acústica no concreto entre consecutivos ciclos de carregamento de compressão uniaxial e usou tais medidas como indicadores da degradação do material. Verificou-se que a emissão acústica detectada durante o primeiro carregamento para um particulai nível de deformação foi ausente durante o descarregamento. No recarregamento não foi detectada emissão acústica até que a deformação máxima previamente atingida fosse ultrapassada, porém nas regiões próximas ao pico e na porção descendente da curva tensão-deformação, a emissão acústica ocorreu novamente antes que a prévia deformação máxima fosse atingida.

No trabalho de MAJI \& SHAH (1988) foi usada a deteç̧ão de emissão acústica para estudar a propagação de uma fissura inicial em espécimes de concreto testados em tração uniaxial. Os resultados ilustrados na figura 1.9 (MAJI \& SHAH (1988)) dizem respeito à indicação de pontos de emissão acústica (AE) em correspondência com diferentes estágios de carregamento num espécime de concreto com inclusão de agregados graúdos. Já na figura 1.10 (MAJI \& SHAH (1988)) os resultados são para um espécime de concreto simples. 

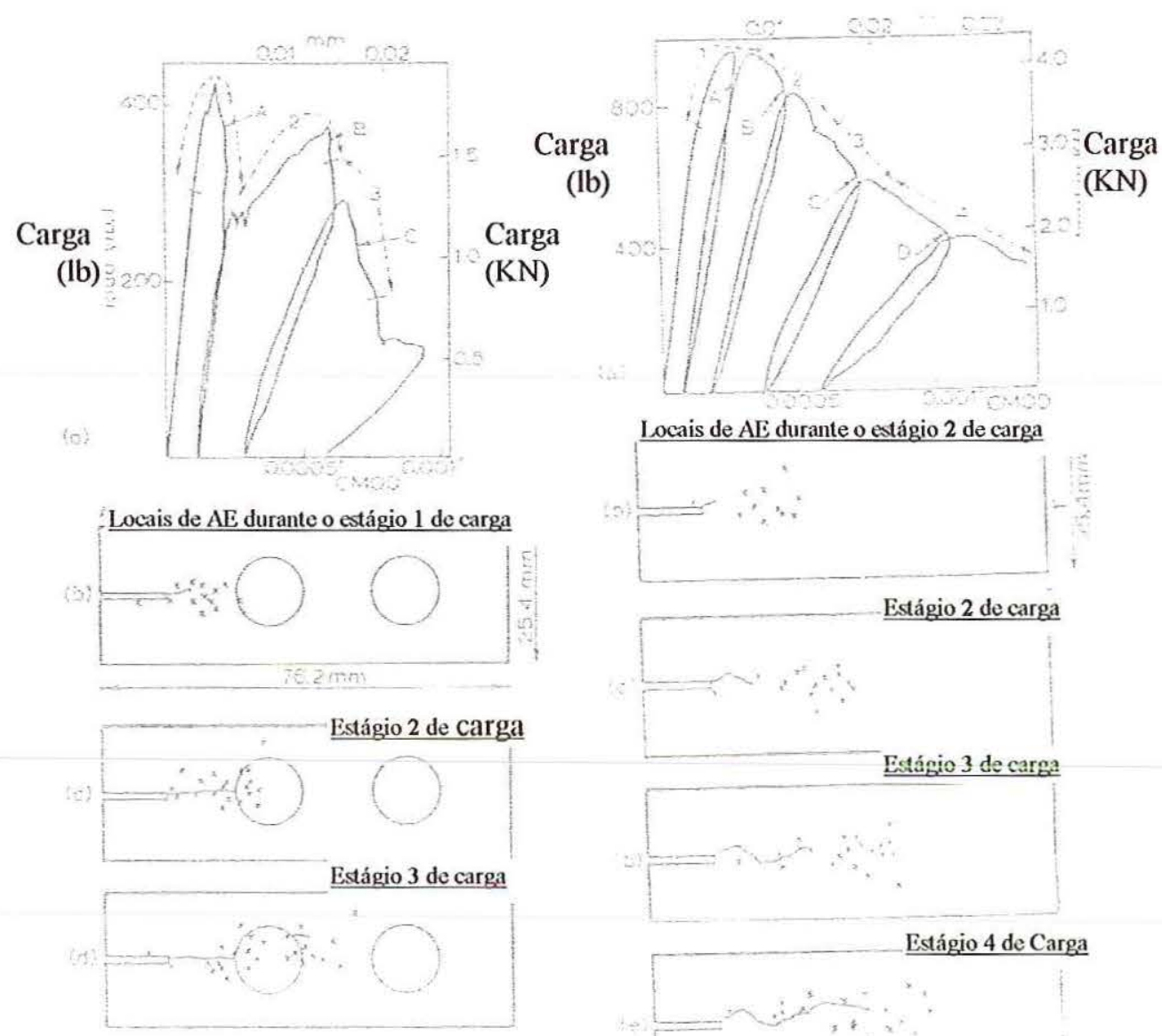

Figura 1.9 - Locais de emissão acústica (AE) Figura 1.10 - Locais de cmissão acústica (AE) no espécime de concreto com agregados no espécime de concreto simples graúdos

De acordo com os testes, de forma resumida, conclui-se que a resposta à emissão acústica continua a ocorrer mesmo numa região anterior à ponta da fissura, indicando que ligamentos continuam transmitindo carga a despeito da caracterização de uma superficie de fissuração. Múltiplos picos ocorrem no espécime de concreto pela presença de agregados, porque a fissura é por ele detida e redirecionada (figura 1.9).

Outra técnica abordada no trabalho de MAJI \& SHAH (1988) foi a técnica da espectrografia (usando luz monocromática de um laser). O objetivo deste ensaio foi o de estudar os deslocamentos relativos entre os pontos da interface argamassaagregado ( A-B e C-D na figura 1.11a) em um espécime carregado verticalmente com duas inclusões de agregado. A figura 1.11b apresenta, para os pontos de observação 
contidos no diagrama de compressão uniaxial da figura 1.11a, os gráficos da relação $\mathrm{dH} / \mathrm{dV}$, onde $\mathrm{dH}$ é a diferença entre os deslocamentos horizontais dos pontos A e B ou $\mathrm{C}$ e $\mathrm{D}$, e dV é a diferença dos deslocamentos verticais dos mesmos pontos em questão. Na figura $1.11 \mathrm{~b}$ pode ser observado que a relação $\mathrm{dH} / \mathrm{dV}$ esteve próxima a 1,0 durante os estágios iniciais de carregamento indicando que a fissura de interface deslizou e abriu na mesma proporção e ao mesmo tempo. Próximo à carga de pico, a relação mostra que houve a predominância de abertura da fissura. Portanto, as fissuras de interface passam de um modo misto para um modo de abertura pura durante a evolução de carregamento.
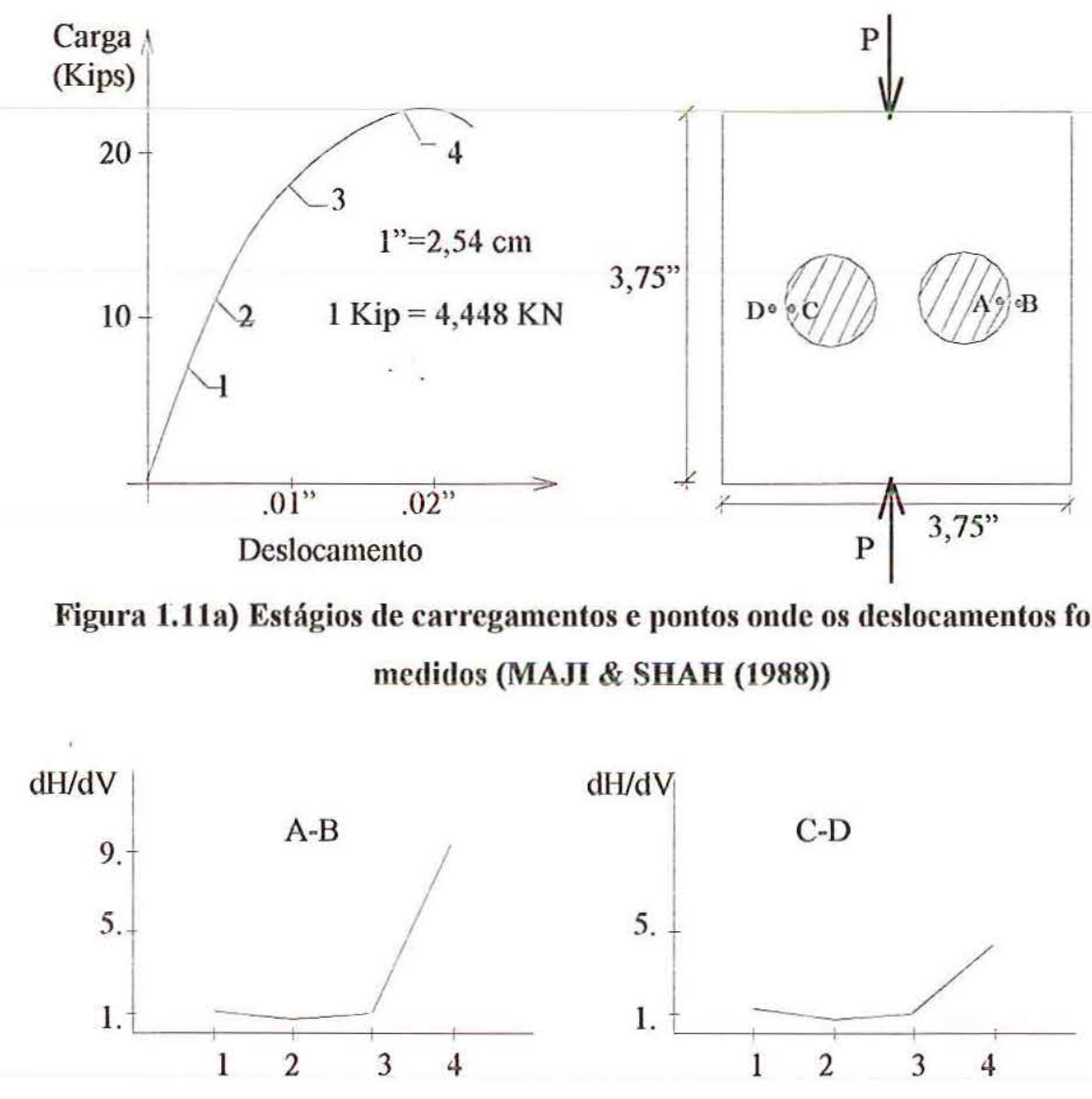

Figura 1.11a) Estágios de carregamentos e pontos onde os deslocamentos foram medidos (MAJI \& SHAH (1988))

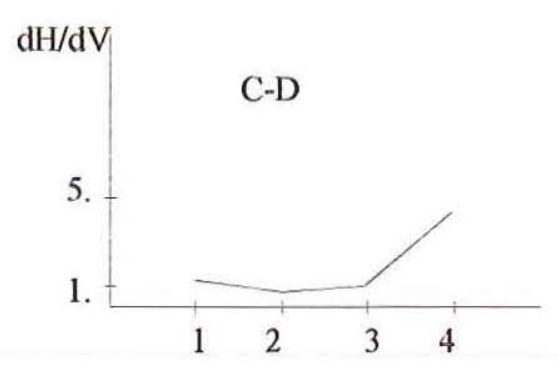

Figura 1.11b) Razão entre deslocamentos verticais e horizontais entre os pontos A-B e C-D

((MAJI \& SHAH (1988)) 
Os resultados do desenvolvimento de fissuras nos espécimes contendo agregados de uma polegada de diâmetro em vários estágios de carregamento são mostrados na figura 1.12 (MAJI \& SHAH (1988)). Os vários pontos em que os hologramas foram feitos são mostrados no diagrama carga-deslocamento. As fissuras observadas em cinco diferentes estágios de carga são mostradas.

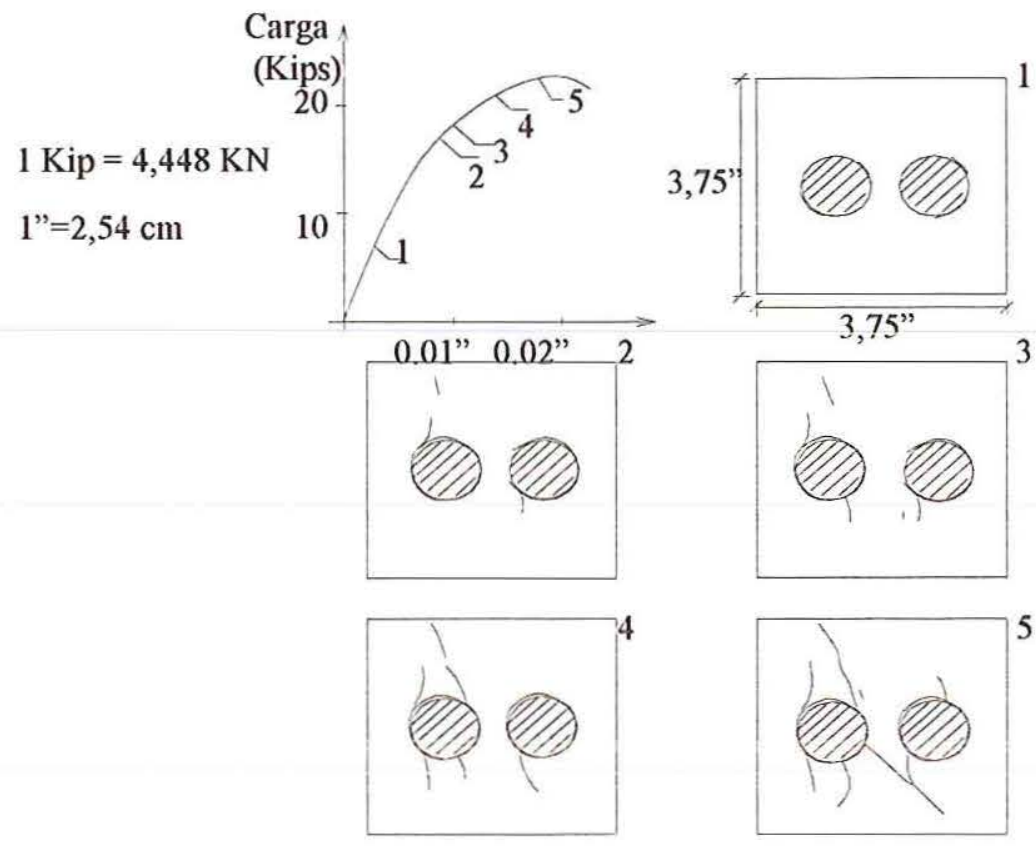

Figura 1.12 - Desenvolvimento de modelos de fissuras em vários estágios de carregamento.

Para fins de análise fenomenológica, a figura 1.13 (PROENÇA (1988)) ilustra a progressiva redução na rigidez inicial à medida que se aumenta o nível de deformação previamente aplicada. A redução do módulo de elasticidade inicial é aparente já em deformações muito baixas, mas a taxa de mudança torna-se grande na região que segue ao pico da curva tensão-deformação. 


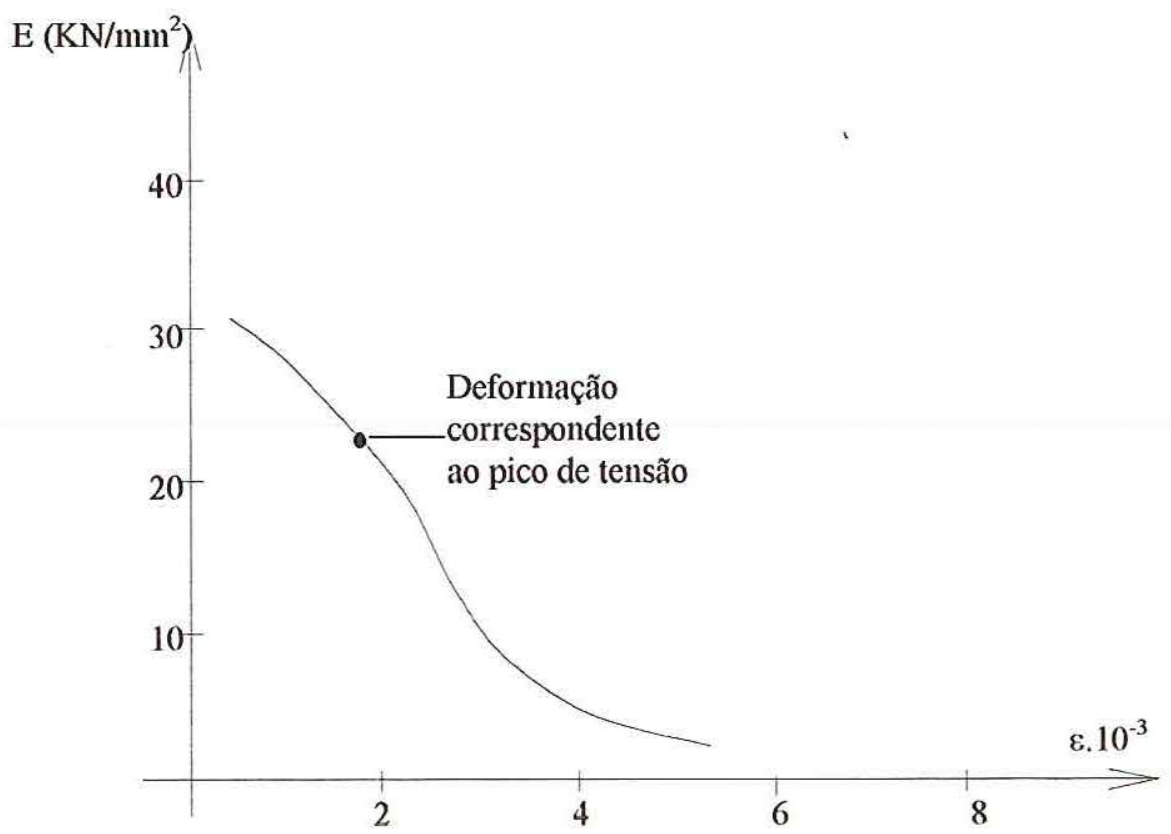

Figura 1.13 - Redução progressiva ḋa rigidez inicial.

Outro indicador da degradação estrutural do material é a energia dissipada no dano definida por SPOONER \& DOUGILL (1975) como a energia dissipada por um material ideal exibindo comportamento similar àquele do concreto (figura 1.14a). A figura 1.14b mostra a evolução da energia dissipada acumulada em um espécime de concreto. Acumulação da

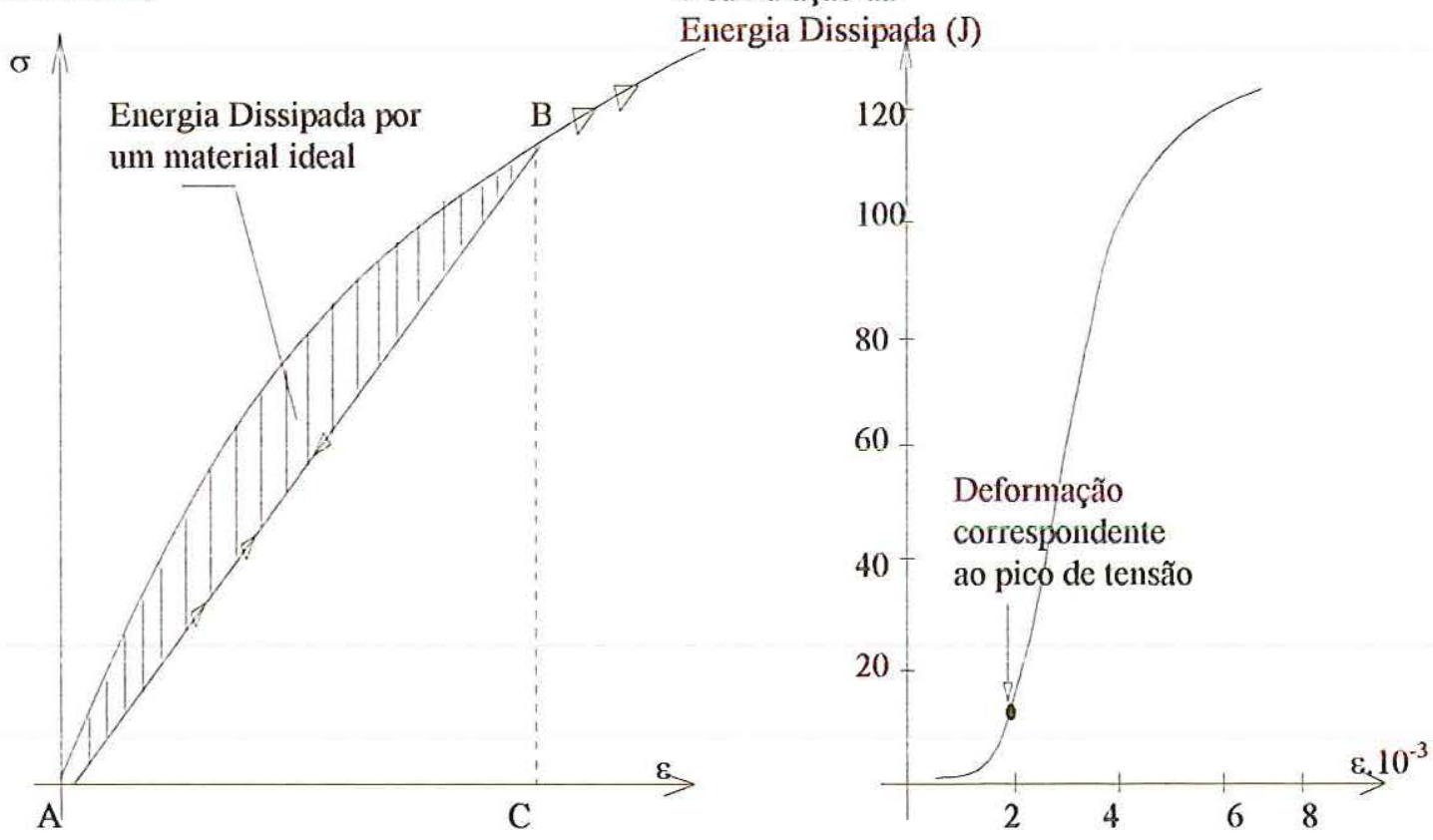

a)

b)

Figura 1.14 a) Energia dissipada por um material ideal

b) Energia dissipada por um espécime de concreto

(SPOONER \& DOUGILL (1975)) 
Dos casos ilustrados nas figuras (1.13) e (1.14), pode-se observar que o dano inicia-se com pequenas deformações, apresentando um desenvolvimento progressivo até atingir a taxa máxima logo após a carga de pico e tendendo a um valor assintótico com o crescimento da deformação.

Dos ensaios observados neste item, conclui-se que não parece haver um limite ou critério inicial de dano, baseado em tensão ou deformação, abaixo do qual o material permanece íntegro. Sendo a redução da rigidez mais evidente após o pico, é essencial a caracterização do comportamento 'softening' para uma apropriada modelagem por uma teoria contínua, do comportamento 'pós-pico'. 


\section{COMENTÁRIOS SOBRE A MECÂNICA DO DANO CONTÍNUO}

\subsection{INTRODUÇ̃̃O}

Este capítulo é dedicado ao estudo de alguns fundamentos da Mecânica do Dano e da Termodinâmica com relação aos meios contínuos fazendo uma revisão de algumas de suas generalidades, uma breve revisão bibliográfica e fornecendo algumas definições necessárias para o melhor entendimento deste trabalho.

Em destaque, apresentam-se as leis da Termodinâmica, a desigualdade de Clausius-Duhem e o método do estado local, ferramenta esta necessária para a formulação dos modelos constitutivos abordados no presente trabalho.

Por último faz-se uma exposição do formalismo da Mecânica do Dano de modo a atender os princípios da termodinâmica em processos irreversíveis. 


\subsubsection{Generalidades}

A resposta não-linear física de sólidos é uma manifestação macroscópica de mudanças irreversíveis na microestrutura. A mecânica do dano contínuo é uma ferramenta para a análise dos efeitos da deterioração do material em sólidos submetidos a ação de natureza mecânica ou térmica. Enquanto que a mecânica da fratura lida com as condições de propagação de fissuras macroscópicas, a mecânica do dano contínuo estuda o efeito de microfissuras distribuídas na resposta do material. A teoria do dano descreve localmente a evolução dos fenômenos que se desenvolvem entre um estado inicial, relativo a uma situação de material íntegro, e um estado final, represcntado pela formação de uma fissura macroscópica ou, em outras palavras, a ruptura do elemento de 'volume representativo' em torno do ponto considerado. No caso do concreto, um material no qual a fissuração é o fenômeno dominante no comportamento não-linear, a mecânica do dano é sem dúvida capaz de formular modelos realísticos.

O dano não é uma grandeza física mensurável diretamente, mas no âmbito de uma modelagem matemática é possível quantificá-lo através da redução progressiva de uma propriedade mecânica global, como por exemplo o módulo de elasticidade.

No que se refere à relação dano-fratura discreta esta pode ser considerada como o resultado da localização do dano evolutivo numa certa região do corpo. Portanto, o dano pertence a uma fase anterior à da fratura.

Em suma, a diferença entre Mecânica do Dano e Mecânica da Fratura pode ser colocada, segundo JANSON \& HULT (1977), da seguinte forma ( figura 2.1 (DRIEMEIER (1995)):

- na Mecânica do Dano, a resistência de uma estrutura carregada é determinada em função da evolução de um campo de defeitos continuamente distribuído, tais como microfissuras ou poros;

- na Mecânica da Fratura, a resistência de uma estrutura carregada é determinada em função da evolução de um defeito em particular, como uma fissura 
pontiaguda pré-definida. O meio em volta da fissura é assumido como mecanicamente intacto.

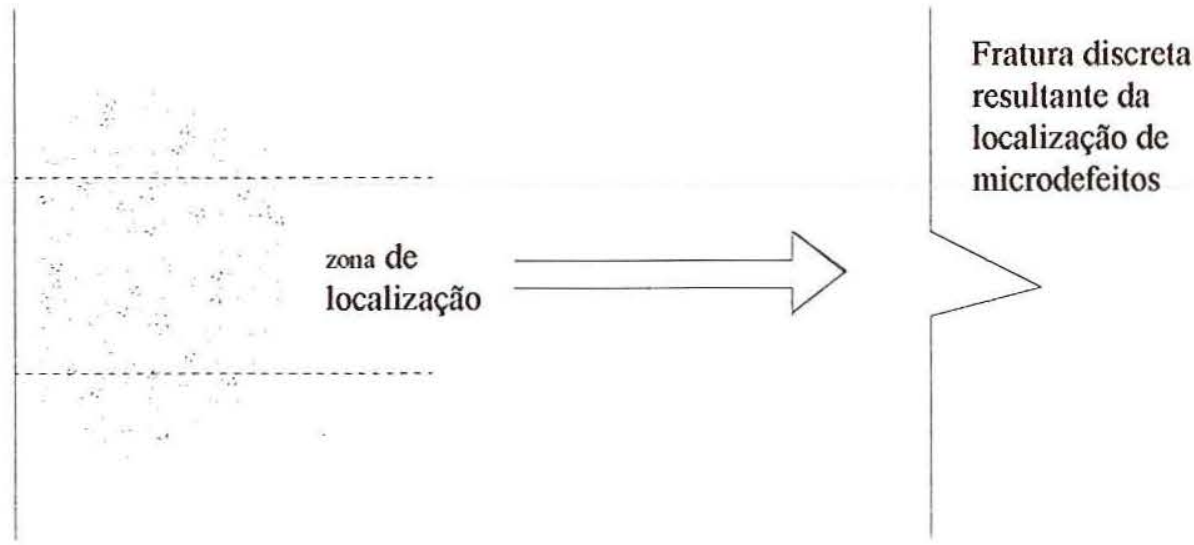

Figura 2.1 - Campo de validade das Mecânicas do Dano e da Fratura.

O trabalho pioneiro que introduziu o conceito de Dano Contínuo foi elaborado por KACHANOV (1958). Este trabalho surgiu do interesse em modelar o efeito da fissuração distribuída na ruptura do tipo frágil observada em metais após um período de deformação lenta. Portanto, foi proposta a consideração de uma variável $\psi$, denominada então de continuidade. Assim, para um material completamente livre de defeitos vale a condição $\psi=1$, enquanto $\psi=0$ caracteriza um material completamente destruído com nenhuma capacidade de carga. A quantidade $\psi$, podese dizer, quantifica a ausência de deterioração do material. A quantidade complementar $\mathrm{D}=1-\psi$ é, por conseguinte, uma medida do estado de deterioração ou dano. Para um material completamente livre de defeitos tem-se $\mathrm{D}=0$, enquanto $\mathrm{D}$ $=1$ corresponde a um estado de completa perda de integridade da estrutura do material.

Enquanto KACHANOV (1958) assumiu D como uma variável de natureza escalar, estudos posteriores levaram à proposição de quantidades tensoriais para descrever o dano. De um modo geral D pode ser de natureza escalar (dano isótropo) ou de natureza tensorial (dano anisótropo).

Um outro trabalho importante é o de RABOTNOV (1969) que propôs incluir a perda de rigidez do material como conseqüência da fissuração. Posteriormente a chamada Mecânica do Dano Contínuo ("Contimuum Damage Mechanics") foi 
formalizada com base na termodinâmica dos processos irreversíveis por LEMAITRE \& CHABOCHE (1985).

Nos últimos anos vários modelos constitutivos que incorporam o conceito de dano têm sido propostos, alguns deles com especial referência ao concreto. Entre eles pode-se citar: KACHANOV (1984) e MURAKAMI (1981) modelando a deterioração lenta do material (creep damage), LEMAITRE (1984), MARIGO (1985), LEMAITRE \& CHABOCHE (1974) e LEMAITRE (1984) na interação dano-fadiga, SIMO \& JU (1987), TAI (1990) e HAN \& MOU(1993) sobre dano em materiais dúcteis, MAZARS (1984) sobre dano em estruturas de concreto armado e LA BORDERIE, PIJAUDIER-CABOT \& MAZARS (1991) dano em estruturas de concreto armado e concreto em fibras sujeitas a carregamento cíclico e FLOREZLÓPEZ (1993) tratando do dano em pórticos de concreto armado.

Dentre os modelos citados, serão abordados no presente trabalho os modelos de MAZARS (1984), de LA BORDERIE, PIJAUDIER-CABOT \& MAZARS (1991) e o de FLOREZ-LÓPEZ (1993).

O modelo escalar de MAZARS (1984) é indicado para o estudo de processo de dano do concreto submetido a carregamento proporcional ou radial. O dano é quantificado como uma função de uma deformação equivalente, que caracteriza o estado local de alongamentos do material. A lei de evolução da variável de dano é definida de tal forma a recuperar, como um caso particular, os resultados experimentais dos testes de tração e compressão uniaxiais ( os mesmos servem de base para identificar os parâmetros do modelo).

Já o modelo de LA BORDERIE, PIJAUDIER-CABOT \& MAZARS (1991) apresenta duas variáveis escalares que descrevem o efeito de dano em tração e compressão respectivamente. As deformações anelásticas são devidas apenas ao dano. $\mathrm{O}$ efeito de fechamento de fissuras é progressivo e controlado pela inversão de sinal das tensões principais.

Em quase todas as publicações e estudos, faz-se o uso do método dos elementos finitos, empregando-se elementos planos ou tridimensionais o que nem sempre é o mais adequado à análise de grande parte das estruturas. Contudo, existem linhas de pesquisa que contemplam o desenvolvimento de modelos simplificados que 
utilizam elementos mais adequados para a análise destas estruturas. FLOREZ-LÓPEZ (1993) propôs um desses modelos, sendo o mesmo abordado neste trabalho. Fundamentado na termodinâmica dos processos irreversíveis, o modelo proposto por FLOREZ-LÓPEZ (1993) é dedicado ao estudo de estruturas reticulares utilizando um elemento finito de barra, onde os efeitos de dano e plasticidade acoplados são concentrados em rótulas anelásticas nas extremidades dos elementos, permanecendo a barra com comportamento elástico.

\subsubsection{Definição da Variável de Dano}

Considere-se um sólido com dano do qual é isolado um elemento de volume. Tal elemento é dito 'representativo' por possuir dimensão suficientemente grande de modo que se possa admitir que contenha uma distribuição homogênea dos defeitos, sendo ao mesmo tempo pequeno para ser considerado como um ponto material do contínuo. Dessa forma admite-se continuidade para as funções representativas dos fenômenos que ocorrem no elemento.

Seja $\mathrm{S}$ a área de uma das faces do elemento representativo, a qual definida por um plano cujo versor normal tem direção n (figura 2.2). Nesta seção, as microfissuras e microdefeitos que contribuem para o dano tem formas e orientações quaisquer. 


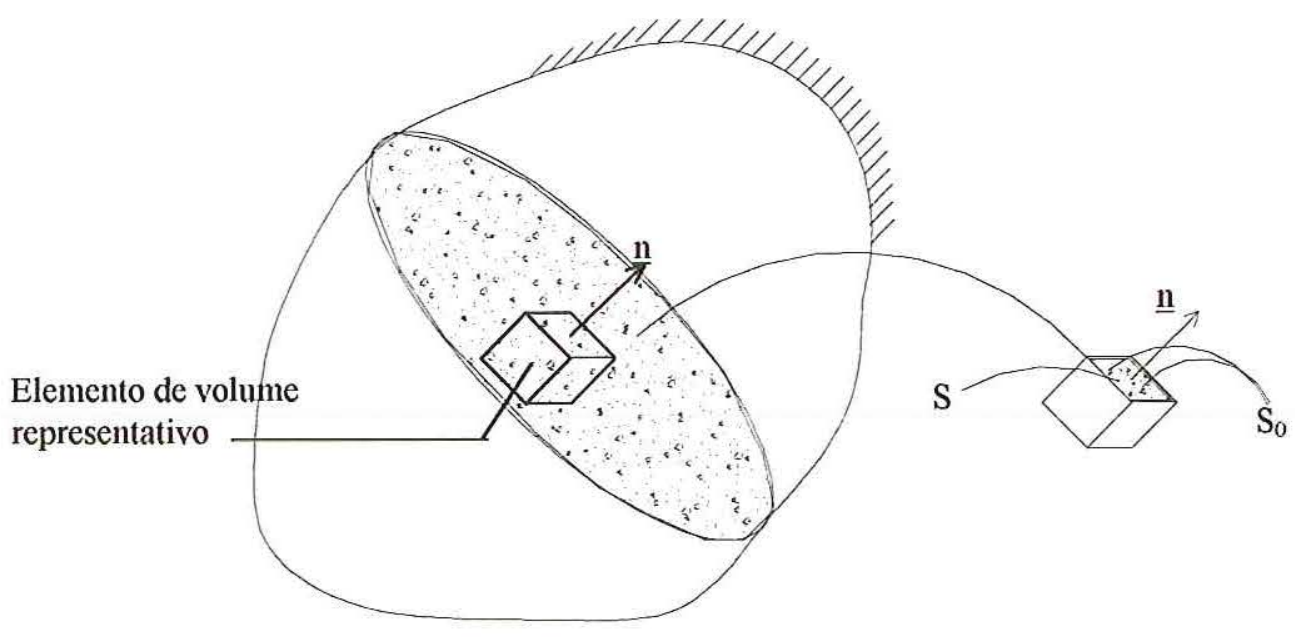

Figura 2.2 - Elemento de volume com dano

No plano da seção considerada, sendo $\widetilde{\mathrm{S}}$ a parcela da área total que efetivamente oferece resistência $(\widetilde{\mathrm{S}} \leq \mathrm{S})$, a diferença

$\mathrm{S}_{\mathrm{o}}=\mathrm{S}-\widetilde{\mathrm{S}}$

define a área de defeitos.

Por definição, LEMAITRE \& CHABOCHE (1985) e LEMAITRE (1984)

$D_{n}=\lim _{S \rightarrow 0} \frac{S_{0}}{S}$

representa uma medida local do dano. A variável de dano assume valores contidos no intervalo $0 \leq D_{n} \leq 1$, sendo que $D_{n}=0$ tem correspondência com a situação de material íntegro e $\mathrm{D}_{\mathrm{n}}=1$ indica um estado de total deterioração.

Imaginando-se uma situação em que as microfissuras se distribuam segundo uma direção privilegiada, os valores da variável $D_{n}$ variam de acordo com a orientação da normal n. Essa situação configura o que se pode definir como dano anisótropo.

O dano isótropo corresponde, então, a uma situação em que os microdefeitos tenham uma distribuição mais ou menos uniforme em qualquer direção, ou seja, 
independente da orientação da normal ñ. Nesse caso, um único valor da variável de dano caracteriza completamente o estado local de deterioração.

$\mathrm{D}=\mathrm{D}_{\mathrm{n}} \quad \forall \underline{\mathrm{n}}$

\subsubsection{Definição da Tensão Efetiva}

A tensão efetiva é a tensão obtida tomando-se a parte de seção que resiste efetivamente ao carregamento.

No caso unidimensional, se $\mathrm{F}$ é a força aplicada numa seção $\mathrm{S}$ do elemento de volume representativo, $\sigma=\mathrm{F} / \mathrm{S}$ é a tensão que satisfaz a equação de equilíbrio. Em presença de um dano isótropo, de medida escalar $\mathrm{D}$, a seção resistente efetiva é:

$\widetilde{\mathrm{S}}=\mathrm{S}-\mathrm{S}_{0}=\mathrm{S}(1-\mathrm{D})$

Portanto, da definição de tensão efetiva $\widetilde{\sigma}$ tem-se que:

$\widetilde{\sigma}=\frac{F}{\widetilde{S}} \quad$, ou, $\quad \widetilde{\sigma}=\frac{\sigma}{(1-D)}$

Obviamente $\widetilde{\sigma} \geq \sigma$ e em particular

$\widetilde{\sigma}=\sigma \quad$ para material íntegro;

$\widetilde{\sigma} \rightarrow \infty \quad$ para material totalmente danificado.

No caso tridimensional de dano isótropo, a razão $\mathrm{S} / \widetilde{\mathrm{S}}$ não depende da orientação da normal e o operador (1-D) se aplica a todos os componentes do estado de tensão. Escreve-se portanto o tensor $\underline{\tilde{\sigma}}$ de tensões efetivas da seguinte forma:

$\widetilde{\widetilde{\sigma}}=\frac{\underline{\sigma}}{1-\mathrm{D}}$ 
A fim de obter um modelo coerente com a hipótese do meio contínuo é indispensável introduzir uma hipótese sobre a deformação $\varepsilon=\varepsilon(D)$. A hipótese de equivalência de deformações proposta por LEMAITRE \& CHABOCHE (1985), é expressa nos seguintes termos:

"O estado de deformação, unidimensional ou tridimensional, de um material com dano é obtido da lei do comportamento do material íntegro onde a tensão normal é substituída pela tensão efetiva.” (figura 2.3)

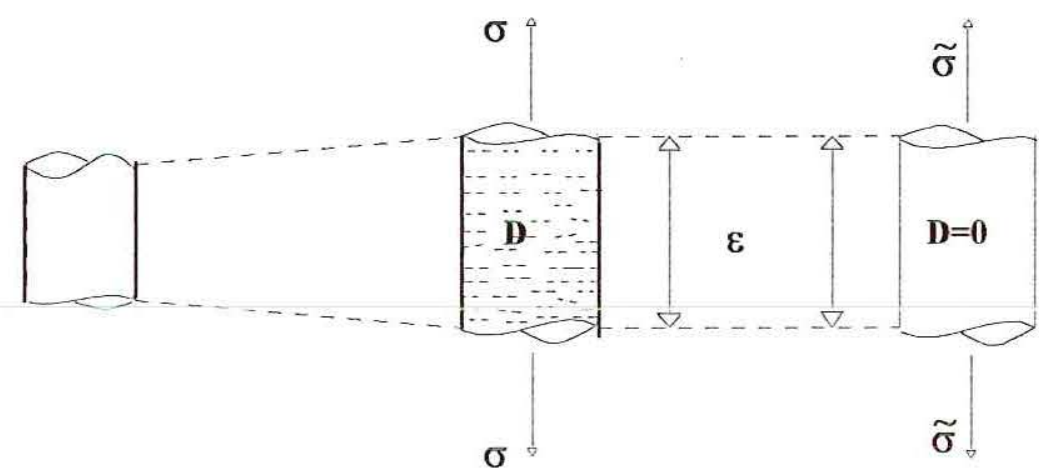

Figura 2.3 - Hipótese de deformação equivalente

De fato, considerando-se um comportamento elástico linear para a parcela íntegra do meio, no caso unidimensional a deformação elástica é dada por:

$\varepsilon_{\mathrm{c}}=\frac{\widetilde{\sigma}}{\mathrm{E}}$

onde $\mathrm{E}$ é o módulo de Young do material íntegro.

Utilizando-se da definição de tensão efetiva, esta última relação passa a ser escrita por:

$$
\varepsilon_{\mathrm{e}}=\frac{\widetilde{\sigma}}{\mathrm{E}}=\frac{\sigma}{(1-\mathrm{D}) \mathrm{E}}
$$


Igualando-se as relações (2.7) e (2.8) obtém-se uma relação que define o módulo de elasticidade $\widetilde{\mathrm{E}}$ para um meio contínuo de resposta equivalente ao meio deteriorado

$\widetilde{\mathrm{E}}=(1-\mathrm{D}) \mathrm{E}$

Essa última relação coloca em evidência a degradação das características mecânicas do material causadas pelo dano.

Fazendo-se referência a materiais com comportamento puramente elástico, de (2.9) obtém-se:

$$
\mathrm{D}=1-\frac{\widetilde{\mathrm{E}}}{\mathrm{E}}
$$

Esta relação é extremamente interessante pois permite, determinar os valores de dano (ver figura 2.4) a partir de medidas dos valores do módulo de elasticidade relativo a sucessivos carregamentos elásticos.

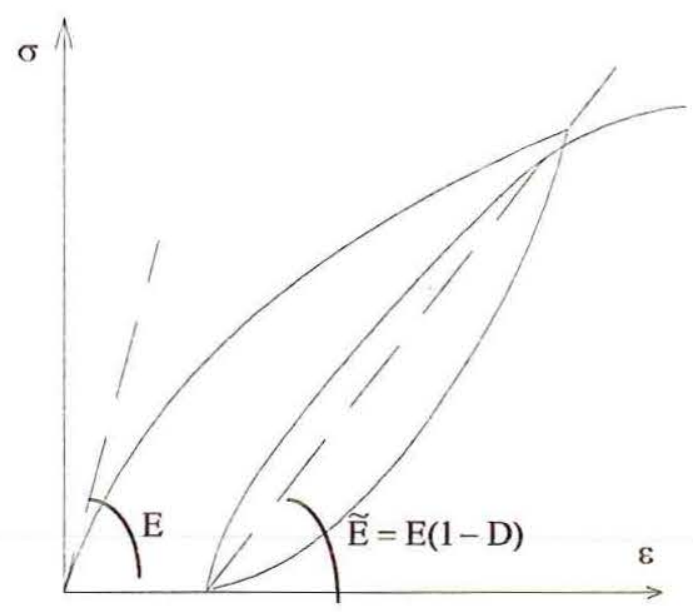

Figura 2.4 - Curva $\sigma-\varepsilon$ do comportamento à compressão do concreto.

Como foi visto, uma variável de dano de natureza escalar age do mesmo modo sobre todos os componentes do tensor de tensões $\underline{\sigma}$, num caso multiaxial, ou ainda sobre todos os componentes do tensor constitutivo elástico como indica a expressão 
2.9. Desse modo o material inicialmente isótropo mantém a isotropia no processo de danificação. Em termos de comportamento real do material, a microfissura superficial, induzida pelo carregamento possui uma certa orientação de modo que o dano é em geral do tipo anisótropo. Em outras palavras o operador de dano é de natureza tensorial e a isotropia inicial do material vem alterada no processo de danificação.

As definições de tensão efetiva e de deformação equivalente, introduzidas por J. L. Chaboche e J. Lemaitre, aplicam-se a um material com comportamento inicial qualquer (elástico ou elastoplástico, isótropo ou anisótropo). Por simplicidade, num caso geral, examina-se em seguida, o caso de elasticidade isotérmica para definir o tensor de tensões efetivas.

Seja pois:

$$
\underline{\sigma}=\underline{\underline{\mathrm{D}}} \underline{\underline{\varepsilon}}
$$

a lei constitutiva do material com dano anisótropo, onde $\underline{\underline{\mathrm{D}}}$ é o tensor constitutivo de quarta ordem.

A lei de comportamento do material íntegro é:

$\underline{\widetilde{\sigma}}=\underline{\underline{D}}_{0} \underline{\varepsilon}$

Combinando as equações (2.11) e (2.12), obtém-se:

$\underline{\sigma}=\left(\underline{\underline{D D D}}_{0}^{-1}\right) \underline{\widetilde{\sigma}}=\underline{\underline{A}} \underline{\widetilde{\sigma}}$

Introduzindo-se o operador de quarta ordem $\underline{\underline{D}}$ tal que:

$(\underline{\underline{I}}-\underline{\underline{D}})=\underline{\underline{A}}$

pode-se escrever: 
$\underline{\underline{\mathrm{D}}}=(\underline{\underline{\mathrm{I}}}-\underline{\underline{\mathrm{D}}}) \underline{\underline{\mathrm{D}}}_{0}$

onde I representa o tensor identidade de quarta ordem. Como conseqüência, resulta:

$\underline{\sigma}=(\underline{\underline{\mathrm{I}}}-\underline{\underline{\mathrm{D}}}) \underline{\widetilde{\sigma}}$

\subsection{FUNDAMENTOS DA TERMODINÂMICA}

\subsubsection{Considerações Gerais}

Considere-se um dado sistema. Quando todas as informações requeridas para sua completa caracterização são avaliáveis, diz-se que o estado do sistema é conhecido. Por exemplo, para um certo meio elástico homogêneo em repouso, uma descrição completa do seu estado termodinâmico requer uma especificação do seu conteúdo material, em termos de quantidade de cada substância química contida; de sua geometria no estado natural ou indeformado; de seus campos de deformação e de tensão; e, dependendo do tipo de aplicação, de uma quantidade independente extra que fixa o grau de quanto está quente ou frio. Estas quantidades são chamadas de variáveis de estado. Se uma certa variável de estado pode ser expressa como uma função de uma série de outras variáveis de estado, então a relação funcional é dita uma equação de estado, e a variável então descrita é chamada de função de estado. A seleção de uma série particular de variáveis de estado independentes é importante em cada problema.

Um sistema está em equilibrio termodinâmico, se para um dado estado, os valores das variáveis de estado são independentes do tempo. Por outro lado, diz-se 
que um sistema pode sofrer um processo se as variáveis de estado dependem do tempo.

Como aplicação dessa idéia no presente trabalho serão abordados modelos constitutivos para o concreto, levando-se em consideração fenômenos de dano e de plasticidade, que são de caráter permanente, através da definição de oportunas variáveis internas. Como se verá, o modelo constitutivo terá garantida a irreversibilidade dos fenômenos, mediante restrições sobre as leis de evolução daquelas variáveis, mantendo-se, dessa forma, consistente com certos princípios fundamentais.

\subsubsection{Primeira Lei da Termodinâmica}

A primeira lei da termodinâmica relaciona a potência mecânica, associada às ações externas, mais a taxa de calor transferida para dentro do sistema, com a mudança da sua energia total. Postula-se a existência de uma quantidade adicional, por unidade de massa, denominada energia interna que compõe juntamente com a energia cinética a energia total do sistema.

Admite-se, portanto, que as formas possíveis de transferência de energia para o sistema são: por trabalho mecânico realizado por forças de superficie $\underline{T}$ e de corpo $\underline{p}$ (por unidade de volume) e transferência de calor por condução através da superficie ou ainda por uma certa fonte que pode gerar internamente uma distribuição de calor.

A equação da taxa de trabalho mecânico, ou a potência externa introduzida ao sistema $\mathrm{P}_{\mathrm{e}}$, realizada sobre uma certa quantidade de massa que ocupa o volume $\Omega$ limitado pela superficie $\partial \Omega$ é expressa pela seguinte equação:

$$
\mathrm{P}_{\mathrm{e}}=\int_{\Omega} \underline{\mathrm{p}} \cdot \underline{\mathrm{v}} \mathrm{d} \Omega+\int_{\partial \Omega} \underline{\mathrm{T}} \cdot \underline{\mathrm{v}} \mathrm{d} \partial \Omega
$$


onde $\underline{\mathrm{v}}$ é o vetor velocidade do ponto material que ocupa a posição $\mathrm{x}$ na configuração atual.

Como $\underline{\mathrm{T}}=\sigma \underline{\mathrm{n}}$ (Teorema de Cauchy) em $\partial \Omega$, onde $\underline{\mathrm{n}}$ é o versor normal ao contorno no ponto, e empregando-se o teorema da divergência, resulta:

$\mathrm{P}_{\mathrm{e}}=\int_{\partial \Omega} \underline{\mathrm{n}} \cdot \sigma^{\mathrm{T}} \underline{\mathrm{v}} \mathrm{d} \partial \Omega+\int_{\Omega} \underline{\mathrm{p}} \cdot \underline{\mathrm{v}} \mathrm{d} \Omega=\int_{\Omega} \operatorname{div}\left(\sigma^{\mathrm{T}} \underline{\mathrm{v}}\right) \mathrm{d} \Omega+\int_{\Omega} \underline{\mathrm{p}} \cdot \underline{\mathrm{v}} \mathrm{d} \Omega$

Lembrando-se ainda que $\operatorname{div}\left(\sigma^{\mathrm{T}} \mathrm{v}\right)=\operatorname{div} \sigma \cdot v+\sigma \cdot \operatorname{grad} \underline{\mathrm{v}}$ Tem-se que:

$P_{\mathrm{e}}=\iint_{\Omega}[(\operatorname{div} \sigma+\underline{p}) \cdot \underline{v}+\sigma \cdot \operatorname{grad} \underline{v}] \mathrm{d} \Omega$

Substituindo-se o primeiro termo entre parênteses da equação anterior pela equação de balanço da quantidade de movimento linear (equação de movimento de Cauchy), que expressa o equilíbrio estático ou dinâmico:

$$
\operatorname{div} \sigma+\underline{p}-\rho \frac{d \underline{v}}{d t}=0 \quad \text { em } \Omega
$$

obtém-se:

$$
\int_{\Omega}\left(\rho \frac{\mathrm{d} \underline{\mathrm{v}}}{\mathrm{dt}} \cdot \underline{\mathrm{v}}+\sigma \cdot \operatorname{grad} \underline{\mathrm{v}}\right) \mathrm{d} \Omega=\frac{\mathrm{d}}{\mathrm{dt}} \int_{\Omega} \frac{1}{2} \rho \underline{v} \cdot \underline{\mathrm{v}} \mathrm{d} \Omega+\int_{\Omega} \sigma \cdot \omega \mathrm{d} \Omega
$$

e portanto,

$$
P_{e}=\frac{d}{d t} \int_{\Omega} \frac{1}{2} \rho \underline{\mathrm{v}} \cdot \underline{\mathrm{v}} \mathrm{d} \Omega+\int_{\Omega} \sigma \cdot \omega \mathrm{d} \Omega
$$


A primeira parcela é a taxa de energia cinética do sistema. A segunda é a denominada potência das tensões (por unidade de volume), sendo $\omega$ o tensor taxa de deformação igual a parte simétrica do tensor gradiente de velocidade.

Assim a potência introduzida pode ser avaliada via taxa de trabalho realizado pelas forças externas (que provocam uma certa variação na quantidade de movimento) ou de forma equivalente pela variação da energia cinética decorrente mais a potência das tensões.

A taxa de calor introduzida no sistema $Q_{e}$ provém, como já mencionado, da condução através da superfície $\partial \Omega$ e de uma fonte de calor que gera internamente uma distribuição por unidade de massa, expressa através de uma variável r.

$Q_{e}=-\int_{\partial \Omega} \underline{q} \cdot \underline{n} d \partial \Omega+\int_{\Omega} \rho r d \Omega$

onde q é o fluxo de calor e o sinal negativo representa o fluxo entrando.

A primeira lei da termodinâmica diz respeito à conservação da energia do sistema, podendo-se enunciá-la da seguinte maneira: a taxa de trabalho mecânico ou potência das cargas externas mais a taxa de calor introduzida no sistema é igual à taxa de energia cinética mais a taxa de variação da energia interna.

$\mathrm{P}_{\mathrm{e}}+\mathrm{Q}_{\mathrm{e}}=\dot{\mathrm{U}}+\dot{\mathrm{E}}_{\mathrm{C}}$

onde:

$\dot{U}=\frac{\mathrm{d}}{\mathrm{dt}} \int_{\Omega} \rho \mathrm{d} \Omega$ é a taxa de energia interna (onde u é a densidde de energia interna por unidade de massa)

$\dot{\mathrm{E}}_{\mathrm{C}}$ é a taxa de energia cinética 
O segundo membro da equação (2.24) é chamado de taxa de energia total do $\operatorname{sistema}\left(\dot{\mathrm{E}}_{\mathrm{T}}\right)$, de modo que:

$\dot{\mathrm{E}}_{\mathrm{T}}=\mathrm{P}_{\mathrm{e}}+\mathrm{Q}_{\mathrm{e}}$

$\mathrm{e}$

$\mathrm{dE}_{\mathrm{T}}=\left(\mathrm{P}_{\mathrm{e}}+\mathrm{Q}_{\mathrm{e}}\right) \mathrm{dt}$

é uma diferencial exata. A equação (2.26) introduz uma outra leitura para a primeira lei de balanço de energia: a potência introduzida é igual à taxa de variação da energia total do sistema.

Substituindo-se as expressões das energias envolvidas na equação (24), obtém-se:

$\frac{\mathrm{d}}{\mathrm{dt}} \int_{\Omega}\left[\frac{1}{2} \rho \underline{v} \cdot \underline{\mathrm{v}}\right] \mathrm{d} \Omega+\int_{\Omega} \sigma \omega \mathrm{d} \Omega-\int_{\hat{o} \Omega} \underline{\mathrm{q}} \cdot \underline{n} \mathrm{~d} \partial \Omega+\int_{\Omega} \rho \operatorname{rd} \Omega=\frac{\mathrm{d}}{\mathrm{dt}} \int_{\Omega}\left[\frac{1}{2} \rho \underline{v} \cdot \underline{\mathrm{v}}+\rho \mathrm{\rho}\right] \mathrm{d} \Omega$

A energia interna por unidade de massa ou energia específica interna é chamada de $u$, então pu é a energia interna por unidade de volume.

Admitindo-se, por um lado, em regime de pequenas deformações:

$\sigma .(1)=\sigma \cdot \dot{\varepsilon}$

e, por outro lado, aplicando-se o teorema da divergência à parcela de fluxo de calor no contorno:

$$
\int_{\partial \Omega} \underline{q} \cdot \underline{n} d \partial \Omega=\int_{\Omega} \operatorname{div} \underline{q} d \Omega
$$


as expressões (2.28) e (2.29) substituídas em (2.27) permitem reescrever a primeira lei em forma local do seguinte modo:

$\rho \dot{u}=\sigma \cdot \dot{\varepsilon}-\operatorname{divq}+\rho \dot{r}$

\subsubsection{Segunda Lei da Termodinâmica}

O primeiro princípio introduz as noções de quantidade de calor recebida e de energia intema do sistema. O segundo princípio introduz as noções de temperatura absoluta e de entropia.

A cada parte $\Omega$ do sistema e a cada instante t, pode-se associar um número $\mathrm{S}$ chamado entropia de $\Omega$ no instante $t$ dado por:

$S=\int_{\Omega} \rho s d \Omega$

onde $\mathrm{s}=\mathrm{s}(\mathrm{x}, \mathrm{t})$ é a entropia específica por unidade de massa da partícula que ocupa a posição $\mathrm{x}$ no instante t.

A segunda lei impõe que num processo qualquer de transformação de um sistema a variação total de entropia deve ser igual ou superar a variação provocada pela transferência de calor. Em particular, num processo irreversível existe produção de entropia positiva. Em forma geral, a lei se exprime por:

$\frac{d}{d t} \int_{\Omega} s \rho d \Omega \geq \int_{\Omega} \frac{r}{T} \rho d \Omega+\int_{\partial \Omega}-\frac{\underline{q}}{T} \cdot \underline{n} d \partial \Omega$

$\mathrm{Na}$ expressão acima aparece a temperatura $\mathrm{T}$, definida como um campo escalar de valores positivos em cada instante $t$ do domínio $\Omega$ em consideração. $O$ 
segundo membro da inequação (2.32) é a taxa de entropia correspondente à transferência de calor.

Empregando-se o teorema da divergência, a relação do segundo princípio passa a

$\int_{\Omega}\left(\rho \frac{\mathrm{ds}}{\mathrm{dt}}+\operatorname{div} \frac{\mathrm{q}}{\mathrm{T}}-\frac{\rho \mathrm{r}}{\mathrm{T}}\right) \mathrm{d} \Omega \geq 0$

Esta desigualdade é válida para qualquer região $\Omega$ do corpo e, portanto, implica na seguinte forma local da irreversibilidade da taxa de produção de entropia:

$\rho \dot{\mathrm{s}}-\frac{\rho \mathrm{r}}{\mathrm{T}}+\operatorname{div}\left(\frac{\mathrm{q}}{\mathrm{T}}\right) \geq 0$

A primeira lei exprime a interconvertibilidade de calor e trabalho mantendo um balanço de energia, mas não impõe nenhuma restrição sobre o sentido em que a troca de energia possa se dar. A segunda lei da termodinâmica através da imposição de variação positiva da entropia, restringe o sentido para a conversão de energia sempre que se manifeste algum processo dissipativo.

\subsubsection{A Desigualdade de Clausius-Duhem}

A primeira e a segunda lei podem ser combinadas conduzindo a uma desigualdade que deve ser observada para que um processo seja termodinamicamente admissível.

Considere-se as relações que exprimem localmente a primeira e a segunda lei:

$$
\rho \dot{u}=\sigma \cdot \dot{\varepsilon}-\operatorname{divq}+\rho r
$$




$$
\rho \dot{\mathrm{s}}-\frac{\rho \mathrm{r}}{\mathrm{T}}+\operatorname{div}\left(\frac{\mathrm{q}}{\mathrm{T}}\right) \geq 0
$$

Da análise tensorial sabe-se que

$$
\operatorname{div} \frac{\underline{q}}{T}=\frac{1}{T} \operatorname{div} \underline{q}-\frac{1}{T^{2}} \operatorname{gradT} \cdot \underline{q}
$$

Substituindo-se essa relação na expressão da segunda lei e combinando-se com a primeira resultam, sucessivamente

$$
\begin{aligned}
& \rho \dot{\mathrm{s}}+\frac{1}{\mathrm{~T}} \operatorname{div} \underline{\mathrm{q}}-\frac{1}{\mathrm{~T}^{2}} \operatorname{gradT} \cdot \underline{\mathrm{q}}-\rho \frac{\mathrm{r}}{\mathrm{T}} \geq 0 \\
& \rho \dot{\mathrm{s}}+\frac{1}{\mathrm{~T}}(\sigma \dot{\varepsilon}+\rho \mathrm{r}-\rho \dot{\mathrm{u}})-\frac{1}{\mathrm{~T}^{2}} \operatorname{gradT} \cdot \underline{\mathrm{q}}-\rho \frac{\mathrm{r}}{\mathrm{T}} \geq 0
\end{aligned}
$$

Finalmente, multiplicando por T e cancelando $\rho r$ a expressão anterior resulta

$$
\rho \mathrm{T} \dot{\mathrm{s}}+\sigma \cdot \dot{\varepsilon}-\rho \dot{\mathrm{u}}-\frac{1}{\mathrm{~T}} \operatorname{gradT} . \underline{\mathrm{q}} \geq 0
$$

É usual trabalhar com o potencial $\psi$ dito de energia livre, definido em função da energia específica u e da entropia s:

$\psi=\mathrm{u}-\mathrm{Ts}$

A derivada deste potencial é dada por:

$$
\dot{\psi}=\dot{\mathrm{u}}-\mathrm{T} \dot{\mathrm{s}}-\mathrm{s} \dot{\mathrm{T}} \Rightarrow \mathrm{T} \dot{\mathrm{s}}-\dot{\mathrm{u}}=-(\dot{\psi}+\mathrm{s} \dot{\mathrm{T}})
$$

Substituindo-se a equação (2.41) na equação (2.39) obtém-se a seguinte forma para a desigualdade de Clausius-Duhem: 


$$
\dot{\psi} \leq \sigma . \dot{\varepsilon}-\rho s \dot{T}-\underline{q} \cdot \frac{1}{T} \nabla T
$$

Processos nos quais a desigualdade de Clausius-Duhem é verificada a cada instante são denominados 'termodinamicamente admissíveis'.

\subsubsection{Método do Estado Local}

Ao formular modelos constitutivos de acordo com os princípios da Termodinâmica dos Processos Irreversíveis, macroscopicamente levam-se em conta fenômenos dissipativos observados na microestrutura por meio de variáveis internas.

O método do estado local, GERMAIN (1973), postula que, num certo instante, o estado termodinâmico de um meio material é completamente definido pelo conhecimento dos valores de um certo número de variáveis naquele instante, que dependem apenas do ponto considerado. Como as derivadas no tempo destas variáveis não estão envolvidas na definição do estado, esta postulação implica em admitir que qualquer evolução possa ser considerada como uma sucessão de estados em equilíbrio.

As variáveis de estado estão relacionadas aos fenômenos a serem descritos pelo modelo e são divididas em dois grupos: observáveis e internas. As variáveis observáveis são aquelas que podem ser quantificadas experimentalmente. Já as variáveis internas não são diretamente medidas.

De um modo geral, em um sistema irreversível, no âmbito das pequenas deformações, o estado termodinâmico local é definido pelas variáveis ditas observáveis, o tensor de deformações $\varepsilon$ e a temperatura $T$, e por um conjunto de variáveis internas $\mathrm{a}_{\mathrm{k}}$ associadas aos processos dissipativos. 


\subsubsection{Potencial de Estado Termodinâmico}

Uma vez definidas as variáveis de estado -observáveis e internas- postula-se a existência de um potencial termodinâmico do qual as leis de estado podem ser derivadas. Um potencial possível é o potencial da energia específica (por unidade de volume) livre $\psi$, dito de Helmholtz:

$\psi=\psi(\underline{\varepsilon}, \mathrm{T}, \underline{\mathrm{a}})$

onde $\underline{\mathrm{a}}^{\mathrm{T}}=\left\{\mathrm{a}_{1}, \mathrm{a}_{2}, \mathrm{a}_{3}, \ldots, \mathrm{a}_{\mathrm{n}}\right\}$ representa um grupo de variáveis internas.

A derivada do potencial pode ser escrita da seguinte forma:

$\dot{\psi}=\frac{\partial \psi}{\partial \varepsilon} \cdot \dot{\varepsilon}+\frac{\partial \psi}{\partial \mathrm{T}} \dot{\mathrm{T}}+\frac{\partial \psi}{\partial \underline{\mathrm{a}}} \cdot \underline{\dot{\mathrm{a}}}$

Relacionando a equação acima com a desigualdade de Clausius-Duhem (2.42) obtém-se:

$\left(\sigma-\frac{\partial \psi}{\partial \varepsilon}\right) \cdot \dot{\varepsilon}-\left(\rho s+\frac{\partial \psi}{\partial \mathrm{T}}\right) \dot{\mathrm{T}}-\left(\frac{\partial \psi}{\partial \underline{\mathrm{a}}}\right) \cdot \underline{\dot{a}}-\left(\frac{1}{\mathrm{~T}}\right) \underline{\mathrm{q}} \cdot \nabla \mathrm{T} \geq 0$

É possível anular independentemente certos termos da desigualdade imaginando-se, por exemplo, um processo elástico que se dê a temperatura constante $(\dot{\mathrm{T}}=0)$ e uniforme $(\nabla T=0)$ e que, portanto, não modifica o conjunto de variáveis internas $(\underline{\dot{a}}=0)$.

Neste caso, para que a desigualdade se verifique qualquer que seja $\dot{\varepsilon}$ é necessário que:

$$
\sigma=\frac{\partial \psi}{\partial \varepsilon}
$$


Por outro lado, pode-se imaginar uma transformação térmica num campo de temperatura uniforme $(\nabla \mathrm{T}=0)$ e que não modifique o vetor de variáveis internas $(\underline{\dot{a}}=0)$ ou variações de deformações. Assim, a desigualdade será sempre verificada se

$$
\rho s=-\frac{\partial \psi}{\partial T}
$$

Denominam-se $\sigma$ e $\mathrm{s}$ como variáveis associadas às variáveis de estado $\varepsilon \mathrm{e} \mathrm{T}$. Por analogia, pode-se definir uma grandeza vetorial associada ao vetor de variáveis internas por:

$$
-\mathrm{A}=\frac{\partial \psi}{\partial \mathrm{a}_{\mathrm{k}}}
$$

As relações (2.46), (2.47) e (2.48) caracterizam as leis de estado. Levam-se em conta as leis de estado, a desigualdade de Clausius-Duhem passa a ser escrita da seguinte maneira:

$$
\text { A. } \underline{\dot{a}}-\left(\frac{1}{T}\right) \nabla T \cdot \underline{q} \geq 0
$$

que exprime a soma da dissipação associada à evolução das variáveis internas e da dissipação térmica por calor.

Segundo DRIEMEIER (1995), no caso de modelos de dano ditos escalares ou isótropos, relativos a processos puramente mecânicos (isotérmicos) aplicando-se aos meios elásticos, desprezam-se as deformações residuais devida à plastificação do material. Nessas condições, a energia específica $\psi$ associada a um comportamento elástico com danificação, passa a ser expressa na forma:

$$
\psi=\frac{1}{2}(1-\mathrm{D}) \underline{\underline{D}}_{0} \varepsilon \cdot \varepsilon
$$


onde D é um parâmetro escalar consistindo na única variável interna considerada e $\underline{\underline{D}}_{0}$ é o tensor de rigidez elástica inicial do material íntegro.

Essa expressão é uma consequência direta da hipótese de que o tensor de rigidez elástica, obtido derivando-se duas vezes $\psi$ em relação ao tensor de deformações $\varepsilon$, é uma função da variável interna de dano:

$\psi_{\infty}=\underline{\underline{\mathrm{D}}}(\mathrm{D})=(1-\mathrm{D}) \underline{\underline{\mathrm{D}}}_{0}$

Das equações (2.46) e (2.50), obtém-se a lei constitutiva:

$\underline{\sigma}=(1-\mathrm{D}) \underline{\underline{\mathrm{D}}}_{0} \varepsilon$

Por outro lado, a equação (2.45) fornece:

$\left(\underline{\underline{D}}_{0} \varepsilon . \varepsilon\right) \dot{\mathrm{D}} \geq 0$

Observando-se que o termo entre parênteses é quadrático definido positivo, resulta que:

$\dot{\mathrm{D}} \geq 0$

Essa condição mostra que os processos de danificação são termodinamicamente admissíveis se conduzem à uma evolução positiva ou nula da variável representativa do dano. 


\subsubsection{Potenciais de Dissipação}

Conhecidas as relações entre as variáveis de estado, observáveis e internas, e suas respectivas variáveis associadas, o modelo constitutivo se completa com o estabelecimento das leis de evolução para as variáveis de estado, sendo este o objetivo dos potenciais de dissipação.

Na equação de Clausius-Duhem (2.49) o primeiro termo é chamado de dissipação intrínseca ou mecânica e está associado à evolução da variável interna de dano. O último termo representa a dissipação térmica devida à condução de calor.

$Y \cdot \dot{D}-\left(\frac{1}{T}\right) \nabla T \cdot \underline{q} \geq 0$

sendo $Y=-A$.

Considerando-se a variável de dano $\mathrm{D}$, por exemplo, definem-se as leis complementares de evolução a partir de derivadas sobre um potencial de dissipação $\Phi$, expresso matematicamente por uma função escalar contínua e convexa das variáveis associadas. Assim sendo, resulta:

$\dot{\mathrm{D}}=-\frac{\partial \Phi}{\partial \mathrm{Y}}$

Portanto assume-se válida, para um material padrão, a lei da normalidade (2.55) e a propriedade de associatividade (a função potencial $\Phi$ de dissipação coincide com a função $\mathrm{F}$ representativa do critério de danificação) de modo que a equação evolutiva possa ser expressa na forma

$$
\begin{aligned}
\dot{\mathrm{D}}=\dot{\lambda} \frac{\partial \mathrm{F}}{\partial \mathrm{Y}} \quad \text { com } \quad & \dot{\lambda}=0 \text { se } \mathrm{F}<0 \text { ou } \mathrm{F}=0 \text { e } \dot{\mathrm{F}}<0 \\
\dot{\lambda} & >0 \text { se } \mathrm{F}=0 \text { e } \dot{\mathrm{F}}=0
\end{aligned}
$$


onde $\lambda$ é o multiplicador de dano e F é uma função convexa representando o critério para a evolução do dano.

\subsection{FORMALISMO DA MECÂNICA DO DANO CONTÍNUO}

Os processos que ocorrem na microestrutura de um material, tais como mudanças de porosidade, escorregamento a nível de cristais, difusão e outros, têm origem em microdefeitos constituídos por inclusões, ou mesmo vazios. Esses processos contribuem, cada qual com sua parcela, na resposta não-linear dos sólidos observada macroscopicamente. Os microdefeitos são genericamente referenciados como dano inicial do material, sendo favorecedores da concentração de microtensões.

Estando o sólido solicitado mecanicamente, ocorre a evolução do dano inicial através do rompimento das ligações entre os átomos. O processo de dano evolutivo tem influência direta na resposta elástica do material sendo evidenciado macroscopicamente por reduções de rigidez e resistência do material. Por outro lado, aquele processo tem influência indireta na resposta elastoplástica devido a redução da área resistente efetiva alterando, por consequência, a velocidade com que se processam as deformações permanentes.

Na maioria dos materiais ditos granulares, sendo este o caso do concreto, temse o dano como processo fundamental na sua resposta não-linear. Já nos metais, a plasticidade é a razão básica de sua resposta não-linear, sendo sua evolução caracterizada pelo movimento de linhas de discordância (a grosso modo, defeitos de continuidade geométrica na distribuição das ligações atômicas). Esse movimento produz deformações irreversíveis, não estando a ele associado uma mudança significativa de volume. Devida à relação indireta entre evolução do dano e plasticidade, na formulação de um modelo constitutivo pode-se propor um acoplamento dito cinético ao nível das leis de evolução das variáveis internas 
representativas destes fenômenos. Um modelo com essas características permite descrever o comportamento de um meio através da redução da rigidez e resistência, além do aparecimento de deformações permanentes.

Dentro deste contexto, a Mecânica do Dano apresenta-se como uma teoria adequada para a formulação de modelos constitutivos de materiais que apresentam defeitos em sua microestrutura. Fundamentada nos princípios gerais da termodinâmica, a Mecânica do Dano segue um formalismo resultante da combinação de conceitos e métodos da termodinâmica com a consideração de variáveis internas, inserindo-se numa teoria mais ampla denominada termodinâmica dos princípios irreversíveis. No entanto, a sua particularidade está no conjunto de hipóteses fundamentais admitidas:

- os processos irreversíveis podem ser aproximados por uma sequência de estados de equilíbrio aos quais correspondem valores instantâneos de um número finito de variáveis internas

- as variáveis internas a serem escolhidas devem representar os processos dissipativos dominantes

- a resposta do meio depende exclusivamente de seu estado atual

Dentro do formalismo que segue são desconsiderados efeitos não-mecânicos, como por exemplo a condução e a irradiação de calor.

Aplicando-se o princípio de balanço de energia (primeira lei da termodinâmica) num processo dissipativo, o qual consiste numa transição entre dois estados de equilíbrio termodinâmico, vale a seguinte relação representada em termos de taxas:

$$
\mathrm{P}_{\mathrm{e}}=\dot{\mathrm{U}}+\dot{\mathrm{E}}_{\mathrm{D}}+\dot{\mathrm{E}}_{\mathrm{C}}
$$

onde:

$\mathrm{P}_{\mathrm{e}}$ é a potência das forças externas

U் é a taxa de energia interna 
$\dot{\mathrm{E}}_{\mathrm{C}}$ é a taxa de energia cinética

$\dot{\mathrm{E}}_{\mathrm{D}}$ é a taxa de energia dissipada

É possível notar que a potência das forças externas é dada pela soma da potência das tensões $\sigma \cdot \dot{\varepsilon}$ mais uma variação de energia cinética. Nessas condições, localmente a relação anterior passa a ser expressa por:

$\sigma \cdot \dot{\varepsilon}=\dot{U}+\dot{\mathrm{E}}_{\mathrm{D}}$

sendo que as grandezas envolvidas passam a ser entendidas com referência à unidade de volume.

A segunda lei da termodinâmica, relacionada à produção de entropia, estabelece que a taxa de energia dissipada é sempre positiva. Portanto, considerandose $\dot{\mathrm{E}}_{\mathrm{D}}>0$ da (2.58) obtém-se a chamada "Desigualdade de Clausius-Duhem":

$$
\sigma \cdot \dot{\varepsilon} \geq \dot{U}
$$

Processos nos quais a desigualdade (2.59) é verificada a cada instante são denominados 'processos termodinamicamente admissíveis'.

A energia interna pode ser denominada energia livre, pois não estão sendo considerados efeitos não-mecânicos. Ela pode ser expressa em função de um conjunto de variáveis, chamadas de "variáveis de estado", as quais definem localmente o estado do material. As variáveis de estado, por sua vez, são expressas por funções contínuas no tempo, e representam grandezas mensuráveis de forma direta ou indireta. De acordo com isto, são classificadas, respectivamente, em variáveis observáveis e internas.

Admitindo-se o caso de pequenas deformações, em processos onde se caracteriza uma deformação residual, o tensor de deformações $\varepsilon$ é normalmente representado em forma aditiva pela soma das partes elástica $\varepsilon^{\mathrm{e}}$, recuperável, e 
permanente $\varepsilon^{\mathrm{p}}$, irrecuperável. $\mathrm{O}$ tensor de deformações $\varepsilon$ é uma variável de estado observável, sendo expressa em termos de taxas por:

$\dot{\varepsilon}=\dot{\varepsilon}^{\mathrm{e}}+\dot{\varepsilon}^{\mathrm{p}}$

Admitindo-se que a parcela permanente seja resultante de algum processo interno dissipativo, e portanto função de alguma variável interna, é razoável tomar para variável de estado observável o tensor elástico das deformações $\varepsilon^{e}$. Assim, representando-se por $\underline{a}_{k}$ o vetor que reúne o conjunto de variáveis internas associadas aos mecanismos dissipativos dominantes, no caso plasticidade e dano, a densidade de energia interna pode ser simbolizada por:

$\mathrm{U}=\mathrm{U}\left(\varepsilon^{\mathrm{e}}, \underline{\mathrm{a}}_{\mathrm{k}}\right)$

Assim sendo, a desigualdade de Clausius-Duhem (2.59) assume a forma:

$\sigma \cdot \dot{\varepsilon} \geq \frac{\partial \mathrm{U}}{\partial \varepsilon^{\mathrm{e}}} \cdot \dot{\varepsilon}^{\mathrm{e}}+\frac{\partial \mathrm{U}}{\partial \underline{\mathrm{a}}_{\mathrm{k}}} \cdot \underline{\dot{\mathrm{a}}}_{\mathrm{k}}$

Levando-se em conta a equação (2.60), segue que:

$\left(\sigma-\frac{\partial U}{\partial \varepsilon^{c}}\right) \cdot \dot{\varepsilon}^{\mathrm{e}}+\sigma \cdot \dot{\varepsilon}^{\mathrm{p}}-\frac{\partial \mathrm{U}}{\partial \underline{\mathrm{a}}_{\mathrm{k}}} \cdot \underline{\dot{\mathrm{a}}}_{\mathrm{k}} \geq 0$

A relação anterior deve ser satisfeita considerando-se processos que envolvam uma variação independente e qualquer das variáveis de estado, incluindo-se os processos puramente elásticos (onde $\dot{\varepsilon}^{\mathrm{p}} \mathrm{e} \underline{\dot{a}}_{\mathrm{k}}$ são nulos). Para garantir que (2.63) seja sempre satisfeita, uma maneira seria impor: 
$\sigma=\frac{\partial \mathrm{U}}{\partial \varepsilon^{\mathrm{e}}} \quad$ e $\quad \sigma \cdot \dot{\varepsilon}^{\mathrm{p}}-\frac{\partial \mathrm{U}}{\partial \underline{\mathrm{a}}_{\mathrm{k}}} \cdot \underline{\dot{\mathrm{a}}}_{\mathrm{k}} \geq 0$

A relação (2.64a) representa uma lei de estado e o tensor de tensões $\sigma$ é a variável associada à variável de estado $\dot{\varepsilon}^{\mathrm{e}}$. Por analogia, o vetor das variáveis termodinâmicas associadas às variáveis internas é definido por:

$$
\mathrm{A}_{\mathrm{k}}=-\frac{\partial \mathrm{U}}{\partial \underline{\mathrm{a}}_{\mathrm{k}}}
$$

Observe-se que $\sigma$ e $-\sigma$ são também associadas a $\varepsilon$ e $\varepsilon^{\mathrm{p}}$, respectivamente, pois considerando-se a decomposição do tensor das deformações:

$$
\begin{aligned}
& \frac{\partial U}{\partial \varepsilon}=\frac{\partial U}{\partial \varepsilon^{\mathrm{e}}} \frac{\partial \varepsilon^{\mathrm{e}}}{\partial \varepsilon}=\sigma \\
& \frac{\partial U}{\partial \varepsilon^{\mathrm{p}}}=\frac{\partial U}{\partial \varepsilon^{\mathrm{e}}} \frac{\partial \varepsilon^{\mathrm{e}}}{\partial \varepsilon^{\mathrm{p}}}=-\sigma
\end{aligned}
$$

Da hipótese de que $\varepsilon^{\mathrm{p}}$ é dependente do vetor de variáveis internas, em termos de taxas é razoável admitir-se uma relação linear do tipo:

$\dot{\varepsilon}^{\mathrm{p}}=\mathrm{B} \underline{\dot{a}}_{\mathrm{k}}$

onde B é uma transformação linear. Desse modo, a desigualdade (2.64b) passa a ser representada por:

$$
\left(B^{*} \sigma+A_{k}\right) \cdot \underline{\dot{a}}_{k} \geq 0 \quad \text { ou } \quad N \cdot \underline{\dot{a}}_{k} \geq 0
$$

sendo $\mathrm{B}^{*}$ uma transformação linear tal que $\sigma \cdot B \underline{\mathrm{a}}_{\mathrm{k}}=\mathrm{B}^{*} \sigma \cdot \underline{\dot{a}}_{\mathrm{k}}$. 
A relação (2.68) mostra que a energia dissipada nos processos dissipativos é positiva e que as leis de variação das variáveis internas devem ser tais que tal desigualdade seja sempre verificada. Na proposição dessas leis reside, talvez, o aspecto arbitrário da modelagem. PROENÇA (1997) descreve que em geral segue-se uma das seguintes estratégias:

a) de um lado as leis de evolução podem ser derivadas diretamente com base na resposta observada diretamente em nível de microestrutura

b) de outro lado, admite-se a existência de um potencial de dissipação, escrito em função das variáveis associadas, que engloba estados que podem ser atingidos sem qualquer dissipação adicional de energia e de cuja variação derivam as leis de evolução.

A primeira estratégia pode conduzir a leis que tenham aplicação restrita a combinações de solicitações similares àquelas dos ensaios realizados.

A segunda estratégia tem um cunho mais teórico, porém com algumas vantagens tais como: aplicação mais geral do modelo obtido, estrutura formal do modelo resultante bastante próxima daquela obtida por outras teorias e manutenção de simetria do tensor constitutivo.

No segundo caso, o modelo acaba por exibir uma estrutura semelhante a de modelos elaborados pela teoria da plasticidade, por exemplo. O potencial com as características descritas em b) implica na possibilidade de um descarregamento, pois o estado resultante estará sempre no interior ou sobre a sua superficie. Além disso, assumindo-se propriedades de convexidade para o potencial, as leis de evolução podem ser expressas de modo a preservar vantagens do tipo manutenção de simetria do tensor constitutivo, por exemplo. Sendo assim, o potencial F pode ser representado da seguinte forma:

$\mathrm{F}=\mathrm{F}\left(\mathrm{A}_{\mathrm{k}} ; \varepsilon^{\mathrm{e}}, \underline{\mathrm{a}}_{\mathrm{k}}\right) \leq 0$

onde $\varepsilon^{\mathrm{e}} \mathrm{e} \underline{\mathrm{a}}_{\mathrm{k}}$ aparecem como parâmetros. Resulta, pela normalidade 
$\underline{\dot{a}}_{\mathrm{k}}=\dot{\lambda} \frac{\partial \mathrm{F}}{\partial \mathrm{A}_{\mathrm{k}}} \quad$ na condição de $\mathrm{F}=0$

ou

$\underline{\dot{a}}_{\mathrm{k}}=0 \quad$ se $\mathrm{F}<0$.

Note-se que $\frac{\partial \mathrm{F}}{\partial \mathrm{A}_{\mathrm{k}}}$ é normal à superfície (lugar geométrico dos pontos que verificam $\mathrm{F}=0$ ) do potencial e $\dot{\lambda}$ é um escalar positivo, figura 2.5 .

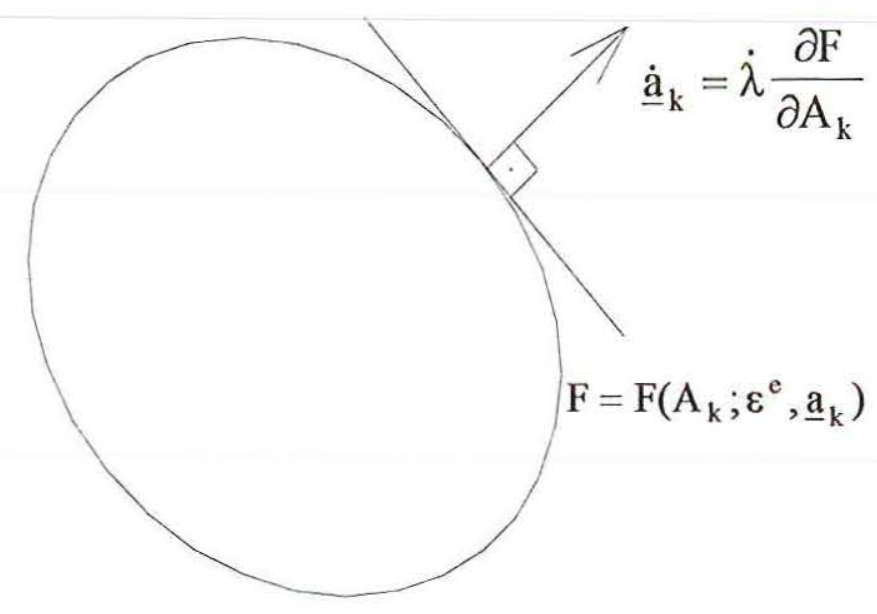

Figura 2.5 - Superfície do potencial de dissipação F.

Em resumo, o formalismo seguido pela Mecânica do dano apresenta três aspectos fundamentais: a escolha das variáveis internas, a forma a ser adotada para a função densidade de energia interna e as equações que exprimem as leis de evolução das variáveis internas.

Atendendo aos aspectos acima mencionados, pode-se formular modelos constitutivos fenomenológicos termodinamicamente consistentes e que refletem, através do conjunto de variáveis internas, os principais fenômenos físicos observados na microestrutura. Apesar do natural questionamento sobre algumas considerações teóricas, particularmente sobre as simplificações adotadas, este tipo de formulação 
pode conduzir a uma modelagem bastante satisfatória dos fenômenos ocorridos no meio. 


\section{MODELOS CONSTITUTIVOS PARA O CONCRETO}

\subsection{INTRODUÇÃO}

Neste capítulo, inicialmente faz-se um estudo do modelo de dano proposto por MAZARS (1984), para o concreto submetido a carregamento proporcionalmente crescente. Logo após, uma extensão do modelo considerando-se o aspecto unilateral no comportamento do concreto é apresentada.

Em seguida, discutem-se o modelo de LA BORDERIE, MAZARS \& PIJAUDIER-CABOT (1991), o modelo simplificado de FLOREZ-LÓPEZ (1993) e sua generalização proposta por ÁLVARES (1998).

Para cada um dos modelos citados abordam-se as hipóteses básicas, as leis de evolução das variáveis de dano, além do estudo da influência de cada parâmetro no comportamento das relações constitutivas. 
3.2 MODELO CONSTITUTIVO DE MAZÁRS (1984)

\subsubsection{Modelo Constitutivo com Variável de Dano Escalar e Carregamento Proporcionalmente Crescente}

O modelo proposto por MAZARS (1984) tem por base algumas evidências experimentais observadas em ensaios uniaxiais de corpo de prova em concreto, tendo por hipóteses fundamentais:

- localmente o dano é devido a extensões (alongamentos) evidenciados por sinais positivos, ao menos um deles, das componentes de deformação principal $\left(\varepsilon_{\mathrm{i}}>\right.$ $0)$;

- o dano é representado por uma variável escalar D $(0 \leq \mathrm{D} \leq 1)$ cuja evolução ocorre quando um valor de referência para o 'alongamento equivalente' é superado;

- considera-se, portanto, que o dano seja isótropo, embora análises experimentais mostrem que o dano conduz, em geral, a uma anisotropia do concreto (o qual pode ser considerado inicialmente como isótropo);

- o concreto com dano comporta-se como meio elástico. Portanto, deformações permanentes evidenciadas experimentalmente numa situação de descarregamento são desprezadas (figura 3.1a, b).
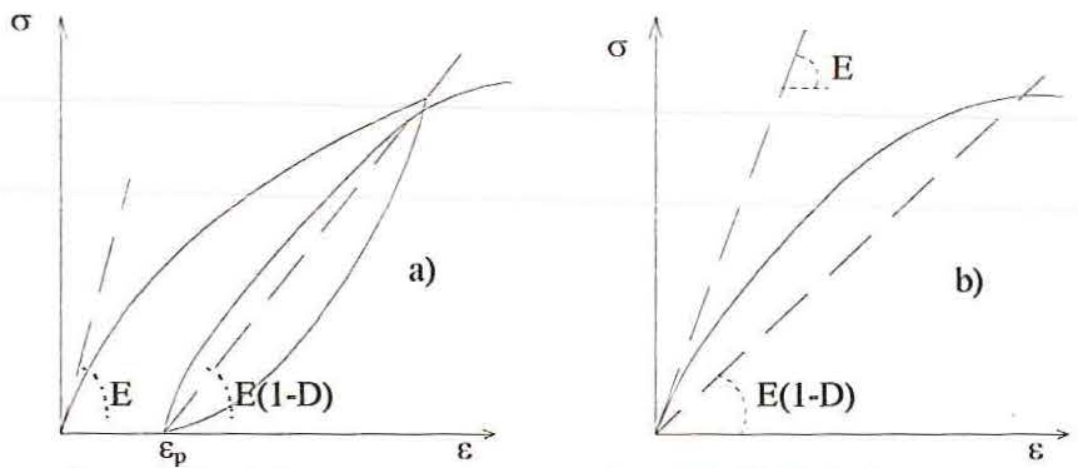

Figura 3.1 - a) Comportamento experimental; b) Modelo constitutivo. 
O estado de extensão é localmente caracterizado por um alongamento ou deformação equivalente, expresso como

$\widetilde{\varepsilon}=\sqrt{\left.\left\langle\varepsilon_{1}\right\rangle_{+}^{2}+\left\langle\varepsilon_{2}\right\rangle_{+}^{2}+<\varepsilon_{3}\right\rangle_{+}^{2}}$

onde $\varepsilon_{\mathrm{i}}$ é uma componente de deformação principal e $\left\langle\varepsilon_{\mathrm{i}}\right\rangle_{+}$é a sua parte positiva definida por:

$<\varepsilon_{\mathrm{i}}>_{+}=\frac{1}{2}\left[\varepsilon_{\mathrm{i}}+\left|\varepsilon_{\mathrm{i}}\right|\right]$

Neste modelo foi adotado que o dano se inicia quando a deformação equivalente atinge um valor de deformação de referência $\varepsilon_{\mathrm{d} 0}$, determinado em ensaios de tração uniaxial em correspondência à tensão máxima (figura 3.2).

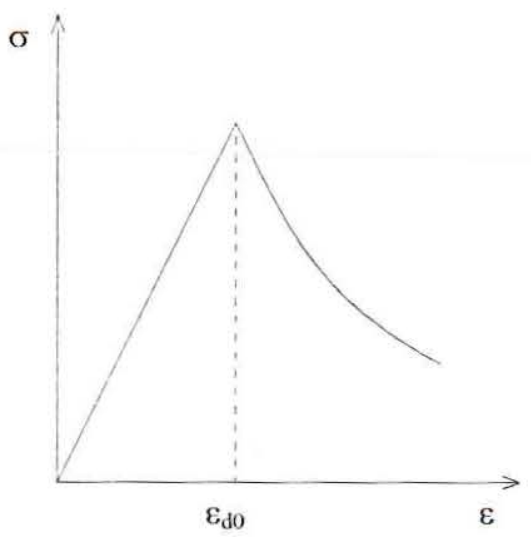

Figura 3.2 - Representação de $\varepsilon_{\mathrm{d} 0}$

Para um estado mais complexo de deformação o critério de dano é expresso como

$f(\widetilde{\varepsilon}, D)=\widetilde{\varepsilon}-S(D) \leq 0 \quad$ com $\quad S(0)=\varepsilon_{d 0}$

onde D representa a variável escalar do dano. 
Admitindo-se a continuidade no tempo para os fenômenos envolvidos, a lei de evolução da variável de dano, sendo este um modelo termodinamicamente admissível, é definida pelas seguintes condições:

$$
\begin{aligned}
& \dot{\mathrm{D}}=0 \quad \text { se } \quad \mathrm{f}<0 \text { ou } \mathrm{f}=0 \text { e } \quad \dot{\mathrm{f}}<0 \\
& \dot{\mathrm{D}}=\mathrm{F}(\widetilde{\varepsilon})<\dot{\widetilde{\varepsilon}}\rangle_{+} \quad \text { se } \mathrm{f}=0 \text { e } \quad \dot{\mathrm{f}}=0
\end{aligned}
$$

(•) indica variação no tempo e $\mathrm{F}(\widetilde{\varepsilon})$ é um a função contínua e positiva da deformação equivalente. Dessa forma resulta que

$$
\dot{\mathrm{D}} \geq 0 \quad \text { para qualquer } \quad \dot{\widetilde{\varepsilon}} \geq 0
$$

Devido à não simetria da resposta do concreto à tração e à compressão, definem-se duas variáveis escalares independentes $\mathrm{D}_{\mathrm{T}}$ e $\mathrm{D}_{\mathrm{C}}$, cujos valores dependem do alongamento equivalente e de parâmetros do material. As relações que permitem determinar aqueles valores, resultam de ajustes sobre as curvas tensão-deformação obtidas em ensaios uniaxias de tração e compressão. Considerando-se carregamento proporcionalmente crescente ou radial, as variáveis de dano, $\mathrm{D}_{\mathrm{T}}$ e $\mathrm{D}_{\mathrm{C}}$, podem ser determinadas da seguinte maneira:

$$
\begin{aligned}
& \mathrm{D}_{\mathrm{T}}(\widetilde{\varepsilon})=1-\frac{\varepsilon_{\mathrm{d} 0}\left(1-\mathrm{A}_{\mathrm{T}}\right)}{\widetilde{\varepsilon}}-\frac{\mathrm{A}_{\mathrm{T}}}{\exp \left[\mathrm{B}_{\mathrm{T}}\left(\widetilde{\varepsilon}-\varepsilon_{\mathrm{d} 0}\right)\right]} \\
& \mathrm{D}_{\mathrm{C}}(\widetilde{\varepsilon})=1-\frac{\varepsilon_{\mathrm{d} 0}\left(1-\mathrm{A}_{\mathrm{C}}\right)}{\widetilde{\varepsilon}}-\frac{\mathrm{A}_{\mathrm{C}}}{\exp \left[\mathrm{B}_{\mathrm{C}}\left(\widetilde{\varepsilon}-\varepsilon_{d 0}\right)\right]}
\end{aligned}
$$

onde $\mathrm{A}_{\mathrm{T}}$ e $\mathrm{B}_{\mathrm{T}}$ são parâmetros característicos do material em tração uniaxial, $\mathrm{A}_{\mathrm{C}}$ e $\mathrm{B}_{\mathrm{C}}$ são parâmetros do material em compressão uniaxial e $\varepsilon_{\mathrm{d} 0}$ é a deformação elástica limite. 
A figura 3.3 mostra as curvas experimentais e aquelas resultantes do ajuste para os casos uniaxiais, mostrando a simplificação decorrente da desconsideração da deformação residual. A figura ilustra em particular a degradação da rigidez pelo dano.
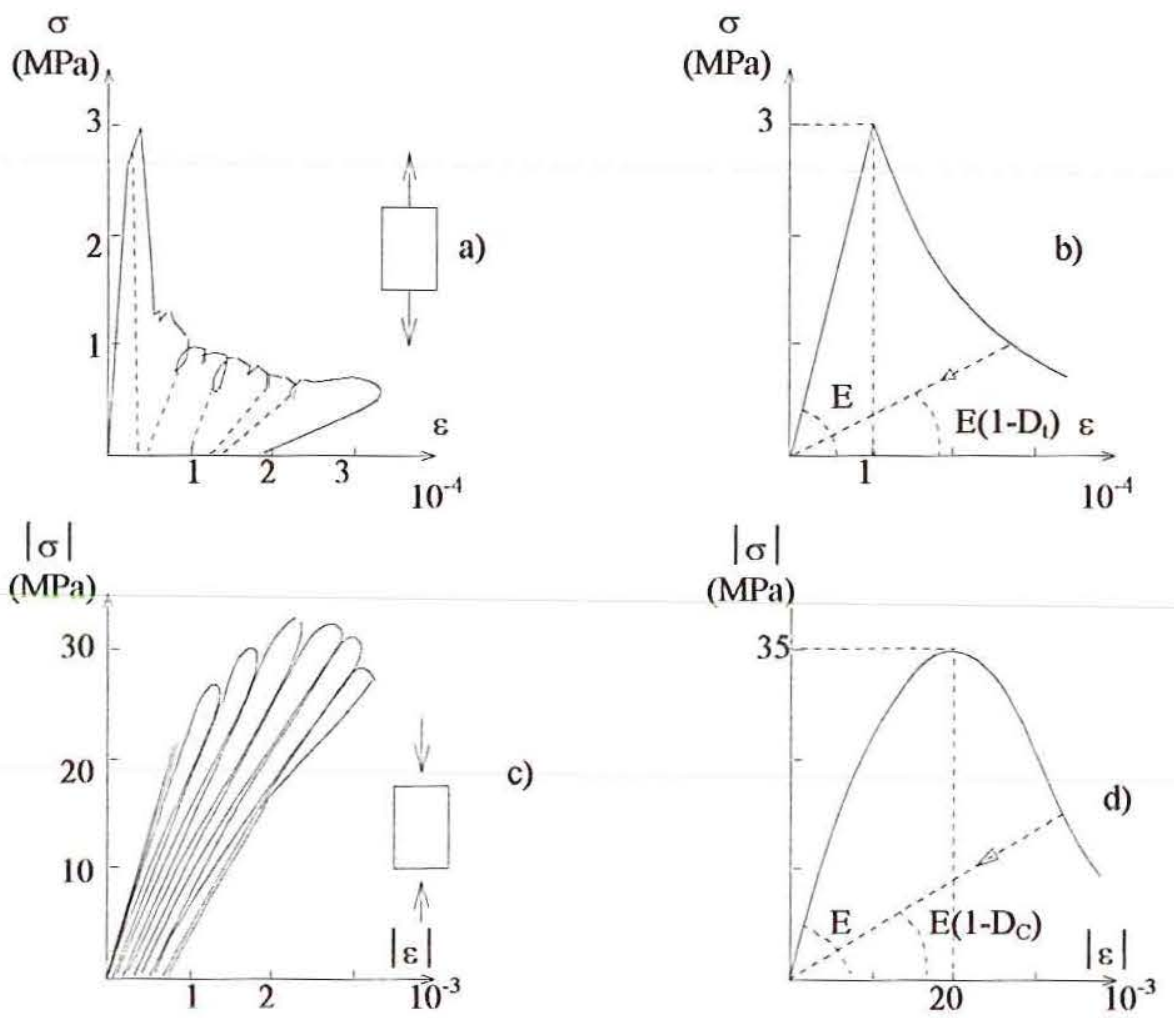

Figura 3.3 - Curvas experimentais e ajustadas para o comportamento à tração $(a, b)$ e à compressão $(c, d)$ do concreto.

Para estados complexos de tensão, propõe-se uma variável de dano determinada por uma combinação linear de $\mathrm{D}_{\mathrm{T}}$ e $\mathrm{D}_{\mathrm{C}}$ através da seguinte condição:

$\mathrm{D}=\alpha_{\mathrm{T}} \mathrm{D}_{\mathrm{T}}+\alpha_{\mathrm{C}} \mathrm{D}_{\mathrm{C}}$

$\alpha_{\mathrm{T}}+\alpha_{\mathrm{C}}=1$

onde os coeficientes $\alpha_{\mathrm{T}}$ e $\alpha_{\mathrm{C}}$ assumem valores no intervalo fechado [0,1], e procuram representar a contribuição de solicitações à tração e à compressão para o estado local de extensão, sendo expressos por 
$\alpha_{\mathrm{T}}=\frac{\sum_{\mathrm{i}}<\varepsilon_{\mathrm{T}_{\mathrm{i}}}>_{+}}{\varepsilon_{\mathrm{V}}^{+}}$

$\alpha_{\mathrm{c}}=\frac{\sum_{\mathrm{i}}<\varepsilon_{\mathrm{c}_{\mathrm{i}}}>_{+}}{\varepsilon_{\mathrm{v}}^{+}}$

Nas relações acima $(3.9 \mathrm{a}, \mathrm{b}), \varepsilon_{\mathrm{Ti}}$ e $\varepsilon_{\mathrm{Ci}}$ são componentes de deformação determinadas pelas partes positiva e negativa, respectivamente, do vetor de tensões principais $\underline{\sigma}^{*}$ associado a $\underline{\varepsilon}$ pela relação elástica isótropa:

$\underline{\sigma}^{*}=\underline{\underline{D}}_{0} \underline{\varepsilon}$

Portanto:

$\underline{\varepsilon}_{\mathrm{T}}=\frac{1+v}{\mathrm{E}}<\underline{\sigma}_{+}>_{+}-\frac{v}{\mathrm{E}}<\sum_{i} \sigma_{\mathrm{i}}>_{+} \underline{\underline{I}}$

$\underline{\varepsilon}_{\mathrm{c}}=\frac{1+v}{\mathrm{E}}<\underline{\sigma}>-\frac{v}{\mathrm{E}}<\sum_{\mathrm{i}} \sigma_{\mathrm{i}}>\underline{\underline{I}}$

onde $\langle\underline{\sigma}\rangle_{+}$é a parte positiva e $\left\langle\underline{\sigma}>\right.$. a parte negativa do vetor de tensões $\underline{\sigma}^{*}$.

Nas expressões (3.9) aparecem também:

$\left.\left.\varepsilon_{\mathrm{V}}^{+}=\sum_{\mathbf{i}}<\varepsilon_{\mathrm{T}_{\mathrm{i}}}\right\rangle_{+}+\sum_{\mathrm{i}}<\varepsilon_{\mathrm{C}_{\mathrm{i}}}\right\rangle_{+}$

Finalmente, na sua forma secante, a relação constitutiva é expressa por:

$\underline{\sigma}=(1-\mathrm{D}) \underline{\underline{D}}_{0} \underline{\varepsilon}$

onde $\underline{\underline{D}}_{0}$ é o tensor elástico do material íntegro.

MAZARS (1984) propôs os seguintes limites de variação para os parâmetros $\mathrm{A}_{\mathrm{T}}, \mathrm{B}_{\mathrm{T}}, \mathrm{A}_{\mathrm{C}}$ e $\mathrm{B}_{\mathrm{C}}$, obtidos a partir da calibração com resultados experimentais: 


$$
\begin{array}{ll}
0.7 \leq \mathrm{A}_{\mathrm{T}} \leq 1 & 10^{4} \leq \mathrm{B}_{\mathrm{T}} \leq 10^{5} \\
1 \leq \mathrm{A}_{\mathrm{C}} \leq 1.5 & 10^{3} \leq \mathrm{B}_{\mathrm{C}} \leq 2 \cdot 10^{3}
\end{array}
$$

No caso de esforço uniaxial de tração uma variação sobre os parâmetros que aparecem nas relações (3.15) fornecem os gráficos ilustrados nas figuras (3.4a,b e c) (PEREGO(1989)).

Na figura 3.4a pode-se observar que a variável $\varepsilon_{\mathrm{d} 0}$ influencia o início e a inclinação inicial do trecho não-linear ("softening") e também o valor assintótico de $\sigma$ , pois $\sigma(\infty)=\mathrm{E} \varepsilon_{\mathrm{d} 0}\left(1-\mathrm{A}_{\mathrm{T}}\right)$.

A figura $3.4 \mathrm{~b}$ mostra a influência do parâmetro $A_{T}$ na inclinação inicial do trecho não-linear e no valor da assíntota horizontal.

Com relação ao parâmetro $\mathrm{B}_{\mathrm{T}}$, a figura $3.4 \mathrm{c}$ mostra sua influência sobre o sinal da inclinação inicial do trecho não-linear e sobre o valor de pico do diagrama $\sigma-\varepsilon$.

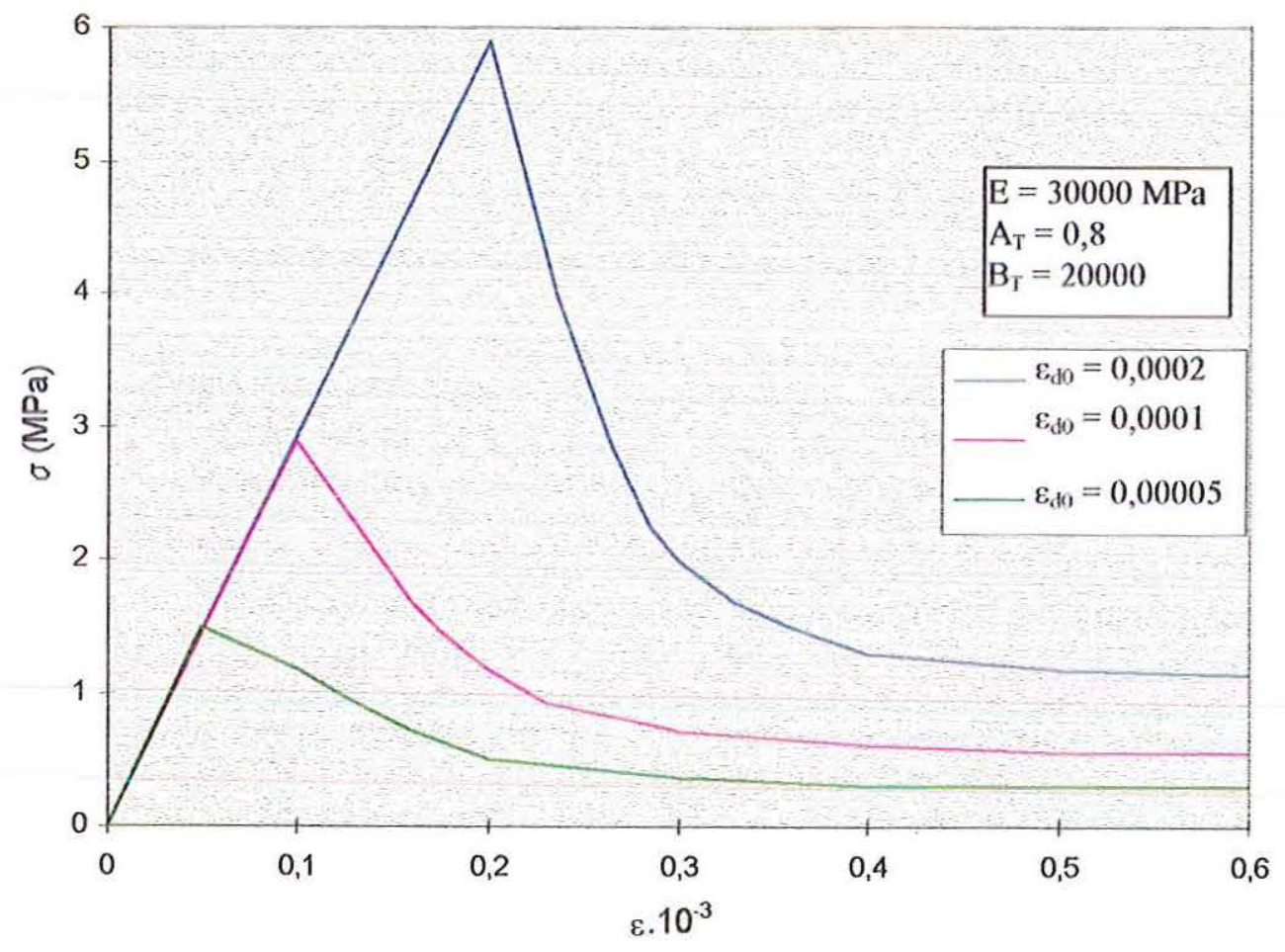

Figura 3.4a - Influência do parâmetro $\varepsilon_{d 0}$. 


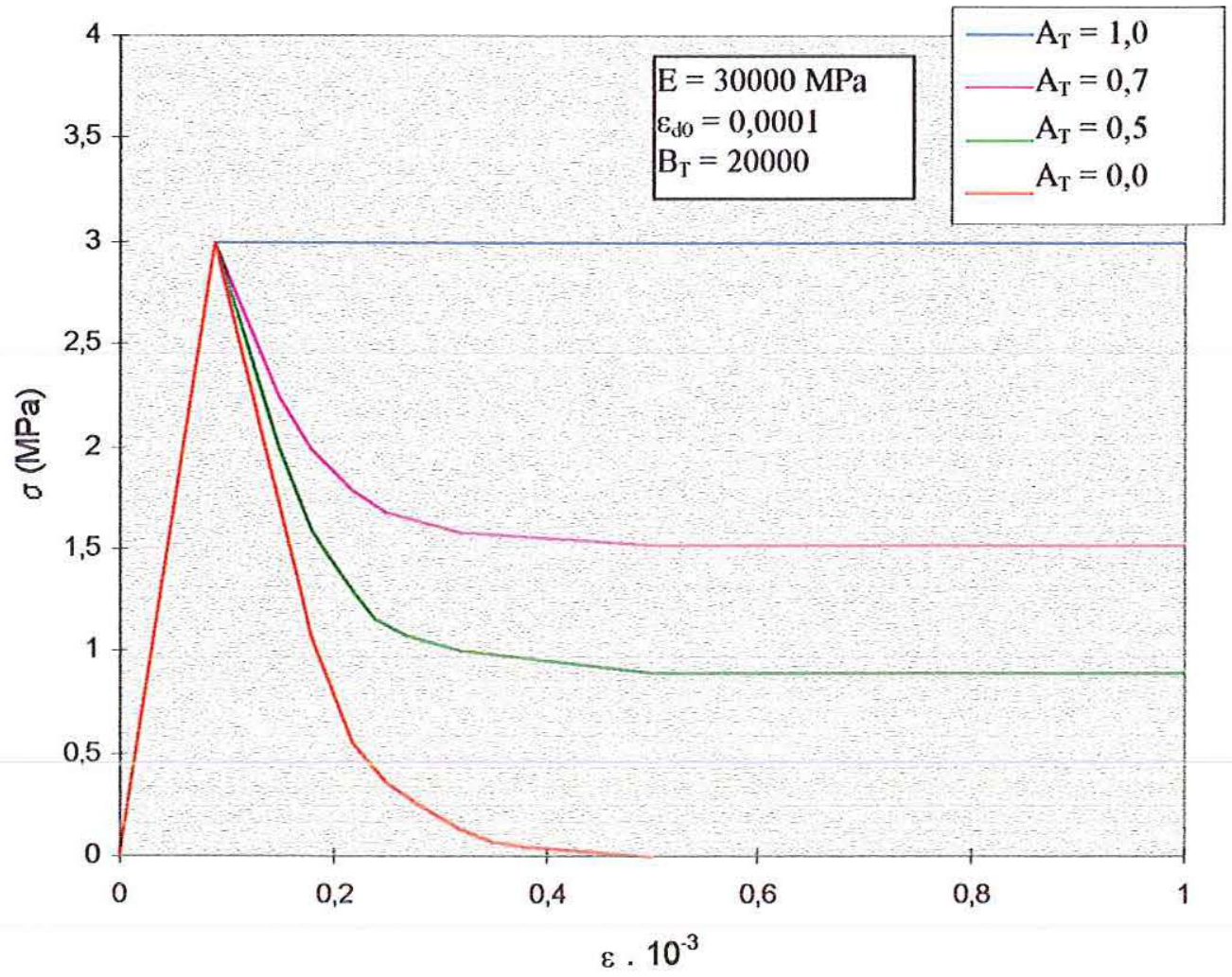

Figura 3.4b - Influência do parâmetro $A_{T}$.

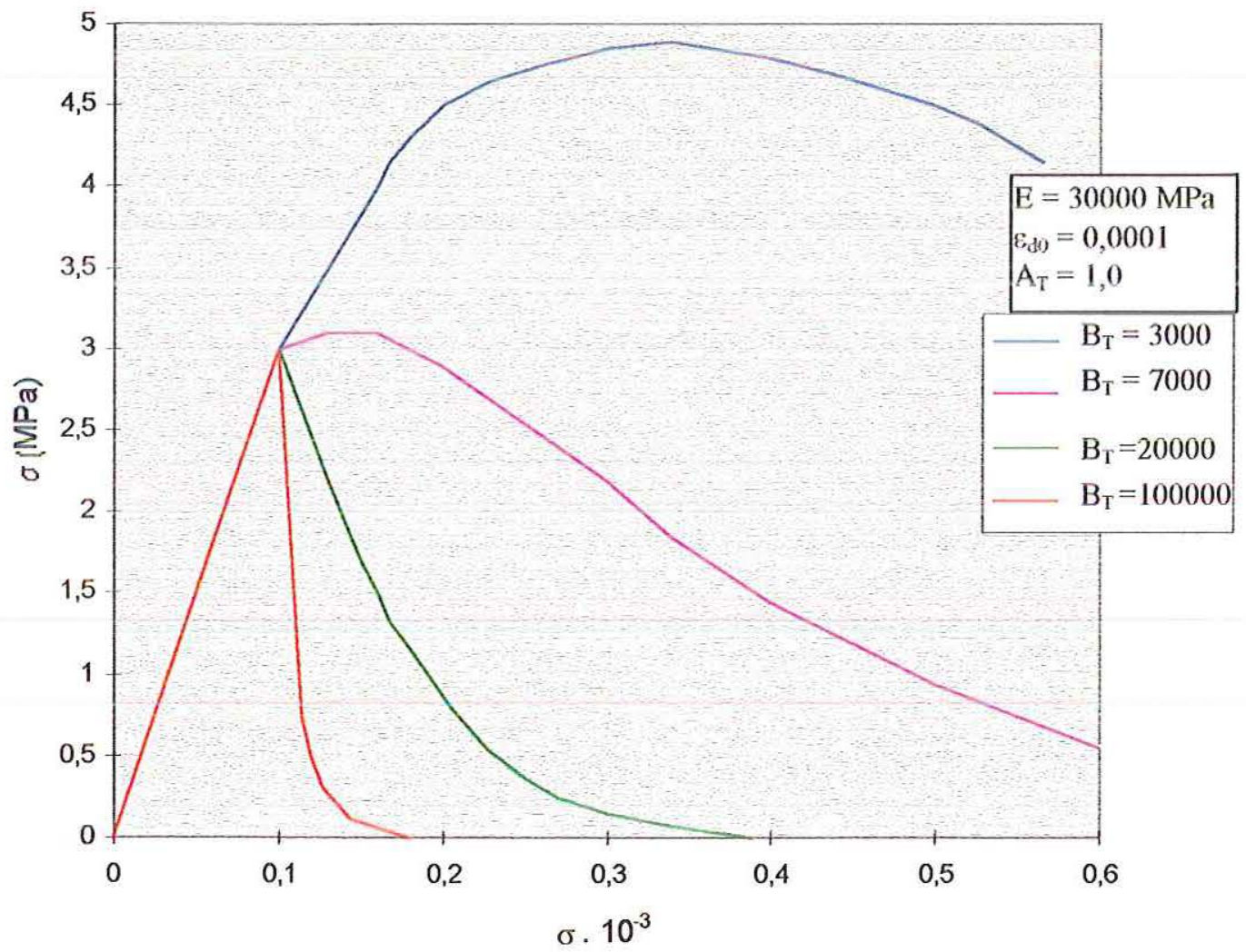

Figura 3.4c - Influência do parâmetro $B_{\mathrm{T}}$. 
No caso de esforço uniaxial de compressão valem os gráficos ilustrados nas figuras (3.5a e b) (PEREGO(1989)).

Da figura $3.5 \mathrm{a}$, observa-se que a influência do parâmetro $\mathrm{B}_{\mathrm{C}}$ é análoga àquela do parâmetro $\mathrm{B}_{\mathrm{T}}$. A figura $3.5 \mathrm{~b}$ pode ser utilizada para confrontar respostas, com $\mathrm{B}_{\mathrm{C}}$ fixo, variando $A_{C}$ e vice-versa.

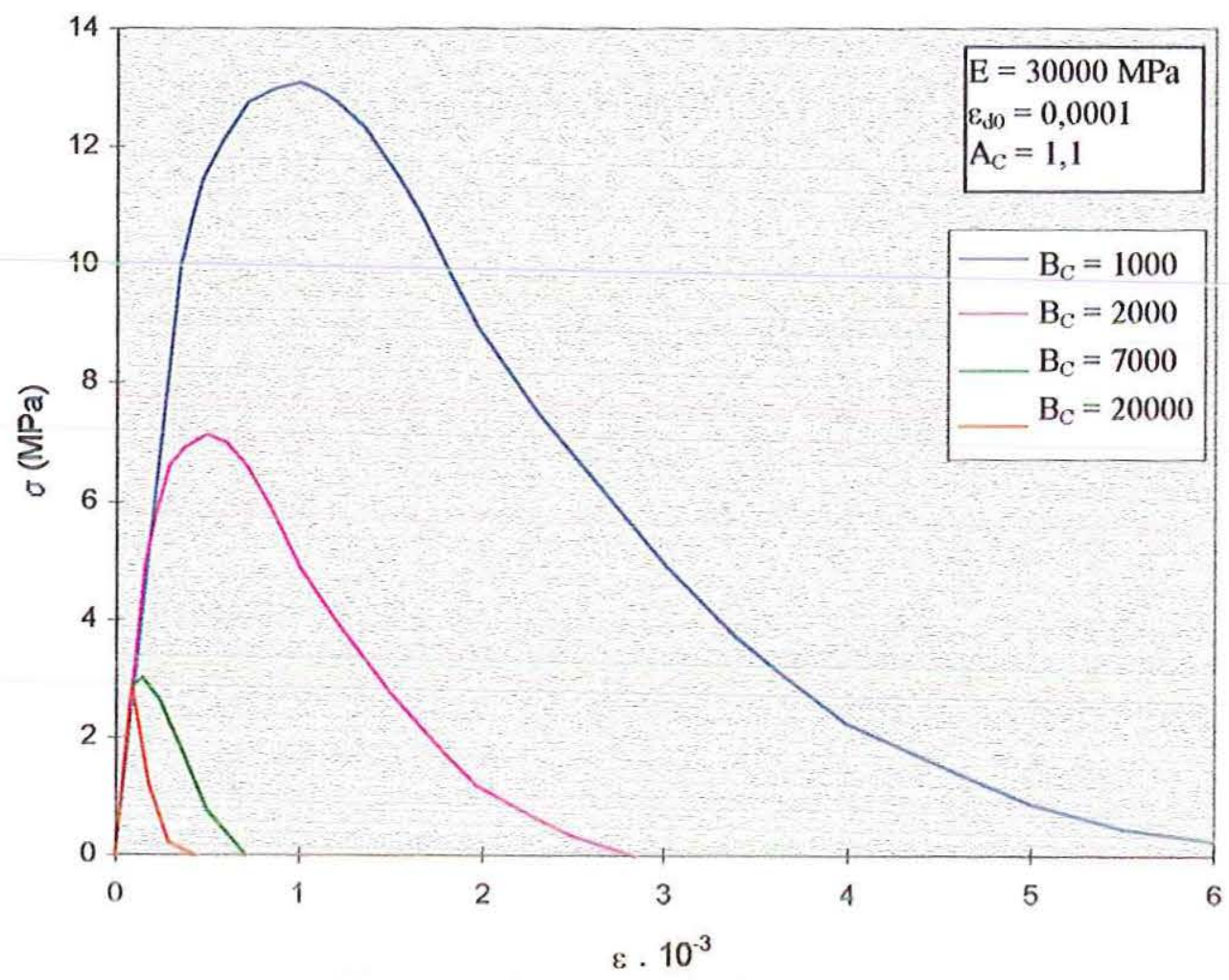

Figura 3.5a - Influência do parâmetro $B_{C}$. 


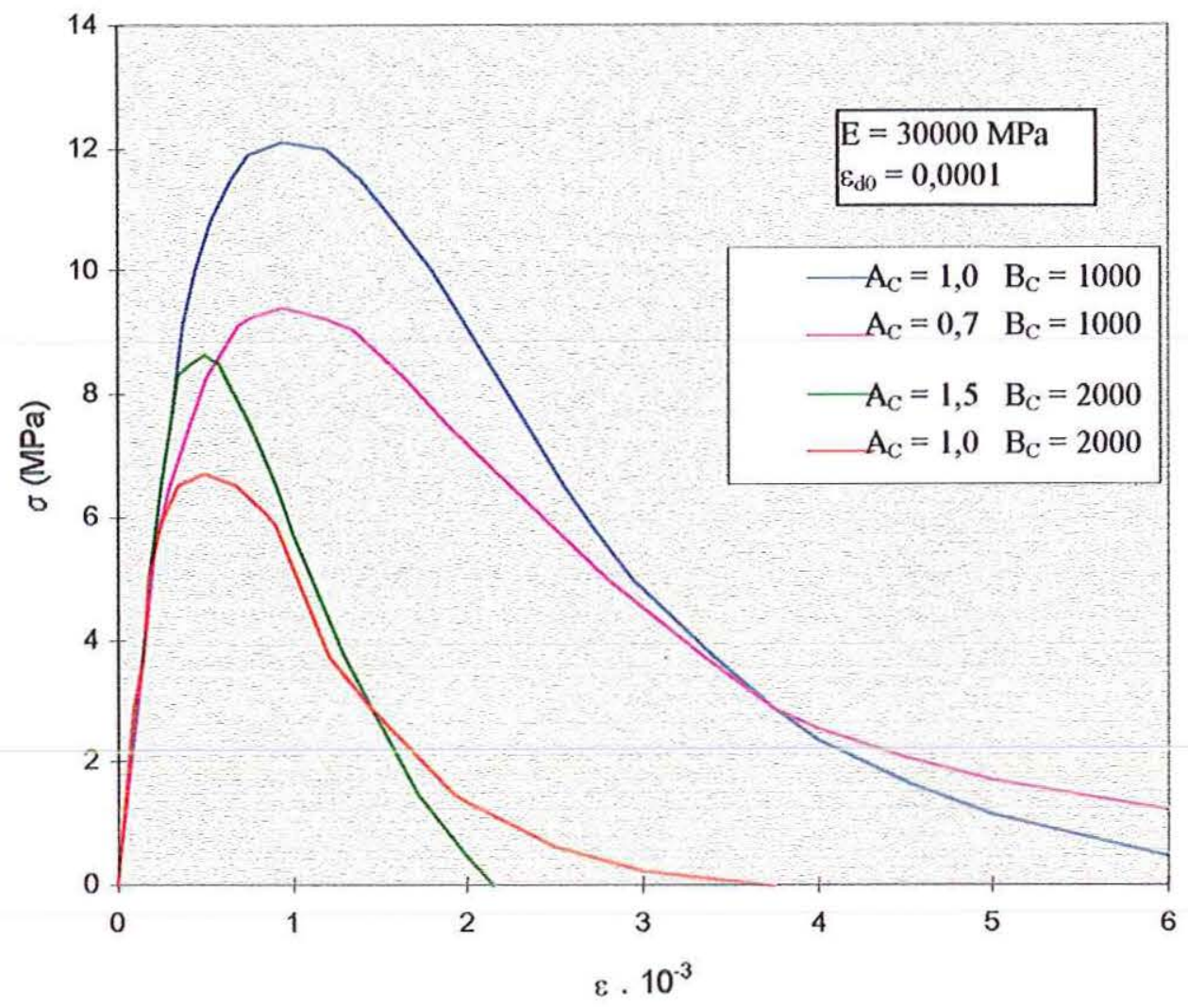

Figura 3.5b - Influência dos parâmetros $A_{C}$ e $B_{C}$.

Em ÁLVARES (1993) e PEREGO (1989) são evidenciadas algumas particularidades deste tipo de análise. São elas: uma instabilidade na resposta, visualizada na curva carga-deslocamento pela irregularidade no seu desenvolvimento ('non-smoth') e uma não-objetividade caracterizada por resultados mais rígidos com o refinamento da malha. Em ÁLVARES (1993) foi adotado um procedimento iterativo para a regularização da resposta e um outro procedimento para reduzir o problema de não-objetividade. Neste último, o problema da dependência de malha provocada pela imposição de uma lei de 'softening' constante foi contornado com a determinação indireta do parâmetro $\mathrm{B}_{\mathrm{T}}$ em função das dimensões do elemento finito, impondo-se como característica do material a taxa de energia dissipada em um teste de tração uniaxial $\left(G_{f}\right)$, também denominada de energia de fratura.Logo impondo-se $A_{T}=1$ e calibrando-se $B_{T}$, os parâmetros do modelo passam a ser: $A_{C}, B_{C}, \varepsilon_{d 0}$ e $G_{f}$ ). 


\subsubsection{Modelo de Dano Unilateral de Mazars}

Quando carregado por uma tensão de tração, o concreto usualmente exibe microfissuras geralmente perpendiculares à direção da tensão e sua rigidez diminui naquela direção. Estas microfissuras se fecham se uma compressão é subseqüentemente aplicada, recuperando-se, então, a rigidez inicial.

Entre vários modelos de dano propostos a fim de levar em conta esse "caráter unilateral" do concreto, Mazars propôs um modelo aplicável a uma situação geral de carregamento multiaxial que considera duas variáveis escalares independentes de dano, $\mathrm{D}_{\mathrm{T}}$ e $\mathrm{D}_{\mathrm{C}}$, associadas, respectivamente, aos estados de esforço de tração e de compressão.

Assim, são necessárias as partes positiva e negativa do estado de tensão, $<\underline{\sigma}$ $>_{+} \mathrm{e}<\underline{\sigma}>_{\text {. }}$, obtidas pela seguinte partição do tensor de tensões:

$\underline{\sigma}=\langle\underline{\sigma}\rangle_{+}+\langle\underline{\sigma}\rangle$.

onde

$$
\begin{aligned}
& \langle\underline{\sigma}\rangle_{+}=\underline{\sigma}^{+}=\frac{\underline{\sigma}+|\underline{\sigma}|}{2} \\
& \langle\underline{\sigma}\rangle_{-}=\underline{\sigma}=\frac{\underline{\sigma}-|\underline{\sigma}|}{2}
\end{aligned}
$$

É importante notar que, enquanto no modelo original as variáveis de dano $\left(D_{c}\right.$ e $\mathrm{D}_{\mathrm{T}}$ ) são funções da deformação equivalente $\widetilde{\varepsilon}$, no modelo unilateral as leis de evolução para $\mathrm{D}_{\mathrm{C}}$ e $\mathrm{D}_{\mathrm{T}}$ são definidos em função de suas variáveis termodinâmicas associadas. Dada a independência dessas variáveis é necessário estabelecer duas superficies de evolução de dano e duas leis de evolução distintas para os parâmetros $\mathrm{D}_{\mathrm{T}}$ e $\mathrm{D}_{\mathrm{C}}$. 
As variáveis que são termodinamicamente conjugadas com $\mathrm{D}_{\mathrm{T}}$ e $\mathrm{D}_{\mathrm{C}}(\mathrm{PEREGO}$ (1989)) são:

$$
\begin{aligned}
& \mathrm{Y}_{\mathrm{T}}=\frac{1}{6 \mathrm{E}_{0}\left(1-\mathrm{D}_{\mathrm{T}}\right)^{2}}\left[(1+v)\left[3\left[\sum_{\mathrm{i}}\left(\sigma_{\mathrm{i}}^{+}\right)^{2}\right]-\left(<\sum_{\mathrm{i}} \sigma_{\mathrm{i}}>_{+}\right)^{2}\right]\right. \\
& \left.+(1-2 v)\left[\left(\sum_{i} \sigma_{i}^{+}\right)^{2}\right]\right] \\
& \mathrm{Y}_{\mathrm{C}}=\frac{1}{6 \mathrm{E}_{0}\left(1-\mathrm{D}_{\mathrm{C}}\right)^{2}}\left[(1+v)\left[3\left[\sum_{\mathrm{i}}\left(\sigma_{\mathrm{i}}^{-}\right)^{2}\right]-\left(<\sum_{\mathrm{i}} \sigma_{\mathrm{i}}>.\right)^{2}\right]\right. \\
& \left.+(1-2 v)\left[\left(\sum_{i} \sigma_{i}^{-}\right)^{2}\right]\right]
\end{aligned}
$$

As funções representativas dos critérios de dano são:

$$
\begin{aligned}
& f_{T}=Y_{T}-S_{T}\left(D_{T}\right) \leq 0 \\
& \operatorname{com} \mathrm{S}_{\mathrm{T}}(0)=\mathrm{Y}_{\mathrm{T}}^{0} \\
& \mathrm{f}_{\mathrm{C}}=\mathrm{Y}_{\mathrm{C}}-\mathrm{S}_{\mathrm{C}}\left(\mathrm{D}_{\mathrm{C}}\right) \leq 0 \quad \operatorname{com} \mathrm{S}_{\mathrm{C}}(0)=\mathrm{Y}_{\mathrm{C}}^{0}
\end{aligned}
$$

onde $\mathrm{Y}_{\mathrm{T}}^{0}$ e $\mathrm{Y}_{\mathrm{C}}^{0}$ são dados pelas seguintes expressões:

$$
\begin{aligned}
& Y_{\mathrm{T}}^{0}=\frac{\sigma_{0 \mathrm{t}}^{2}}{2 \mathrm{E}_{0}} \\
& \mathrm{Y}_{\mathrm{C}}^{0}=\frac{\sigma_{0 \mathrm{C}}^{2}}{2 \mathrm{E}_{0}}
\end{aligned}
$$

Assumem-se também as seguintes leis de evolução para o dano:

$$
\begin{aligned}
& \dot{\mathrm{D}}_{\mathrm{T}}=\left\{\begin{array}{llllll}
\mathrm{F}_{\mathrm{T}}\left(\mathrm{Y}_{\mathrm{T}}\right)<\mathrm{Y}_{\mathrm{T}} \dot{ }_{+} & & \text {se } \mathrm{f}_{\mathrm{T}}=0 & \text { e } & \dot{\mathrm{f}}_{\mathrm{T}}=0 \\
0 & \text { se } \mathrm{f}_{\mathrm{T}}<0 & \text { ou } \quad \mathrm{f}_{\mathrm{T}}=0 & \text { e } & \dot{\mathrm{f}}_{\mathrm{T}}<0
\end{array}\right. \\
& \dot{\mathrm{D}}_{\mathrm{c}}=\left\{\begin{array}{llllll}
\left.\mathrm{F}_{\mathrm{C}}\left(\mathrm{Y}_{\mathrm{C}}\right)<\mathrm{Y}_{\mathrm{C}}\right\rangle_{+} & & \text {se } \mathrm{f}_{\mathrm{C}}=0 & \text { e } & \dot{\mathrm{f}}_{\mathrm{C}}=0 \\
0 & \text { se } \mathrm{f}_{\mathrm{C}}<0 & \text { ou } \quad \mathrm{f}_{\mathrm{C}}=0 & \text { e } & \dot{\mathrm{f}}_{\mathrm{C}}<0
\end{array}\right.
\end{aligned}
$$


onde $\mathrm{F}_{\mathrm{T}}$ e $\mathrm{F}_{\mathrm{C}}$ são funções contínuas positivas de $\mathrm{Y}_{\mathrm{T}}$ e $\mathrm{Y}_{\mathrm{C}}$ e dadas pelas seguintes expressões:

$$
\begin{aligned}
& F_{T}=\frac{\sqrt{Y_{T}^{0}}\left(1-A_{T}\right)}{2\left(Y_{T}\right)^{3 / 2}}+\frac{A_{T} B_{T}}{2 \sqrt{Y_{T}} \exp \left[B_{T}\left(\sqrt{Y_{T}}-\sqrt{Y_{T}^{0}}\right)\right]} \\
& F_{C}=\frac{\sqrt{Y_{C}^{0}}\left(1-A_{C}\right)}{2\left(Y_{C}\right)^{3 / 2}}+\frac{A_{C} B_{C}}{2 \sqrt{Y_{C}} \exp \left[B_{C}\left(\sqrt{Y_{C}}-\sqrt{Y_{C}^{0}}\right)\right]}
\end{aligned}
$$

A relação constitutiva secante para o material com dano torna-se:

$$
\begin{aligned}
& \underline{\varepsilon}=\frac{1}{\mathrm{E}_{0}\left(1-\mathrm{D}_{\mathrm{T}}\right)}\left[(1+v) \underline{\sigma}^{+}-v<\sum_{\mathrm{i}} \sigma_{\mathrm{i}}>_{+} \mathrm{I}\right] \\
& +\frac{1}{\mathrm{E}_{0}\left(1-\mathrm{D}_{\mathrm{C}}\right)}\left[(1+v) \underline{\sigma}^{-}-v<\sum_{\mathrm{i}} \sigma_{\mathrm{i}}>{ }_{.} \mathrm{I}\right]
\end{aligned}
$$

onde E e $v$ são respectivamente o módulo de elasticidade e o coeficiente de Poisson do material íntegro e I é o tensor identidade.

\section{Algo mais sobre Modelos Unilaterais}

Segundo LEMAITRE (1987), em muitos casos, o dano pode ser considerado isótropo. Entretanto, existe uma grande diferença na evolução da danificação para estados de tração e de compressão. Por exemplo, no caso do concreto, evidencia-se uma ruptura estática bastante diversa em tração e em compressão.

Em termos de formulação do modelo, a 'tensão efetiva' deve ser uma função diferente da variável D nas situações de tração e de compressão.

No caso unidimensional, uma forma de escrever é 


$$
\begin{array}{llll}
\widetilde{\sigma}=\frac{\sigma}{1-\mathrm{D}} & \text { se } & \sigma \geq 0 \\
\widetilde{\sigma}=\frac{\sigma}{1-\mathrm{Dh}} & \text { se } & \sigma<0
\end{array}
$$

onde h é o coeficiente de fechamento que caracteriza o fechamento de microfissuras e microcavidades, variando no intervalo $0 \leq \mathrm{h} \leq 1$ :

$\mathrm{h}=0$ corresponde ao caso de condição unilateral de microfissuras de superficie pura ou que se fecham completamente;

$\mathrm{h}=1$ corresponde ao caso de condições bilaterais de microcavidades que não se fecham;

$0<\mathrm{h}<1 \quad$ corresponde aos casos intermediários.

Uma representação esquemática da variação do coeficiente h é mostrada na figura a seguir:

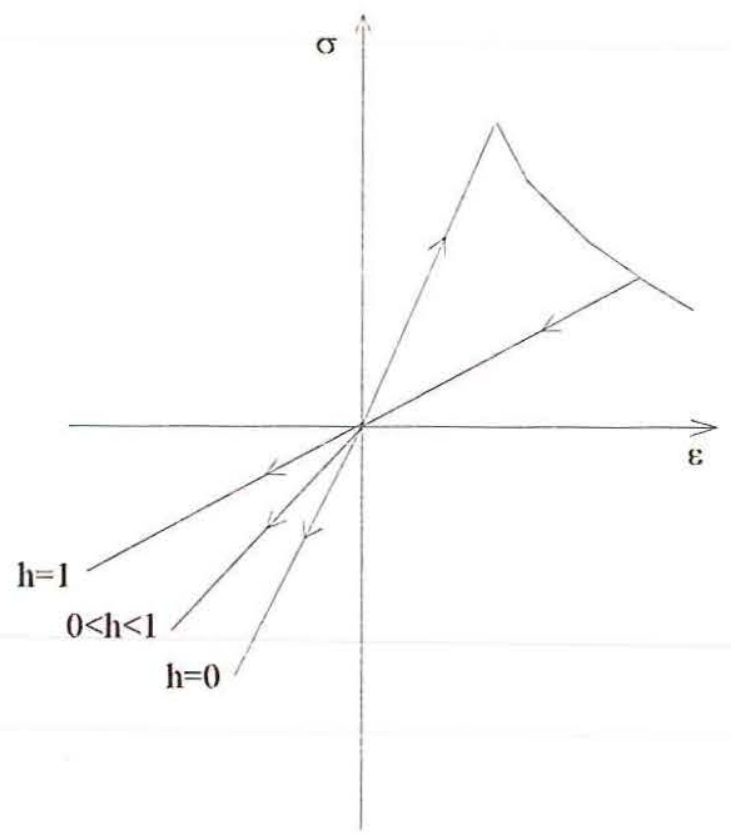

Figura 3.6 - Variação do coeficiente h. 
Este conceito simples é dificil de estender para o caso tridimensional. Porém, uma solução foi proposta por LADEVEZE \& LEMAITRE (1984), que consistia em dividir o tensor de tensões de Cauchy numa parte positiva $\langle\sigma\rangle_{+}$e uma parte negativa $<\sigma>-$

$\left.\sigma=\langle\sigma\rangle_{+}+<\sigma\right\rangle_{-}$

definido pelas partes positiva e negativa das tensões principais $\sigma_{i}$

$<_{\sigma}>_{+}=\left[\begin{array}{ccc}\left\langle\sigma_{1}\right\rangle_{+} & 0 & 0 \\ 0 & \left\langle\sigma_{2}\right\rangle_{+} & 0 \\ 0 & 0 & \left\langle\sigma_{3}\right\rangle_{+}\end{array}\right]$
$<_{\sigma}>_{-}=\left[\begin{array}{ccc}\left.<\sigma_{1}\right\rangle_{-} & 0 & 0 \\ 0 & \left\langle\sigma_{2}\right\rangle_{-} & 0 \\ 0 & 0 & \left\langle\sigma_{3}\right\rangle_{-}\end{array}\right]$

onde o símbolo $\left\langle\sigma_{\mathrm{i}}\right\rangle_{+}$significa

$\begin{array}{llll}<\sigma_{\mathrm{i}}>_{+}=\sigma_{\mathrm{i}} & \text { se } & \sigma_{\mathrm{i}} \geq 0 \\ <_{\sigma_{\mathrm{i}}>_{+}}=0 & \text { se } & \sigma_{\mathrm{i}}<0\end{array}$

$\mathrm{O}$ coeficiente $\mathrm{h}$ depende da densidade e da forma dos defeitos. Como uma primeira aproximação por simplicidade, pode-se considerar h como uma constante. Na elasticidade, h está diretamente relacionado com a rigidez em compressão:

$$
\begin{array}{ll}
\sigma=(1-\mathrm{D}) \mathrm{E} \varepsilon_{\mathrm{e}} & \text { em tração }(\sigma>0) \\
\sigma=(1-\mathrm{Dh}) \mathrm{E} \varepsilon_{\mathrm{e}} & \text { em compressão }(\sigma<0)
\end{array}
$$

Se o módulo de elasticidade inicial é conhecido, então uma medida do 
módulo de elasticidade em tração atualizado é: $\widetilde{\mathrm{E}}_{\mathrm{t}}=\mathrm{E}(1-\mathrm{D})$.

Para o módulo de elasticidade em compressão atualizado vale: $\widetilde{\mathrm{E}}_{\mathrm{c}}=\mathrm{E}(1-\mathrm{Dh})$

Tais relações indicam uma possibilidade de identificação experimental das variáveis $\mathrm{D}$ e $\mathrm{h}$. De fato, das expressões de $\widetilde{\mathrm{E}}_{\mathrm{t}}$ e $\widetilde{\mathrm{E}}_{\mathrm{c}}$ resultam:

$$
\begin{aligned}
& \frac{\widetilde{E}_{c}}{\widetilde{E}_{t}}=\frac{1-D h}{1-D} \\
& \text { e } D=1-\frac{\widetilde{E}_{t}}{E}
\end{aligned}
$$

Portanto, segue que

$$
h=\frac{E-\widetilde{E}_{c}}{E-\widetilde{E}_{t}}
$$

Como visto, o modelo estendido, introduz duas variáveis escalares de dano, uma associada à resposta em tração e outra associada à resposta em compressão. Os valores das variáveis dependem das parcelas positiva e negativa do tensor de tensões devidamente particionado. Além disso, pela equação 3.23 nota-se que o modelo constitutivo é colocado numa forma tal que o estado de deformação é determinado em função do estado de tensão e dos valores das variáveis de dano. Ocorre que, nessas condições, pode manifestar-se uma perda de unicidade de solução em correspondência a valores particulares das variáveis de dano, mas que no fundo é decorrente do fato de que o modelo é baseado numa partição do tensor de tensões.

Um estudo sobre a perda de unicidade de solução na simulação da resposta unilateral do concreto através do modelo de Mazars, foi desenvolvido por PAPA \& PROENÇA (1992). Neste trabalho, a característica de perda de unicidade é ilustrada com um exemplo simples, propondo-se, ainda, um critério complementar para indicar 
a solução correta do modelo constitutivo. O critério adotado é baseado numa minimização da energia de deformação e decorre da idéia de que a solução correta entre outras possíveis é aquela que proporciona maior dissipação. A aplicação do critério é exemplificada num caso simples de compressão uniaxial e a extensão a estados multiaxiais é discutida removendo-se, portanto, uma dificuldade que se manifestaria na fase de resolução numérica.

\subsection{MODELO CONSTITUTIVO DE LA BORDERIE, MAZARS \& PIJAUDIER-CABOT (1991)}

O modelo permite levar-se em conta o aspecto unilateral através da definição de duas variáveis representativas do dano em tração e do dano em compressão. A ativação de um ou outro processo de danificação é feita através de um controle sobre o sinal das tensões principais. Consideram-se também deformações anelásticas devidas apenas ao dano.

Na formulação do modelo proposto por LABORDERIE, MAZARS \& PIJAUDIER-CABOT (1991) define-se um conjunto de variáveis de estado e de variáveis associadas, reunidas na tabela 3.1.

Tabela 3.1 - Variáveis de estado e variáveis associadas no modelo de dano

\begin{tabular}{|c|c|c|c|c|}
\hline & \multicolumn{2}{|c|}{$\begin{array}{c}\text { VARIÁVEIS } \\
\text { DE ESTADO }\end{array}$} & \multicolumn{2}{|c|}{ ASSOCIADAS } \\
& Primária & Interna & & \\
\cline { 2 - 5 } & $\sigma$ & & $\varepsilon$ & Deformação \\
\hline Tensão & & $\mathrm{D}_{1}$ & $\mathrm{Y}_{1}$ & Taxa de energia livre 1 \\
\hline Dano 1 & & $\mathrm{D}_{2}$ & $\mathrm{Y}_{2}$ & Taxa de energia livre 2 \\
\hline Dano 2 & & $\mathrm{z}_{1}$ & $\mathrm{Z}_{1}$ & \\
\hline Encruamento 1 & & $\mathrm{z}_{2}$ & $\mathrm{Z}_{2}$ & \\
\hline Encruamento2 & & &
\end{tabular}


No quadro acima $D_{1}$ e $D_{2}$ são variáveis de dano, $Y_{1}$ e $Y_{2}$ são as variáveis associadas, interpretadas como taxa de energia liberada durante o processo de evolução de dano, e $Z_{1}$ e $Z_{2}$ são variáveis associadas a $Z_{1}$ e $z_{2}$ que, respectivamente, controlam o processo de encruamento e estão inseridas nas funções representativas dos critérios de danificação.

As relações entre as variáveis de estado e as associadas é dada por um potencial de estado do qual derivam as relações constitutivas. Neste modelo sugere-se o potencial de energia livre de $\operatorname{Gibbs}(\chi)$ como potencial de estado, adotando-se a seguinte expressão:

$$
\begin{array}{r}
\chi=\chi\left(\sigma, D_{1}, D_{2}, z_{1}, z_{2}\right)=\frac{\sigma^{+}: \sigma^{+}}{2 E_{0}\left(1-D_{1}\right)}+\frac{\sigma^{-}: \sigma^{-}}{2 E_{0}\left(1-D_{2}\right)}+\frac{v_{0}}{2 E_{0}}\left(\sigma: \sigma-\operatorname{Tr}^{2}(\sigma)\right) \\
+\frac{\beta_{1} D_{1}}{E_{0}\left(1-D_{1}\right)} f(\sigma)+\frac{\beta_{2} D_{2}}{E_{0}\left(1-D_{2}\right)} \operatorname{Tr}(\sigma)+G_{1}\left(z_{1}\right)+G_{2}\left(z_{2}\right)
\end{array}
$$

onde $\sigma^{+}$e $\sigma^{-}$são, respectivamente, as partes positiva e negativa do tensor de tensões, $\operatorname{Tr}(\sigma)$ é o primeiro invariante do tensor de tensões, E é o módulo de Young do material íntegro $\left(D_{1}=D_{2}=0\right)$, v é o coeficiente de Poisson do material virgem, $\beta_{1}$ e $\beta$ 2 são os parâmetros anelásticos a serem identificados. Na equação acima a operação “:”representa uma contração dupla de índices característica de um produto interno entre tensores de segunda ordem. A função $f(\sigma)$ controla as condições de abertura e de fechamento da 'fissura':

$$
\begin{array}{ll}
\mathrm{f}(\operatorname{Tr}(\sigma))=\operatorname{Tr}(\sigma) & \text { quando } \operatorname{Tr}(\sigma) \in] 0, \infty] \\
\mathrm{f}(\operatorname{Tr}(\sigma))=\left(1+\frac{\operatorname{Tr}(\sigma)}{2 \sigma_{\mathrm{f}}}\right) \operatorname{Tr}(\sigma) & \text { quando } \operatorname{Tr}(\sigma) \in\left[-\sigma_{\mathrm{f}}, 0\right] \\
\mathrm{f}(\operatorname{Tr}(\sigma))=-\frac{\sigma_{\mathrm{f}}}{2} \operatorname{Tr}(\sigma) & \text { quando } \operatorname{Tr}(\sigma) \in\left[-\infty,-\sigma_{\mathrm{f}}\right]
\end{array}
$$

onde $\sigma_{\mathrm{f}}$ é a tensão de fechamento de fissura (parâmetro do modelo). Finalmente, $\mathrm{G}_{1}$ $\left(z_{1}\right)$ e $G_{2}\left(z_{2}\right)$ são funções de encruamento. 
As leis de estado derivam do potencial (3.31) e definem as variáveis associadas em função das variáveis de estado. Por exemplo, o tensor de deformações resulta de:

$\varepsilon=\frac{\partial \chi}{\partial \sigma}=\varepsilon_{\mathrm{e}}+\varepsilon_{\mathrm{sn}}$

onde $\varepsilon_{\mathrm{e}}$ é o tensor de deformações elásticas e $\varepsilon_{\mathrm{an}}$ é o tensor de deformações anelásticas. Esses tensores são dados por:

$$
\begin{aligned}
& \varepsilon_{\mathrm{e}}=\frac{\sigma^{+}}{\mathrm{E}_{0}\left(1-\mathrm{D}_{1}\right)}+\frac{\sigma^{-}}{\mathrm{E}_{0}\left(1-\mathrm{D}_{2}\right)}+\frac{\nu_{0}}{\mathrm{E}_{0}}(\sigma-\operatorname{Tr}(\sigma) \mathrm{I}) \\
& \text { e } \quad \varepsilon_{\text {aи }}=\frac{\beta_{1} \mathrm{D}_{1}}{\mathrm{E}_{0}\left(1-\mathrm{D}_{1}\right)} \frac{\partial \mathrm{f}}{\partial \sigma}+\frac{\beta_{2} \mathrm{D}_{2}}{\mathrm{E}_{0}\left(1-\mathrm{D}_{2}\right)} \mathrm{I}
\end{aligned}
$$

onde I é o tensor identidade.

Por sua vez, as variáveis associadas às variáveis de dano resultam de:

$$
\begin{aligned}
& \mathrm{Y}_{1}=\frac{\partial \chi}{\partial \mathrm{D}_{1}}=\frac{\sigma^{+}: \sigma^{+}+2 \beta_{1} \mathrm{f}(\sigma)}{2 \mathrm{E}_{0}\left(1-\mathrm{D}_{1}\right)^{2}} \\
& \mathrm{Y}_{2}=\frac{\partial \chi}{\partial \mathrm{D}_{2}}=\frac{\sigma^{-}: \sigma^{-}+2 \beta_{2} \operatorname{Tr}(\sigma)}{2 \mathrm{E}_{0}\left(1-\mathrm{D}_{2}\right)^{2}}
\end{aligned}
$$

Também variáveis associadas às variáveis de encruamento podem ser definidas, propondo-se, neste caso, uma expressão resultante do ajuste sobre resultados experimentais. A forma proposta é a seguinte:

$$
\mathrm{Z}_{\mathrm{i}}=\frac{\partial \mathrm{G}_{\mathrm{i}}\left(\mathrm{z}_{\mathrm{i}}\right)}{\partial \mathrm{z}_{\mathrm{i}}}=\mathrm{g}_{\mathrm{i}}\left(\mathrm{z}_{\mathrm{i}}\right)=\left[\mathrm{Y}_{\mathrm{oi}}+\frac{1}{\mathrm{~A}_{\mathrm{i}}}\left(\frac{-\mathrm{z}_{\mathrm{i}}}{1+\mathrm{z}_{\mathrm{i}}}\right)^{1 / \mathrm{B}_{\mathrm{i}}}\right] \quad(\mathrm{i}=1,2)
$$

onde $A_{i}, B_{i}$ e $Y_{o i}$ são parâmetros a serem identificados. 
Nota-se que as variáveis $Z_{\mathrm{i}}$ tem um valor inicial dado por $Z_{\mathrm{i}}\left(\mathrm{Z}_{\mathrm{i}}=0\right)=\mathrm{Y}_{\mathrm{o} \text {. }}$. As expressões (3.38) definem, na verdade, um critério de danificação que caracteriza a existência ou não de condições para a evolução do dano. Assim sendo, valem as condições:

Se $\mathrm{Y}_{\mathrm{i}}<\mathrm{Z}_{\mathrm{i}}$ então $\dot{\mathrm{D}}_{\mathrm{i}}=0$ : a resposta é elástica linear.

Se $Y_{i}=Z_{i}$ e $\dot{Y}_{i}>0$ então $\dot{Z}_{i}=\dot{Y}_{i}$ e $\dot{D}_{i} \neq 0$.

As leis de evolução das variáveis internas resultam de derivadas de um pseudo-potencial de dissipação escrito em função das correspondentes variáveis associadas. Alternativamente, com base em evidências experimentais, La Borderie propõe a seguinte lei para a evolução do dano:

$$
D_{i}=1-\frac{1}{1+\left[A_{i}\left(Y_{i}-Y_{o i}\right)\right]^{B_{i}}}
$$

Por outro lado, em LA BORDERIE (1991) agrupam-se os parâmetros a identificar em quatro grupos:

- Parâmetros elásticos: E, v;

- parâmetros de danificação de tração $\left(\mathrm{Y}_{01}, \mathrm{~A}_{1}, \mathrm{~B}_{1}\right) \mathrm{e}$ de compressão $\left(\mathrm{Y}_{02}, \mathrm{~A}_{2}, \mathrm{~B}_{2}\right)$

- parâmetros anelásticos $\beta_{1}$ e $\beta_{2}$;

- parâmetro de fechamento de fissura $\sigma_{f}$.

Os parâmetros elásticos são identificados em ensaios clássicos de compressão simples.

Os parâmetros anelásticos $\beta_{1}$ e $\beta_{2}$ são identificados através de ensaios de tração e de compressão com deformação controlada, respectivamente, operando-se ciclos de carregamento e descarregamento RAMTANI (1990). Os parâmetros que aparecem nas leis de evolução das variáveis de dano podem ser identificados pelos mesmos ensaios. 
Os ensaios que incluem inversão de sinal da solicitação e que permitem colocar em evidência $\sigma_{\mathrm{f}}$ não são, até o momento, suficientemente numerosos para realizar uma identificação completa. $\mathrm{O}$ valor de $\sigma_{\mathrm{f}}$ será adotado aproximadamente igual à tensão de ruptura em tração do concreto.

Com relação aos parâmetros de danificação $\mathrm{Y}_{0 \mathrm{i}}, \mathrm{A}_{\mathrm{i}}, \mathrm{B}_{\mathrm{i}}$, as figuras seguintes ilustram a influência de cada um deles na relação tensão-deformação. Os ensaios numéricos foram feitos variando cada parâmetro a partir dos seguintes valores:

$$
\begin{array}{ll}
E=33500 \quad \mathrm{MPa} \\
\mathrm{Y}_{01}=3,35 \cdot 10^{-4} \mathrm{MPa} \\
\mathrm{Y}_{02}=1,50 \cdot 10^{-2} \mathrm{MPa} \\
\mathrm{A}_{1}=4,00 \cdot 10^{+3} \mathrm{MPa} \\
\mathrm{A}_{2}=7,00 \quad \mathrm{MPa}^{-1} \\
\mathrm{~B}_{1}=1,2 \\
\mathrm{~B}_{2}=1,5 \\
\beta_{1}=1,00 \quad \mathrm{MPa} \\
\beta_{2}=-40,0 \quad \mathrm{MPa} \\
\sigma_{\mathrm{f}}=3,5 \quad \mathrm{MPa}
\end{array}
$$

No caso de esforço uniaxial de tração obtiveram-se os gráficos ilustrados nas figuras (3.7a,b e c) (LA BORDERIE (1991)).

$\mathrm{Na}$ figura 3.7a pode-se observar que a variável $\mathrm{Y}_{01}$ influencia o início e a inclinação inicial do trecho não-linear ("softening").

A figura $3.7 \mathrm{~b}$ mostra a influência do parâmetro $A_{1}$ sobre a inclinação inicial do trecho não-linear e no valor da assíntota horizontal.

Com relação ao parâmetro $B_{1}$, a figura $3.7 c$ ilustra sua influência sobre a curvatura do trecho não-linear e sobre o valor da assíntota horizontal. 


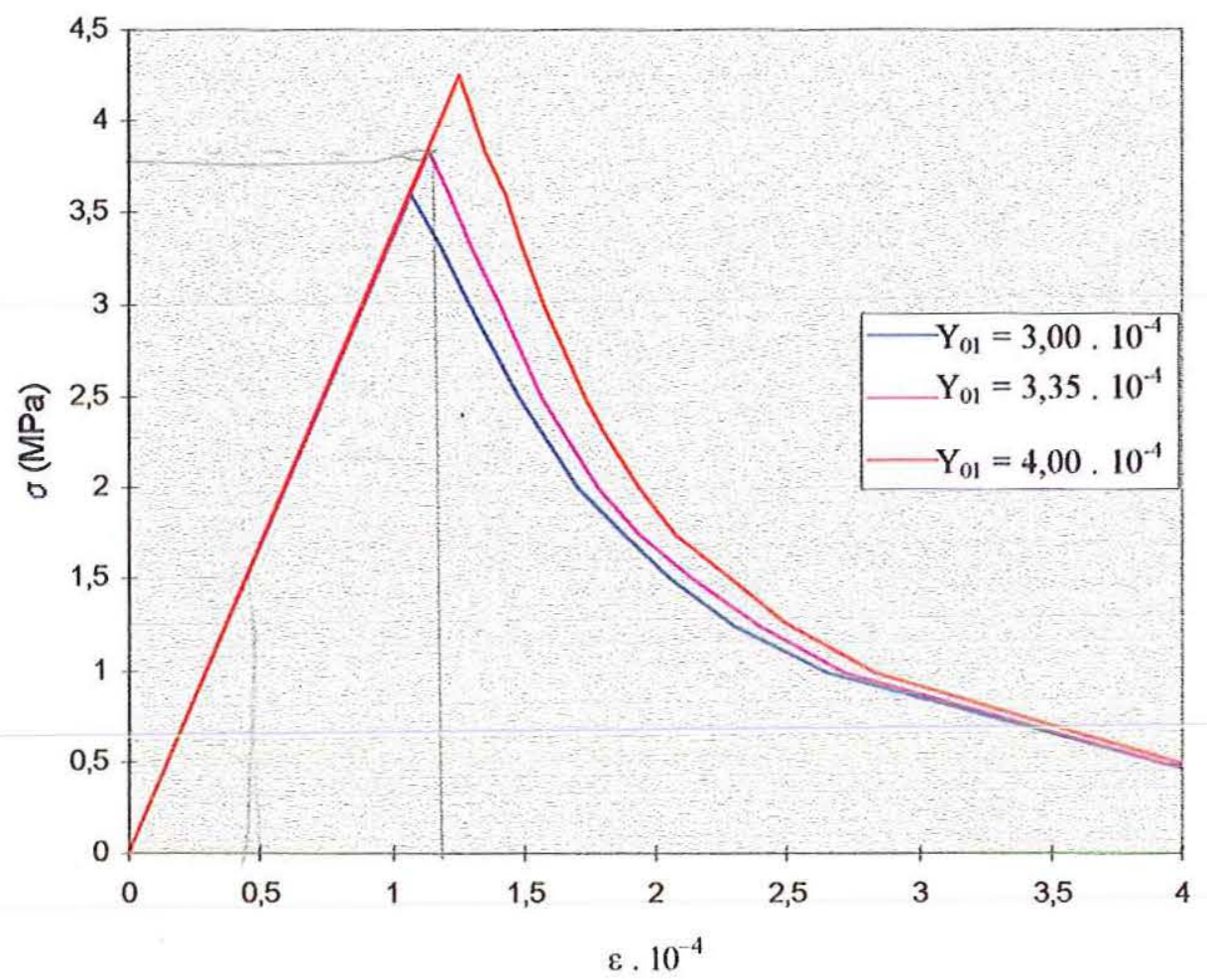

Figura 3.7a - Influência de $Y_{01}$ sobre o comportamento em tração

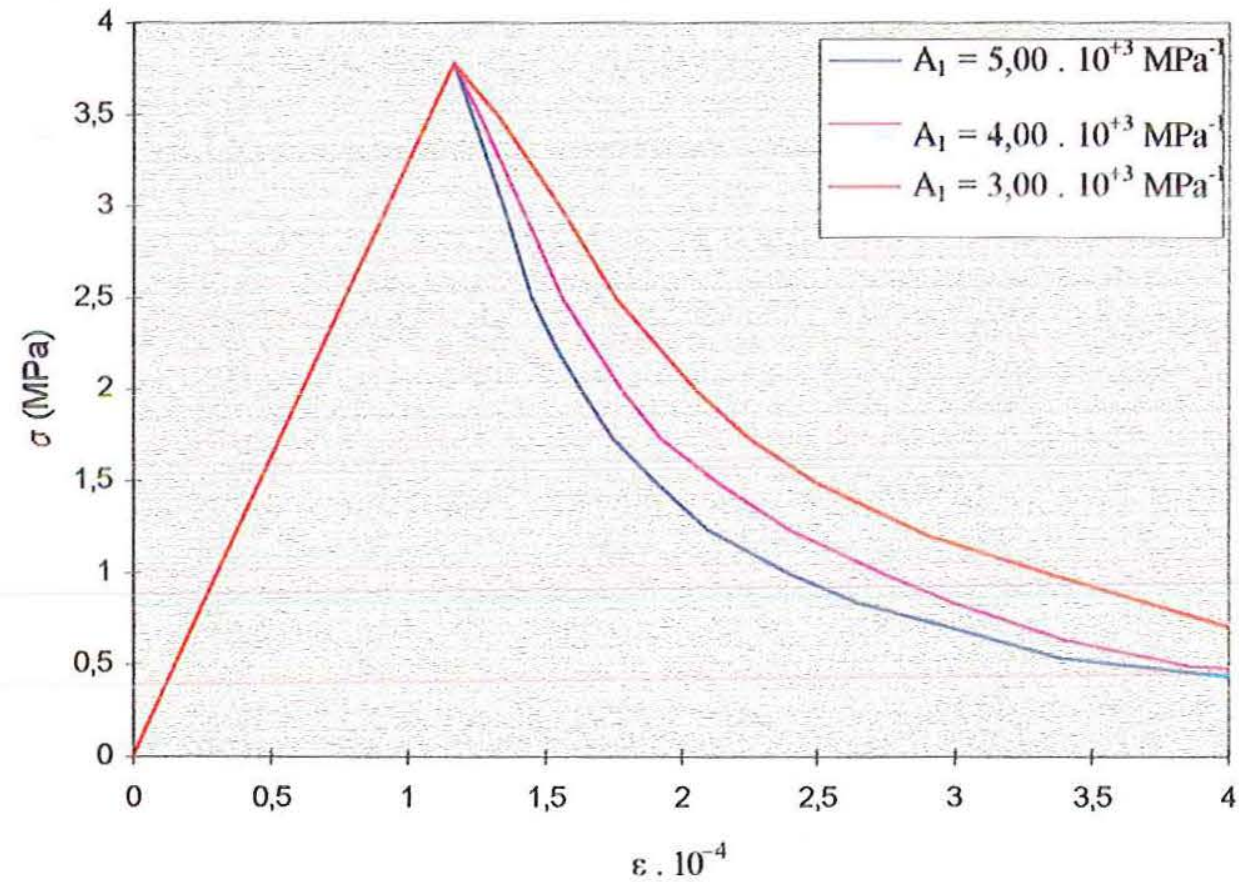

Figura 3.7b - Influência de $A_{1}$ sobre o comportamento em tração 


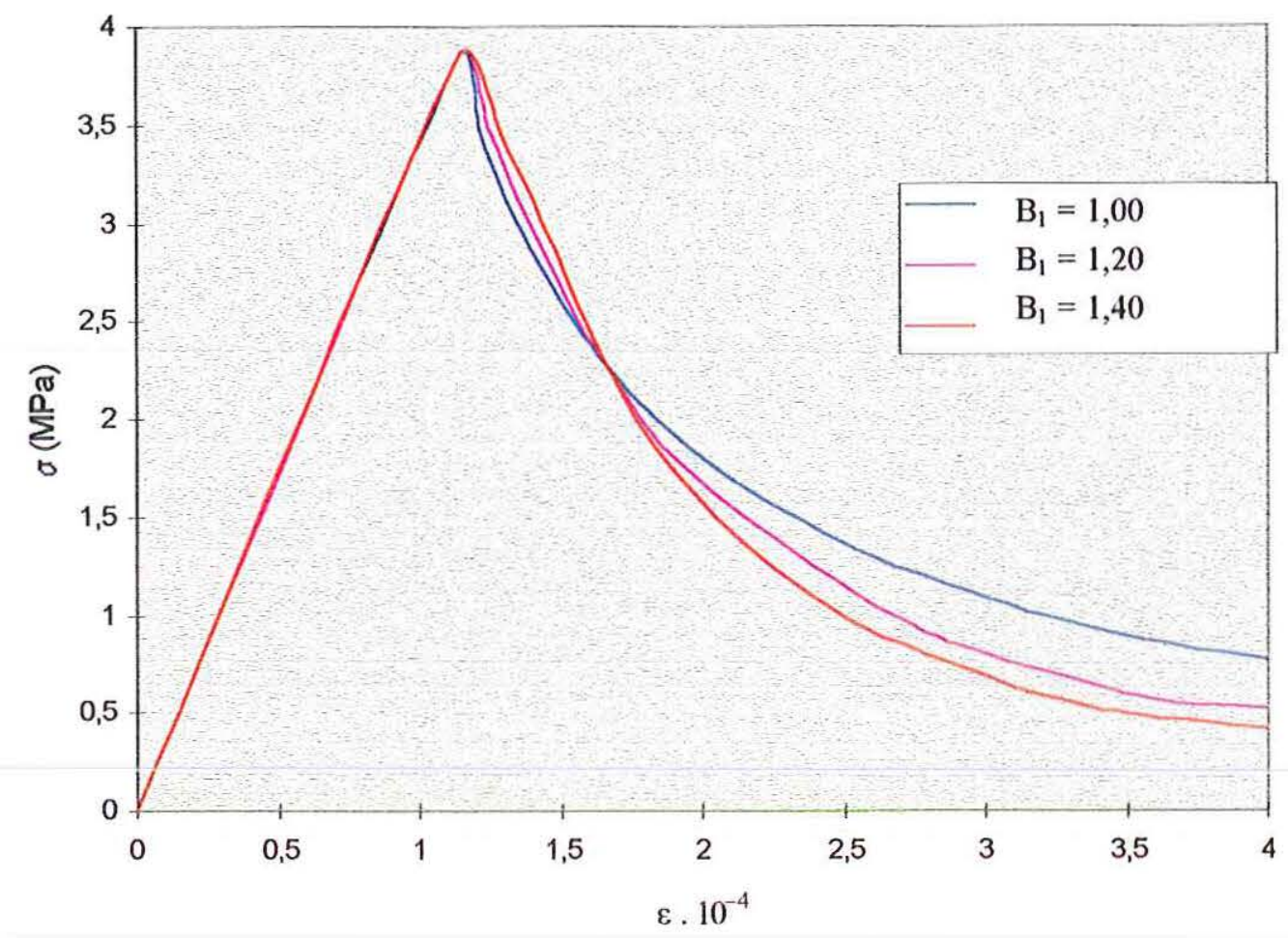

Figura 3.7c - Influência de $B_{1}$ sobre o comportamento em tração

No caso de esforço uniaxial de compressão valem os gráficos ilustrados nas figuras (3.8a,b e c) (LA BORDERIE (1991)).

Da figura 3.8a, observa-se que o parâmetro $\mathrm{Y}_{02}$ influencia o início e a inclinação inicial do trecho não-linear.

A figura $3.8 \mathrm{~b}$ mostra a influência do parâmetro $\mathrm{A}_{2}$ sobre o comportamento em compressão na inclinação inicial do trecho não-linear, além no valor da tensão de pico.

Com relação ao parâmetro $\mathrm{B}_{2}$, a figura $3.8 \mathrm{c}$ mostra sua influência sobre a curvatura do trecho não-linear. 
$\varepsilon \cdot 10^{-3}$

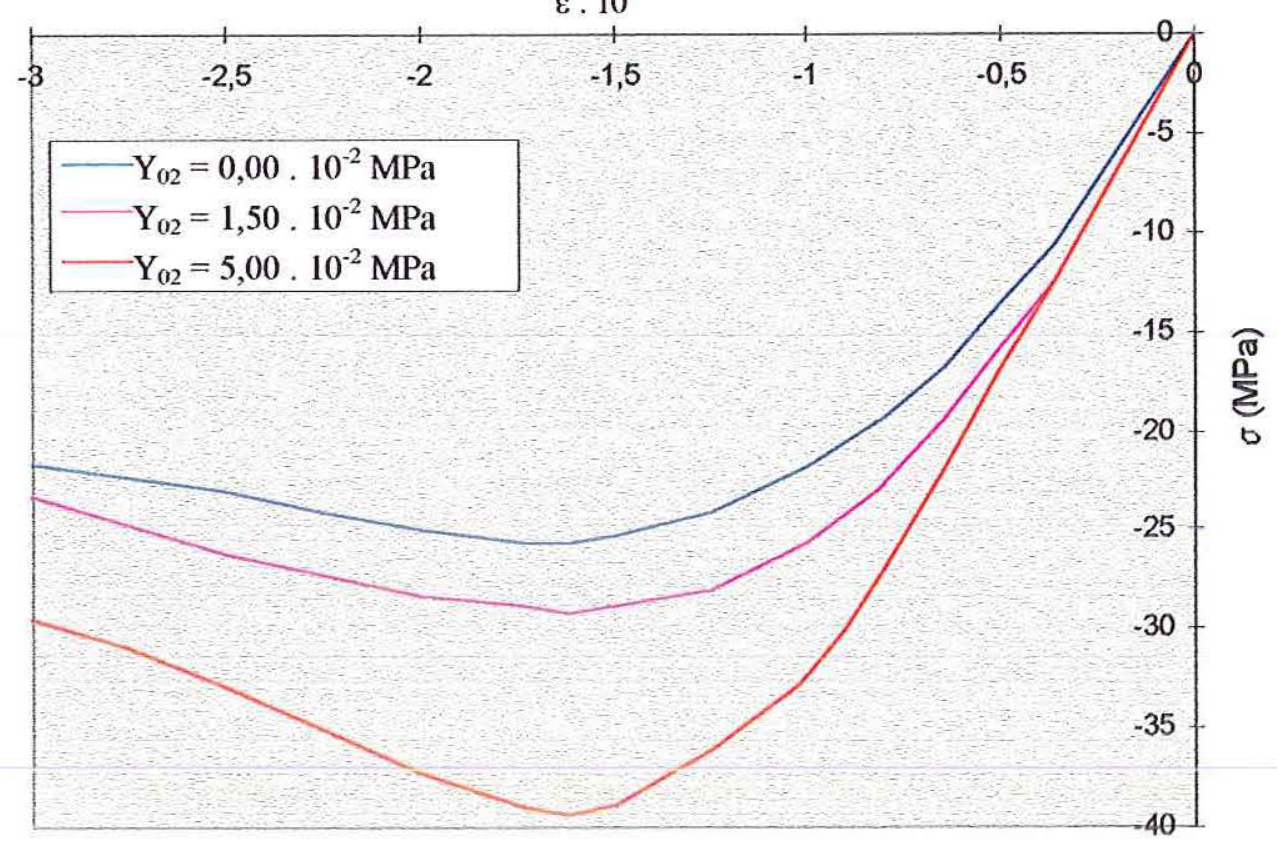

Figura 3.8a - Influência de $Y_{02}$ sobre o comportamento em compressão

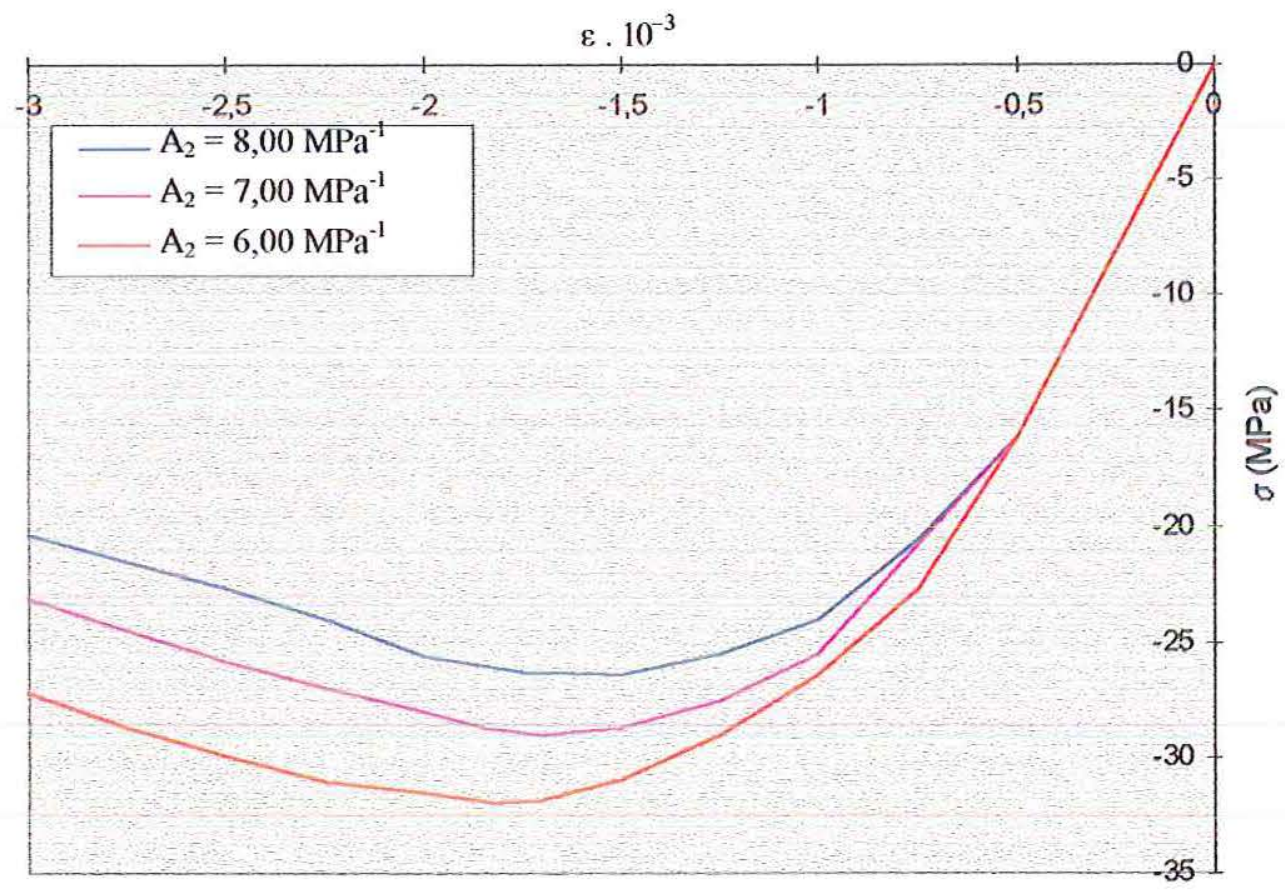

Figura3.8b - Influência de $A_{2}$ sobre o comportamento em compressão 


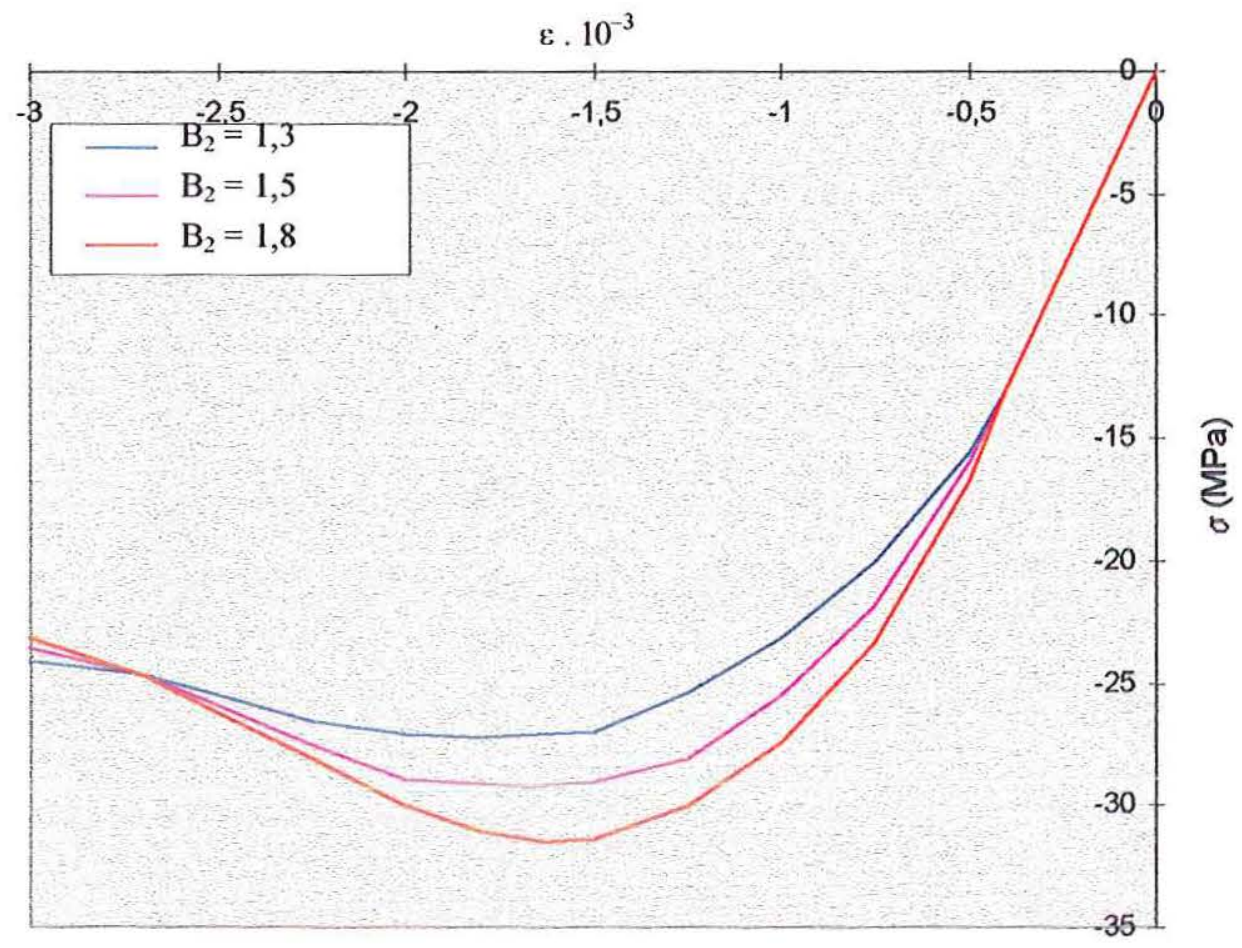

Figura 3.8c - Influência de $B_{2}$ sobre o comportamento em compressão

\subsection{MODELO CONSTITUTIVO DE FLOREZ-LÓPEZ (1993)}

Num regime de pequenas deformações, a relação constitutiva elástica de um elemento de barra envolvendo esforços e deformações generalizadas pode ser dada por:

$$
\{\mathrm{M}\}=\left[\mathrm{S}^{0}\right]\{\phi\} \quad \text { ou } \quad\{\phi\}=\left[\mathrm{F}^{0}\right]\{\mathrm{M}\}
$$


onde:
$\{\mathrm{M}\}^{\mathrm{T}}=\left(\mathrm{M}_{\mathrm{i}}, \mathrm{M}_{\mathrm{j}}, \mathrm{N}\right)$ (Figura 3.9a)
$\{\phi\}=\left\{\phi_{i}, \phi_{j}, \delta\right\}$ (Figura 3.9b)
$\left[\mathrm{S}^{0}\right]$ é a matriz de rigidez do elemento
$\left[\mathrm{F}^{0}\right]$ é a matriz de flexibilidade do elemento

Em muitos casos o modelo elástico é obviamente inadequado porque o elemento pode conter plasticidade e dano, por exemplo. Uma equação constitutiva mais geral pode ser obtida utilizando-se os 'modelos de dissipação concentrada' como indicado na figura $3.9 \mathrm{c}$. O elemento é caracterizado pela união de uma vigacoluna elástica e duas rótulas anelásticas de comprimento zero nas suas extremidades às quais está associada a energia dissipada. Nesse caso, as deformações generalizadas podem ser expressas por:

$\{\phi\}=\left[\mathrm{F}^{\mathrm{e}}\right]\{\mathrm{M}\}+\left\{\phi^{\mathrm{r}}\right\}$

A primeira parcela do lado direito da igualdade em (3.42) corresponde às deformações da viga-coluna sendo $\left[\mathrm{F}^{\mathrm{e}}\right.$ ] a matriz de flexibilidade elástica, citada em (3.41). A última parcela reúne as chamadas 'deformações de rótula'.

O equilíbrio determina a relação entre as forças internas (figura 3.9d) e as tensões generalizadas (figura 3.9a) dada a seguir:

$$
\{\mathrm{Q}\}=\left[\mathrm{B}^{0}\right]^{\mathrm{T}}\{\mathrm{M}\}
$$

Já as deformações de rótula são resultantes da soma das deformações plásticas $\left\{\phi^{\mathrm{P}}\right\}$ e das deformações devidas ao dano $\left\{\phi^{\mathrm{d}}\right\}$

$$
\left\{\phi^{\mathrm{r}}\right\}=\left\{\phi^{\mathrm{p}}\right\}+\left\{\phi^{\mathrm{d}}\right\}
$$




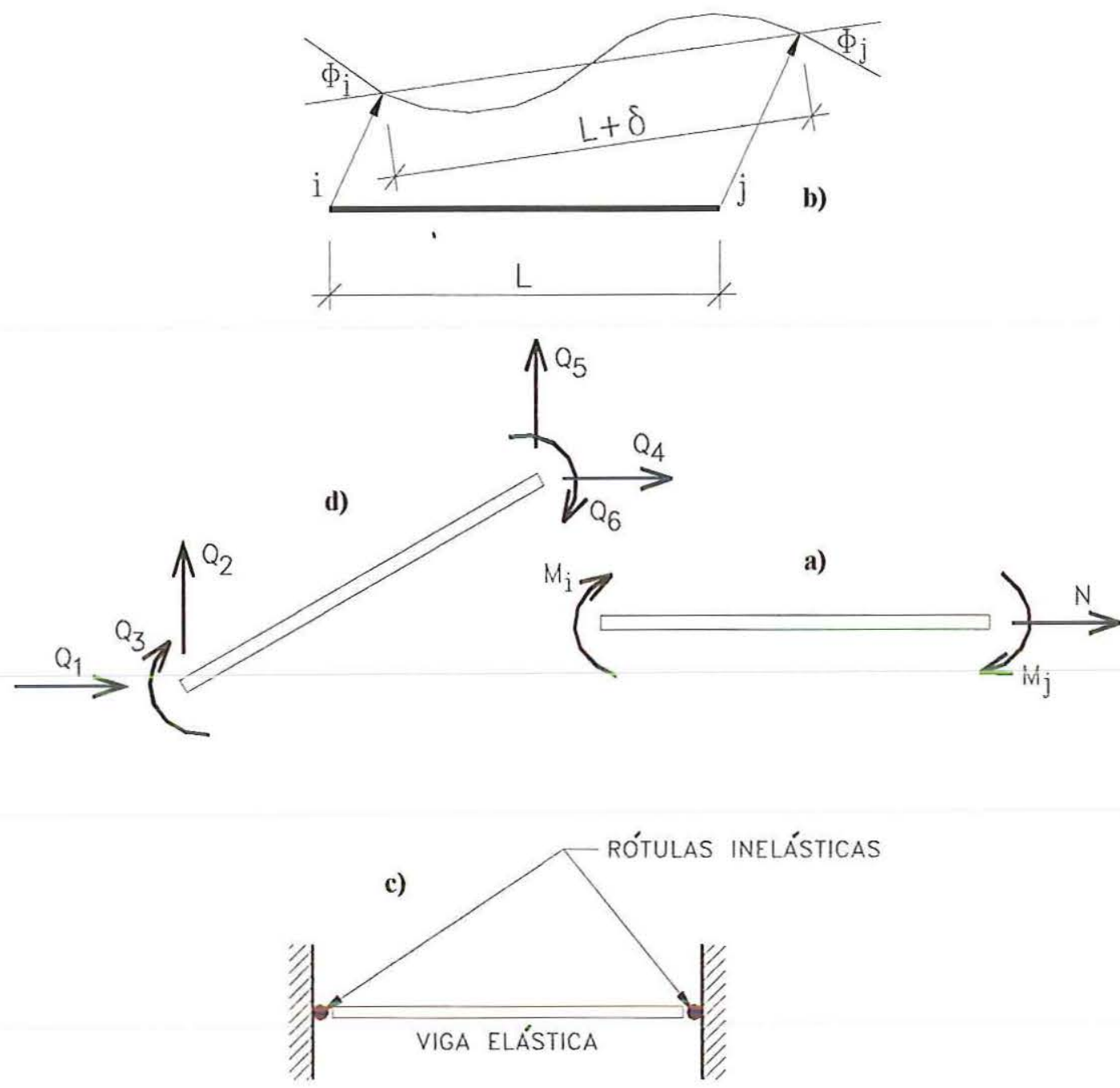

Figura 3.9 - Deformações, forças internas, tensões generalizadas e elemento finito empregado.

Uma componente importante na formulação é a matriz de flexibilidade que relaciona os esforços generalizados com dano $\left\{\phi^{\mathrm{d}}\right\}$. Para exemplificar de modo simples a forma de obtenção dos elementos da matriz considere-se o caso particular de um elemento de treliça . Então apenas tensões e deformações generalizadas axiais têm de ser levadas em conta. Neste caso, empregando-se a hipótese da tensão efetiva (conf. item 2.1 .4 (eq. 2.8)), a variação de comprimento da barra com dano e plastificação pode ser expressa na forma:

$\delta=\frac{\mathrm{N}}{(1-\mathrm{D}) \mathrm{S}_{33}^{0}}+\delta^{\mathrm{p}}$ 
onde $\mathrm{S}_{33}^{0}=\mathrm{EA} / \mathrm{L}, \mathrm{N}$ é o esforço normal axial e $\delta^{\mathrm{p}}$ é o alongamento devido ao efeito de plasticidade.

Das relações (3.42) e (3.44), obtém-se

$\delta=\frac{\mathrm{N}}{\mathrm{S}_{33}^{0}}+\delta^{\mathrm{p}}+\delta^{\mathrm{d}}$

Igualando-se (3.46) e (3.45), resulta que o alongamento da barra devido ao dano é dado por

$$
\delta^{\mathrm{d}}=\frac{\mathrm{D}}{(1-\mathrm{D}) \mathrm{S}_{33}^{0}} \mathrm{~N}
$$

Assim no modelo de dissipação concentrada a deformação axial devido ao dano nas rótulas é dada pela equação (3.47). Em particular, para D igual a zero obtém-se ligações com flexibilidade nula e rigidez axial infinita. Quando D assume o valor unitário, obtém-se ligações com flexibilidade axial infinita ou rigidez nula (rótulas e viga elástica estão desconectadas).

No caso da viga-coluna em consideração postula-se um conjunto de parâmetros $\{D\}^{T}=\left(d_{i}, d_{j}, d_{n}\right)$ contidos no intervalo [0,1], e correspondentes aos graus de liberdade associados aos giros nos nós i e j e deslocamento axial. A deformação devido ao dano será

$$
\left\{\phi^{\mathrm{d}}\right\}=[\mathrm{C}(\mathrm{D})]\{\mathrm{M}\}
$$

onde [C(D)] é a matriz de flexibilidade de um elemento com duas rótulas, definida por 


$$
[C(D)]=\left[\begin{array}{ccc}
\frac{d_{i}}{\left(1-d_{i}\right) S_{11}^{0}} & 0 & 0 \\
0 & \frac{d_{j}}{\left(1-d_{j}\right) S_{22}^{0}} & 0 \\
0 & 0 & \frac{d_{n}}{\left(1-d_{n}\right) S_{33}^{0}}
\end{array}\right] \quad \begin{gathered}
S_{11}=\frac{4 E E}{L} \\
S_{21}=\frac{4 E L}{L} \\
S_{1,1}=\frac{E A}{L}
\end{gathered}
$$

A forma diagonal da matriz de flexibilidade resulta da hipótese de independência dos processos de danificação em cada um dos graus de liberdade.

Da combinação de $(3.42),(3,44)$ e $(3.48)$ define-se a relação tensãodeformação de uma barra com dano

$$
\left\{\phi-\phi^{\mathrm{P}}\right\}=\left[\mathrm{F}^{\mathrm{d}}(\mathrm{M}, \mathrm{D})\right]\{\mathrm{M}\}
$$

onde

$\left[F^{\mathrm{d}}(\mathrm{M}, \mathrm{D})\right]=\left[\mathrm{F}^{\mathrm{e}}(\mathrm{M})\right]+[\mathrm{C}(\mathrm{D})]$

é a matriz de flexibilidade de uma barra com dano. Vale ressaltar que os parâmetros $d_{i}$ e $\mathrm{d}_{\mathrm{j}}$ medem respectivamente o dano devido à flexão nas rótulas $\mathrm{i}$ e j,e $\mathrm{d}_{\mathrm{n}} \mathrm{o}$ dano devido ao esforço axial na barra. O caso particular da barra de treliça é obtido quando $\mathrm{M}_{\mathrm{i}}$ e $\mathrm{M}_{\mathrm{j}}$ assumem valores nulos.

Se os parâmetros de dano à flexão assumem o valor nulo (sem dano) então o modelo em questão recae no modelo de plasticidade concentrada padrão. Se os valores de dano são unitários, diz-se que a situação é de 'rótula totalmente danificada' reproduzindo-se o mesmo comportamento de uma articulação interna de uma estrutura de barras.

Como um exemplo, para uma barra de inércia $\mathrm{I}$, área $\mathrm{A}$ e comprimento $\mathrm{L}$, considerando-se pequenos deslocamentos, a matriz de rigidez (obtida por inversão da matriz de flexibilidade) é dada por 


$$
\left[S^{d}(D)\right]=\left[\begin{array}{ccc}
\frac{\left(1-d_{i}\right)\left(4-d_{j}\right)}{4-d_{i} d_{j}} 4 E I / L & \frac{4\left(1-d_{i}\right)\left(1-d_{j}\right)}{4-d_{i} d_{j}} 2 E I / L & 0 \\
\text { SIMETRIA } & \frac{\left(1-d_{j}\right)\left(4-d_{i}\right)}{4-d_{i} d_{j}} 4 E I / L & 0 \\
& \left(1-d_{n}\right) \frac{A E}{L}
\end{array}\right]
$$

Pode-se observar que para $\{\mathrm{D}\}=0$, obtém-se a matriz de uma barra com comportamento elástico. Quando os parâmetros $d_{i}$ e $d_{j}$ são iguais a 1,0 obtém-se a matriz de rigidez de uma barra de treliça.

Tendo-se em vista a definição das forças termodinâmicas associadas ao conjunto de variáveis internas, o modelo postula a existência de um potencial termodinâmico expresso da seguinte forma

$$
\chi=U^{*}(M, D)+U^{p}(\alpha)
$$

A parcela $U^{*}$ contém a influência da danificação nas rótulas e a energia potencial complementar $\mathrm{W}^{*}$ da viga elástica.

$$
U^{*}(M, D)=\frac{1}{2}\{M\}^{T}[C(D)]\{M\}+W^{*}
$$

$\mathrm{U}^{\mathrm{P}}(\alpha)$ é um 'potencial plástico' dependente de um conjunto de variáveis internas $\{\alpha\}^{\mathrm{T}}$ $=\left(\alpha_{1}, \alpha_{2}, \ldots\right)$ que correspondem, por exemplo, ao encruamento plástico cinemático ou isótropo.

As leis de estado podem agora ser definidas na forma:

$$
\{\phi\}^{\mathrm{e}}=\left\{\phi-\phi^{\mathrm{p}}\right\}=\left\{\frac{\partial \chi}{\partial \mathrm{M}}\right\}
$$


As forças termodinâmicas conjugadas as variáveis de dano e reunidas no vetor $\{G\}$ são definidas de forma similar por

$$
\{G\}=-\left\{\frac{\partial \chi}{\partial D}\right\}
$$

Essas 'forças' podem ser interpretadas como taxas de energia liberada para a evolução do dano. Elas têm as seguintes expressões:

$$
\begin{aligned}
& \mathrm{G}_{\mathrm{i}}=-\frac{\partial \chi}{\partial \mathrm{d}_{\mathrm{i}}}=\frac{1}{2 \mathrm{~S}_{11}^{0}}\left[\frac{\mathrm{M}_{\mathrm{i}}}{\left(1-\mathrm{d}_{\mathrm{i}}\right)}\right]^{2} \\
& \mathrm{G}_{\mathrm{j}}=-\frac{\partial \chi}{\partial \mathrm{d}_{\mathrm{j}}}=\frac{1}{2 \mathrm{~S}_{22}^{0}}\left[\frac{\mathrm{M}_{\mathrm{j}}}{\left(1-\mathrm{d}_{\mathrm{j}}\right)}\right]^{2} \\
& \mathrm{G}_{\mathrm{n}}=-\frac{\partial \chi}{\partial \mathrm{d}_{\mathrm{n}}}=\frac{1}{2 \mathrm{~S}_{33}^{0}}\left[\frac{\mathrm{N}}{\left(1-\mathrm{d}_{\mathrm{n}}\right)}\right]^{2}
\end{aligned}
$$

As forças termodinâmicas associadas aos parâmetros de encruamento plástico $\{\alpha\}$ são, por sua vez, dadas por :

$$
\{\beta\}=-\left\{\frac{\partial \chi}{\partial \alpha}\right\}
$$

A dissipação decorrente dos processos de evolução dos fenômenos de dano e plasticidade é agora dada por

$$
\xi=\{\dot{D}\}^{T}\{G\}+\left\{\phi^{p}\right\}^{\top}\{M\}+\{\dot{\alpha}\}\{\beta\} \geq 0
$$

A dissipação de energia deve ser positiva para atender a segunda lei da termodinâmica. Se for considerado que os mecanismos de dissipação de energia são 
independentes, no sentido de que não há acoplamento ao nível de leis de evolução, então cada parcela de (3.59) deve ser positiva, o que pode ser satisfeito se:

$\phi_{\mathrm{i}}^{\mathrm{p}} \mathrm{M}_{\mathrm{i}}+\delta^{\mathrm{p}} \mathrm{N}+$ termos de encruamento (rótula i) $\geq 0$

$\phi_{\mathrm{j}}^{\mathrm{p}} \mathrm{M}_{\mathrm{j}}+\delta^{\mathrm{p}} \mathrm{N}+$ termos de encruamento (rótula $\mathrm{j}$ ) $\geq 0$

$\dot{\mathrm{d}}_{\mathrm{i}} \mathrm{G}_{\mathrm{i}}+\dot{\mathrm{d}}_{\mathrm{n}} \mathrm{G}_{\mathrm{n}}+$ termos de encruamento (rótula $\mathrm{i}$ ) $\geq 0$

$\dot{\mathrm{d}}_{\mathrm{j}} \mathrm{G}_{\mathrm{j}}+\dot{\mathrm{d}}_{\mathrm{n}} \mathrm{G}_{\mathrm{n}}+$ termos de encruamento (rótula $\mathrm{j}$ ) $\geq 0$

As leis de evolução das variáveis internas são agora introduzidas seguindo-se uma regra de normalidade com relação a um potencial de dissipação, e de tal modo que recai nos modelos de plasticidade concentrada clássicos se o dano permanece constante $(\{\dot{\mathrm{D}}\}=0)$.

A) Leis de evolução das componentes de deformação plástica:

$\dot{\phi}_{\mathrm{i}}^{\mathrm{p}}=\dot{\lambda}_{\mathrm{i}}^{\mathrm{p}} \frac{\partial \mathrm{f}_{\mathrm{i}}}{\partial \mathrm{M}_{\mathrm{i}}} \quad \dot{\phi}_{\mathrm{j}}^{\mathrm{p}}=\dot{\lambda}_{\mathrm{j}}^{\mathrm{p}} \frac{\partial \mathrm{f}_{\mathrm{j}}}{\partial \mathrm{M}_{\mathrm{j}}} \quad \dot{\delta}^{\mathrm{p}}=\dot{\lambda}_{\mathrm{i}}^{\mathrm{p}} \frac{\partial \mathrm{f}_{\mathrm{i}}}{\partial \mathrm{N}}+\dot{\lambda}_{\mathrm{j}}^{\mathrm{p}} \frac{\partial \mathrm{f}_{\mathrm{j}}}{\partial \mathrm{N}}$

onde $\mathrm{f}_{\mathrm{i}} \leq 0$ e $\mathrm{f}_{\mathrm{j}} \leq 0$ são respectivamente as funções de plastificação das rótulas ' $\mathrm{i}$ ' e ' $\mathrm{j}$ '. Elas reproduzem as funções de plastificação usuais quando os parâmetros de dano permanecem constantes. Os multiplicadores plásticos são caracterizados segundo a maneira clássica por

$\dot{\lambda}^{p}\left\{\begin{array}{ccccc}=0 & \text { se } & \mathrm{f}<0 & \text { ou } & \dot{\mathrm{f}}<0 \text { (sem plasticidade) } \\ >0 & \text { se } & \mathrm{f}=0 & \text { e } & \dot{\mathrm{f}}=0 \text { (incremento de plasticidade) }\end{array}\right.$

B) Leis de evolução das variáveis de dano:

$\dot{\mathrm{d}}_{\mathrm{i}}=\dot{\lambda}_{\mathrm{i}}^{\mathrm{d}} \frac{\partial \mathrm{g}_{\mathrm{i}}}{\partial \mathrm{G}_{\mathrm{i}}} \quad \dot{\mathrm{d}}_{\mathrm{j}}=\dot{\lambda}_{\mathrm{j}}^{\mathrm{d}} \frac{\partial \mathrm{g}_{\mathrm{j}}}{\partial \mathrm{G}_{\mathrm{j}}} \quad \dot{\mathrm{d}}_{\mathrm{n}}=\dot{\lambda}_{\mathrm{i}}^{\mathrm{d}} \frac{\partial \mathrm{g}_{\mathrm{i}}}{\partial \mathrm{G}_{\mathrm{n}}}+\dot{\lambda}_{\mathrm{j}}^{\mathrm{d}} \frac{\partial \mathrm{g}_{\mathrm{j}}}{\partial \mathrm{G}_{\mathrm{n}}}$ 
onde $g_{i} \leq 0$ e $g_{j} \leq 0$ são chamadas 'funções ou critérios de danificação' e têm o mesmo papel das funções de plasticidade, isto é, indicam se um processo de dano iniciou-se ou está em evolução numa rótula. As condições impostas sobre os multiplicadores de dano são:

$\dot{\lambda}_{\mathrm{d}}\left\{\begin{array}{ccccc}=0 & \text { se } & \mathrm{g}<0 & \text { ou } & \dot{\mathrm{g}}<0 \text { (sem dano) } \\ >0 & \text { se } & \mathrm{g}=0 & \text { e } & \dot{\mathrm{g}}=0 \text { (incremento de dano) }\end{array}\right.$

Se outras variáveis internas $\{\alpha\}$ são presentes no modelo, então suas leis de evolução podem também ser obtidas a partir das funções de plasticidade ou de dano, ou de funções independentes, aplicando-se a regra da normalidade.

Em FLÓREZ-LÓPEZ (1993) apresenta-se um procedimento de identificação das leis de evolução das variáveis de dano e de plasticidade afim de definir completamente o modelo constitutivo. Estas funções deveriam ser específicas para cada tipo de elemento estrutural variando de acordo com o tipo de concreto, distribuição de armadura, etc. A identificação pode ser feita em testes padronizados de ligações viga-coluna sendo que, no artigo citado, ela é feita para um elemento em concreto armado submetido a uma história de deslocamento controlado que implica em carregamento e descarregamento, porém sem inversão de sinal.

De modo simplificado, o ensaio está esquematizado na figura (3.10). O modelo de dissipação concentrada equivalente é ilustrado na figura (3.11), tomandose partido da simetria da estrutura. Pequenos deslocamentos e deformações são assumidos. Apenas uma rótula aparece na figura (3.11) porque em virtude do movimento nulo da extremidade esquerda assume-se, naturalmente, que $d_{i}$ e $\phi_{i}^{p}$ são iguais a zero. Admite-se também que $d_{n}, \delta$ e $\delta^{p}$ são iguais a zero devido a não existência de força axial. Então, chega-se ao valor da carga

$$
P=\frac{4-4 D}{4-D}\left(\frac{6 E I}{L^{3}}\right)\left(t-t^{p}\right)=Z(D)\left(t-t^{p}\right)
$$


onde $\mathrm{t}$ indica o deslocamento imposto no ponto médio da viga, $\mathrm{P}$ é a força aplicada na viga, $D=d_{j}$ e $t^{p}=L \phi_{j}^{p}$.
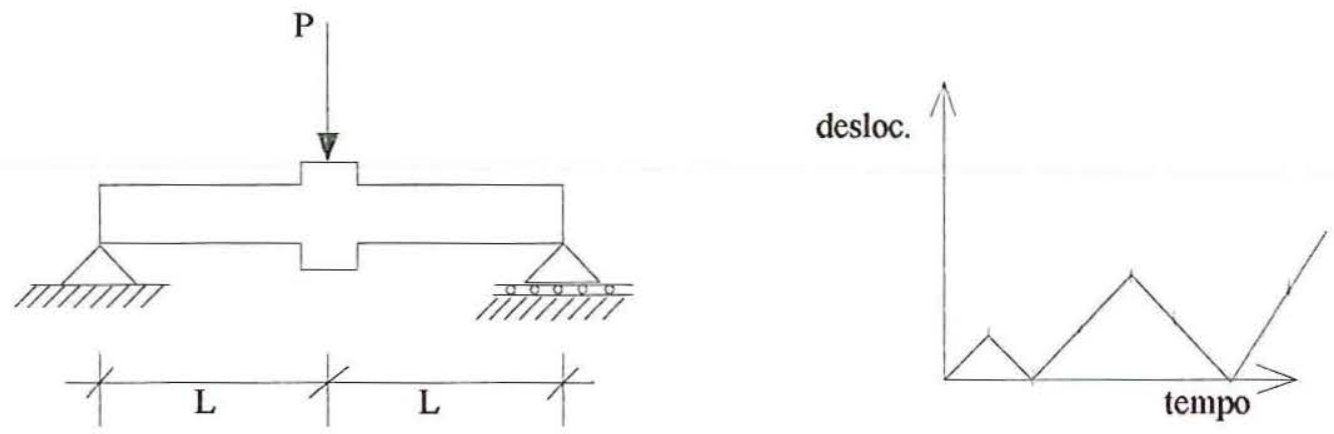

Figura 3.10 - Ensaio para identificação paramétrica: espécime e história de carregamento.
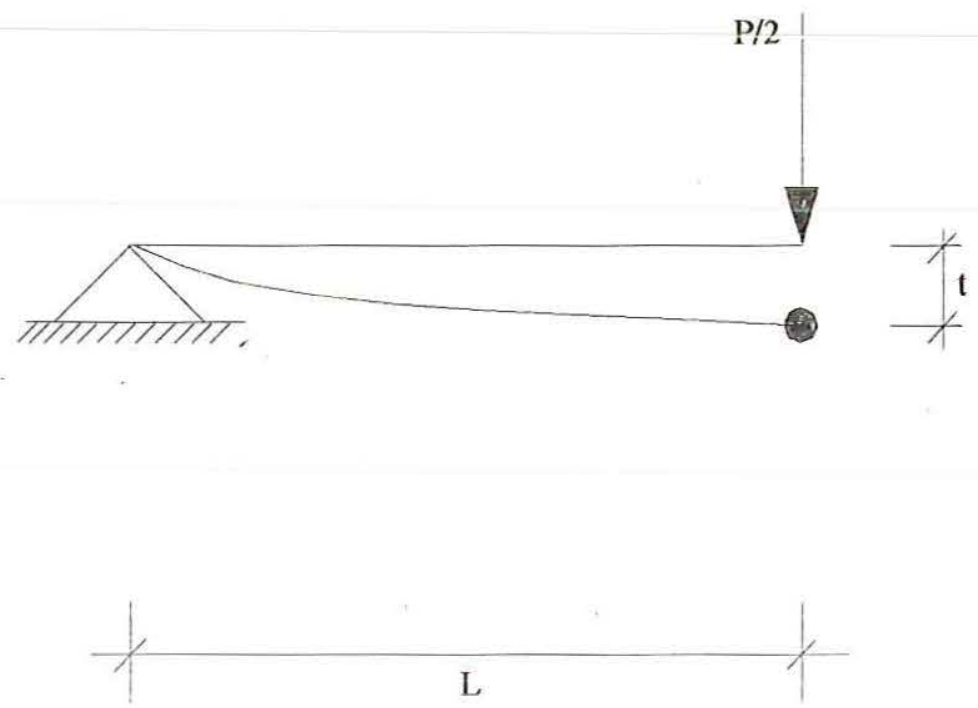

Figura 3.11 - Modelo de dissipação concentrada do ensaio.

As séries de carregamentos e descarregamentos permitem a determinação experimental da rigidez elástica $\mathrm{Z}$ e da parcela plástica $\mathrm{t}^{\mathrm{p}}$ do deslocamento $\mathrm{e}$, em consequência, dos diferentes valores da força P. Os valores experimentais de interesse relacionam-se com as variáveis de dano e rotação plástico da rótula, do modelo de dissipação concentrada, através das seguintes expressões:

$\mathrm{Z}=\frac{4-4 \mathrm{D}}{4-\mathrm{D}} \mathrm{Z}_{0} ; \quad \mathrm{Z}_{0}=\left(\frac{6 \mathrm{EI}}{\mathrm{L}^{3}}\right) ; \quad \mathrm{t}^{\mathrm{p}}=\mathrm{L} \phi_{\mathrm{j}}^{\mathrm{p}}$ 
Essas relações, de modo inverso permitem determinar as medidas dos parâmetros de dano ' $D$ ' e da deformação plástica ‘ $\phi^{p}$ ', por:

$$
\mathrm{D}=4\left(1-\frac{\mathrm{Z}}{\mathrm{Z}_{0}}\right) /\left(4-\frac{\mathrm{Z}}{\mathrm{Z}_{0}}\right) ; \quad \phi^{\mathrm{p}}=\frac{\mathrm{t}^{\mathrm{p}}}{\mathrm{L}}
$$

As medidas de M e G (variáveis conjugadas de $\phi^{\mathrm{p}}$ e D) são dadas por:

$$
\mathrm{M}=\frac{\mathrm{PL}}{2} ; \quad \mathrm{G}=\frac{\mathrm{L}}{8 \mathrm{EI}}\left(\frac{\mathrm{M}}{1-\mathrm{D}}\right)^{2}
$$

As funções de plasticidade e de dano podem ser identificadas a partir das curvas de M em função de $\phi^{p}$ e de D como função de G. FLOREZ-LÓPEZ (1993) propõe as seguintes expressões para os critérios:

$$
\begin{aligned}
& f=\left|M-\left(\frac{1-d}{4-d}\right) c \phi^{p}\right|-4\left(\frac{1-d}{4-d}\right) M_{y} \\
& g=G-\left(G_{c r}+q \frac{\ln (1-d)}{(1-d)}\right)
\end{aligned}
$$

onde c, $\mathrm{M}_{\mathrm{y}}, \mathrm{G}_{\mathrm{cr}}$ e q são constantes características do elemento.

Pode-se notar que as equações $(3.69 \mathrm{a}, \mathrm{b})$ particularizam-se para um modelo elasto-plástico perfeito se o dano permanece constante e c assume o valor zero. Se c é positivo, mas não existe se considera o dano, obtém-se um modelo elasto-plástico bilinear com encruamento cinemático. No caso geral, a dimensão da zona elástica resulta da combinação entre o encruamento produzido pela plasticidade e o 'soflening' devido ao dano.

A função de dano (3.69b) exibe um termo de encruamento dado pela expressão escrita entre parêntesis. Se q assume o valor zero, a função reproduz um critério equivalente ao critério de Griffith, da mecânica da fratura, aplicado ao elementode barra em questão. 
Os parâmetros c, $M_{y}, G_{c r}$ e q não têm interpretações mecânicas bem definidas. No caso, determinam-se essas constantes indiretamente através da resolução numérica do sistema de equações não-lineares seguinte:

$\mathrm{M}=\mathrm{M}_{\mathrm{cr}} \quad \Rightarrow \quad \mathrm{d}=0$

$M=M_{p} \quad \Rightarrow \quad \phi^{p}=0$

$M=M_{u} \quad \Rightarrow \quad \frac{d M}{d \phi^{p}}=0$

$\mathrm{M}=\mathrm{M}_{\mathrm{u}} \quad \Rightarrow \quad \phi^{\mathrm{p}}=\phi_{\mathrm{u}}^{\mathrm{p}}$

onde $\mathrm{M}_{\mathrm{cr}}$ é o momento de fissuração, $\mathrm{M}_{\mathrm{p}}$ é o momento de plastificação ou de escoamento, $\mathrm{M}_{\mathrm{u}}$ é o momento último e $\phi_{\mathrm{u}}^{\mathrm{p}}$ é a deformação plástica correspondente ao momento último.

Segundo FLOREZ-LÓPEZ (1993), estes parâmetros podem ser obtidos da teoria clássica de concreto armado, podendo ainda ser estimados em função de características conhecidas como: comprimento, área da seção transversal, quantidade e distribuição de armadura e propriedades do concreto. Obviamente o desempenho do modelo depende muito da qualidade dos métodos usados para os seus cálculos.

\subsubsection{Modelo Constitutivo de ÁLVARES (1998)}

O modelo original abordado na seção anterior contém apenas três coordenadas para as tensões generalizadas $\left(\{M\}^{T}=\left(M_{i}, M_{j}, N\right)\right.$ (figura 3.9a)), ou seja, no modelo original não se leva em conta a contribuição do esforço cortante nos elementos. ÁLVARES (1998) introduziu mais três coordenadas para que esta contribuição fosse levada em conta. Na análise de pórticos, a contribuição do esforço cortante na energia de deformação pode ter uma importância relevante. A energia 
produzida pelo esforço cortante é um processo dissipativo a mais a ser levado em conta.

Apresenta-se a seguir a matriz de rigidez de um elemento de pórtico plano, segundo as coordenadas globais da estrutura elaborada por ÁLVARES (1998), bem como uma ilustração das tensões generalizadas admitas para o elemento (figura 3.12).

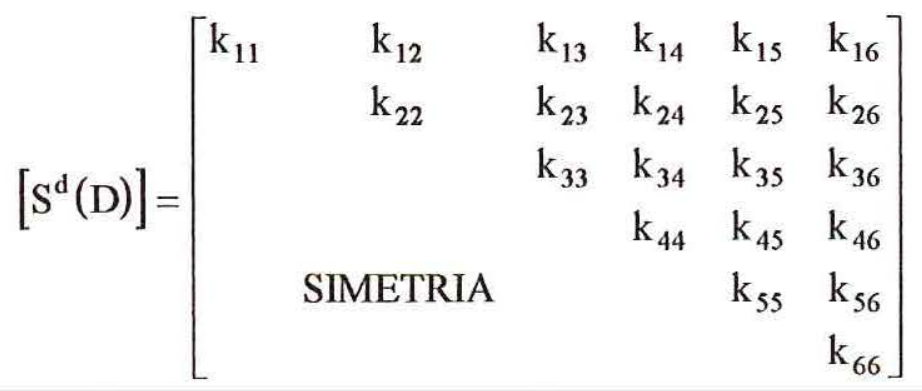

$$
\begin{aligned}
& K_{11}=\left(\cos ^{2} \alpha \cdot \frac{E A}{L}\right)\left(1-d_{n}\right)+\left(12 \sin ^{2} \alpha \cdot \frac{E I}{L^{3}}\right)\left(1-c_{1}-c_{2}+c_{3}\right) \\
& \mathrm{K}_{12}=\left(\frac{\mathrm{EA}}{\mathrm{L}}-\frac{12 \mathrm{EI}}{\mathrm{L}^{3}}\right) \sin \alpha \cos \alpha \\
& \mathrm{K}_{13}=\left(\frac{-\cos \alpha \cdot \mathrm{EAy}_{\mathrm{k}}}{\mathrm{L}}-\frac{6 \sin \alpha \cdot \mathrm{EI}}{\mathrm{L}^{2}}\right)\left(1-\mathrm{d}_{\mathrm{i}}-\mathrm{c}_{7}+\mathrm{c}_{3}\right) \\
& \mathrm{K}_{14}=-\mathrm{K}_{11} \\
& \mathrm{~K}_{15}=-\mathrm{K}_{12} \\
& \mathrm{~K}_{16}=\left(\frac{\cos \alpha \cdot \mathrm{EAy} \mathrm{y}_{\mathrm{k}}}{\mathrm{L}}-\frac{6 \sin \alpha \cdot \mathrm{EI}}{\mathrm{L}^{2}}\right)\left(1-\mathrm{d}_{\mathrm{j}}-\mathrm{c}_{6}+\mathrm{c}_{3}\right) \\
& K_{22}=\left(12 \cos ^{2} \alpha \cdot \frac{E I}{L^{3}}\right)\left(1-c_{1}-c_{2}+c_{3}\right)+\left(\sin ^{2} \alpha \cdot \frac{E A}{L}\right)\left(1-d_{n}\right) \\
& \mathrm{K}_{23}=\left(6 \cos \alpha \frac{\mathrm{EI}}{\mathrm{L}^{2}}-\sin \alpha \cdot \frac{\mathrm{EAy_{k }}}{\mathrm{L}}\right)\left(1-\mathrm{d}_{\mathrm{i}}-\mathrm{c}_{7}+\mathrm{c}_{3}\right) \\
& \mathrm{K}_{24}=-\mathrm{K}_{12} \\
& \mathrm{~K}_{25}=-\mathrm{K}_{22} \\
& \mathrm{~K}_{26}=\left(6 \cos \alpha \frac{\mathrm{EI}}{\mathrm{L}^{2}}+\sin \alpha \cdot \frac{\mathrm{EAy}_{\mathrm{k}}}{\mathrm{L}}\right)\left(1-\mathrm{d}_{\mathrm{j}}-\mathrm{c}_{6}+\mathrm{c}_{3}\right) \\
& \mathrm{K}_{33}=\left(4 \frac{\mathrm{EI}}{\mathrm{L}}\right)\left(1-\mathrm{d}_{\mathrm{i}}-\mathrm{c}_{9}+\mathrm{c}_{4}\right)
\end{aligned}
$$




$$
\begin{aligned}
& \mathrm{K}_{34}=-\mathrm{K}_{13} \\
& \mathrm{~K}_{35}=-\mathrm{K}_{23} \\
& \mathrm{~K}_{45}=\mathrm{K}_{12} \\
& \mathrm{~K}_{46}=-\mathrm{K}_{16} \\
& \mathrm{~K}_{55}=\mathrm{K}_{22} \\
& \mathrm{~K}_{56}=\left(6 \cos \alpha \frac{\mathrm{EI}}{\mathrm{L}^{2}}-\sin \alpha \cdot \frac{\mathrm{EAy}_{\mathrm{K}}}{\mathrm{L}}\right)\left(1-\mathrm{d}_{\mathrm{i}}-\mathrm{c}_{7}+\mathrm{c}_{3}\right)
\end{aligned}
$$

onde $\mathrm{y}_{\mathrm{K}}$ é a distância do eixo médio da camada $\mathrm{k}$ ao eixo neutro da seção transversal da barra, pois o modeio de ÁLVARES (1998) foi implementado num programa em elementos finitos unidimensionais estratificado em camadas (EFICoS), porém utilizase um processo de homogeneização da seção transversal desconsiderando a estratificação (ver 4.2.2). O símbolo $\alpha$ representa o ângulo entre o eixo do elemento e o sistema de referência da estrutura.

Os coeficientes $c_{i}$ estão a seguir relacionados:

$$
\begin{array}{rlrl}
c_{1} & =\frac{3 d_{i}}{4} & c_{6} & =\frac{d_{i}}{2} \\
c_{2} & =\frac{3 d_{j}}{4} & c_{7} & =\frac{d_{j}}{2} \\
c_{3} & =\frac{d_{i} d_{j}}{2} & c_{8} & =\frac{d_{i}}{4} \\
c_{4} & =\frac{d_{i} d_{j}}{4} & c_{9} & =\frac{d_{j}}{4} \\
c_{5} & =d_{i} d_{j} &
\end{array}
$$




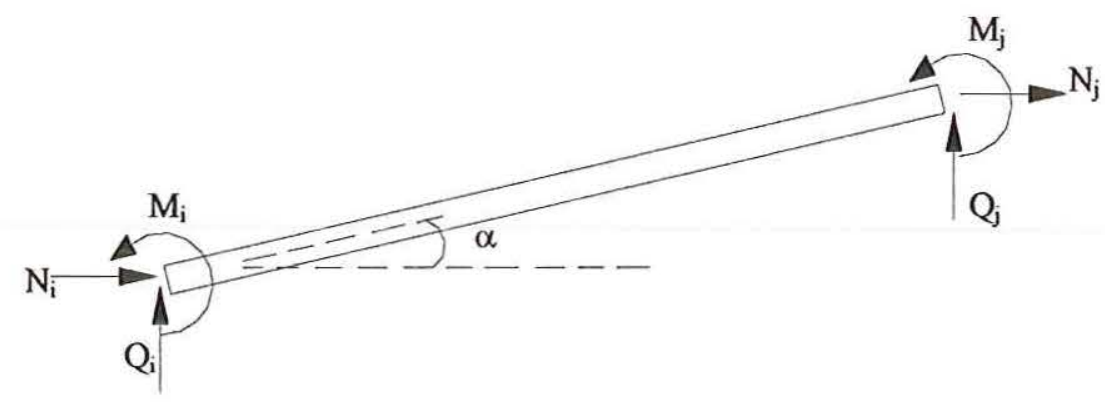

Figura 3.12 - Tensões generalizadas do modelo de ÁLVARES (1998).

Com base em ensaios numéricos realizados na viga da figura 3.10 , ilustra-se a seguir um estudo da variabilidade dos parâmetros do modelo.

A viga representa uma ligação viga-coluna. As características da viga são: $\mathrm{L}=$ $0,705 \mathrm{~m}, \mathrm{~A}=15 \times 20 \mathrm{~cm}^{2}$, armadura $4 \phi 9,525 \mathrm{~mm}\left(3 / 8^{\prime \prime}\right), \mathrm{f}_{\mathrm{c}}=25 \mathrm{~N} / \mathrm{mm}^{2}$ e $\mathrm{f}_{\mathrm{y}} \approx 420$ $\mathrm{N} / \mathrm{mm}^{2}$.

Nas figuras 3.13,3.14, 3.15 ilustra-se a influência das constantes que caracterizam o membro. As curvas são compostas por carga aplicada no centro da viga por deslocamentos verticais neste mesmo ponto.

Na figura 3.13 pode-se observar que a constante c influencia na inclinação inicial do trecho não-linear após a ocorrência de plastificação.

Com relação a constante $M_{y}$, a figura 3.14 mostra sua influência sobre o início do processo de plastificação, porém com valores menores que o momento de plastificação $\left(M_{p}\right)$, o comportamento permaneceu inalterado, pois a constante $M_{y}$ assume valores imediatamente superiores aos valores de $M_{p}$.

A figura 3.15 mostra a influência da constante $Q$ na inclinação inicial e na curvatura do trecho não-linear após a ocorrência de plastificação.

Vale notar que todas as curvas convergem para o valor da carga crítica suportada pela viga, com exceção das curvas da figura 3.15 , pois a constante $Q$ influencia na sua curvatura. 


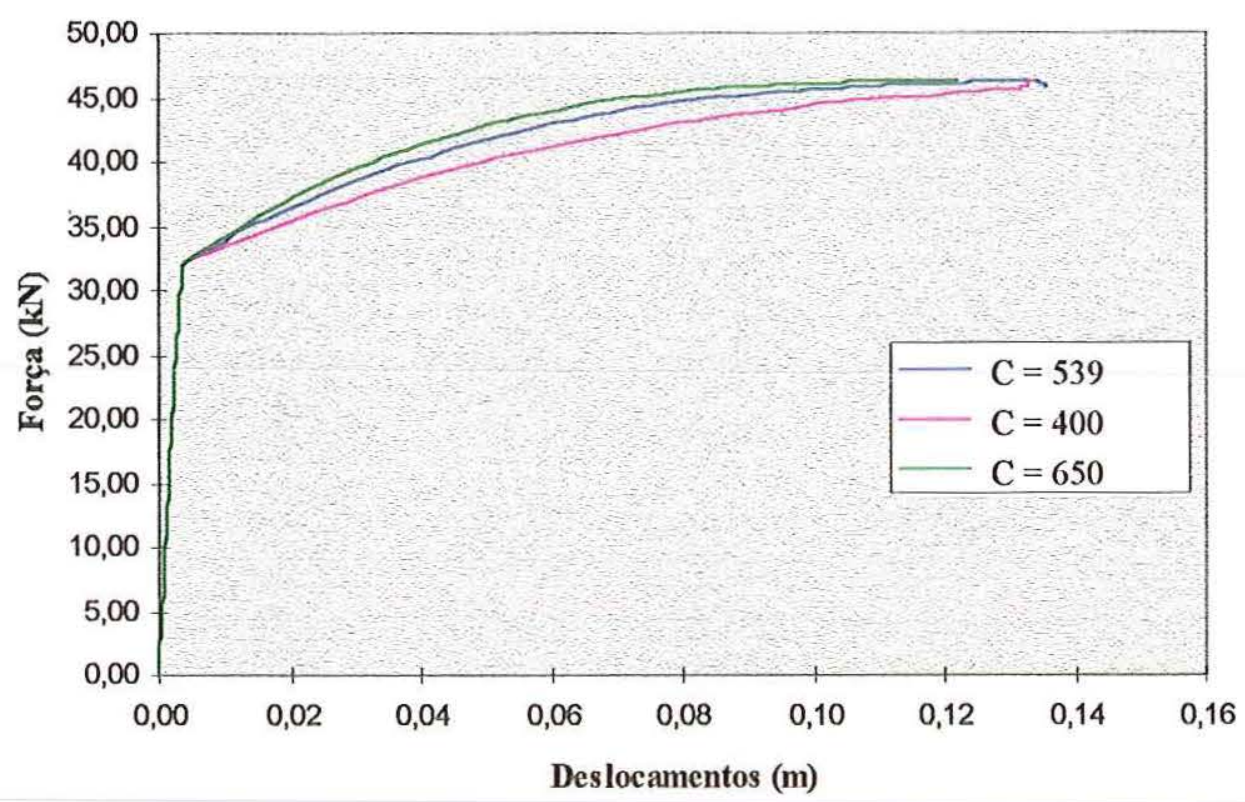

Figura 3.13 - Influência da constante C na curva Força x Deslocamento.

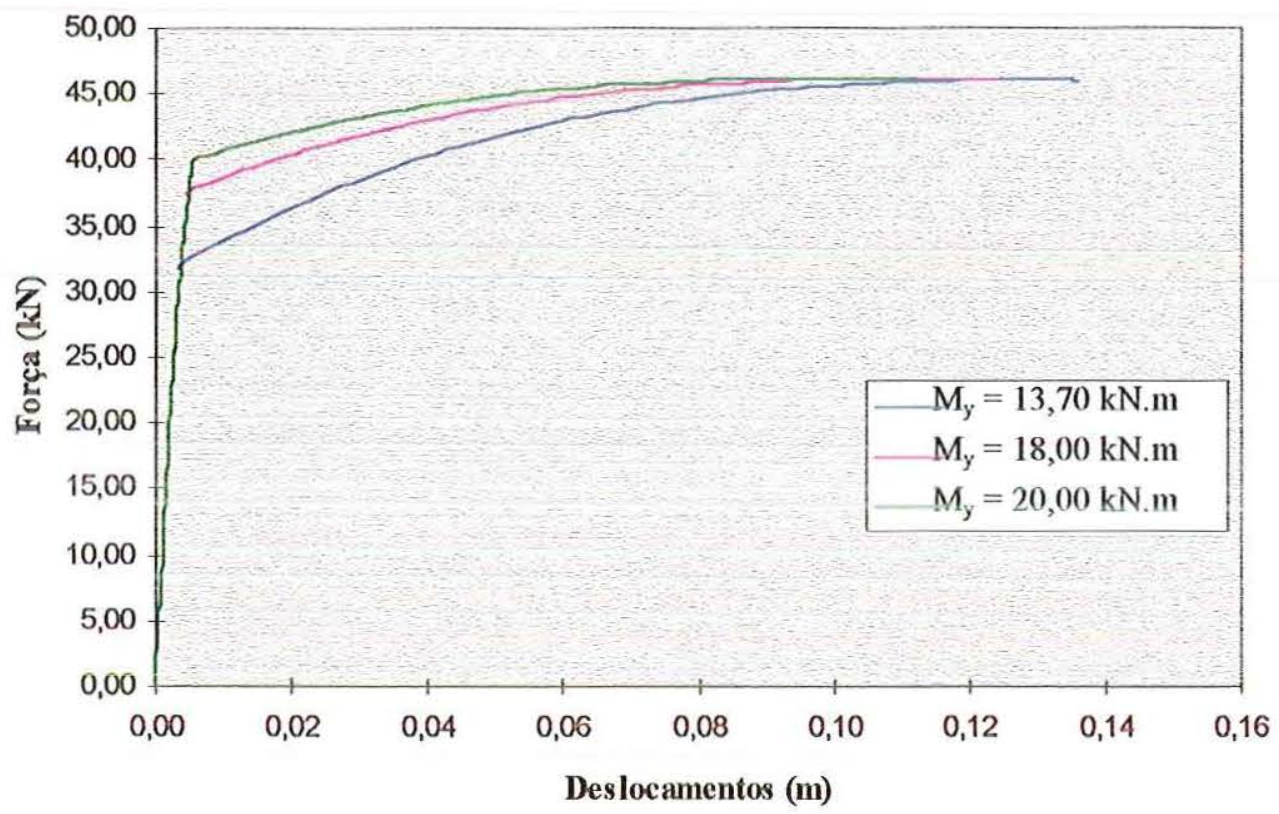

Figura 3.14 - Influência da constante $M_{y}$ na curva Força x Deslocamento. 


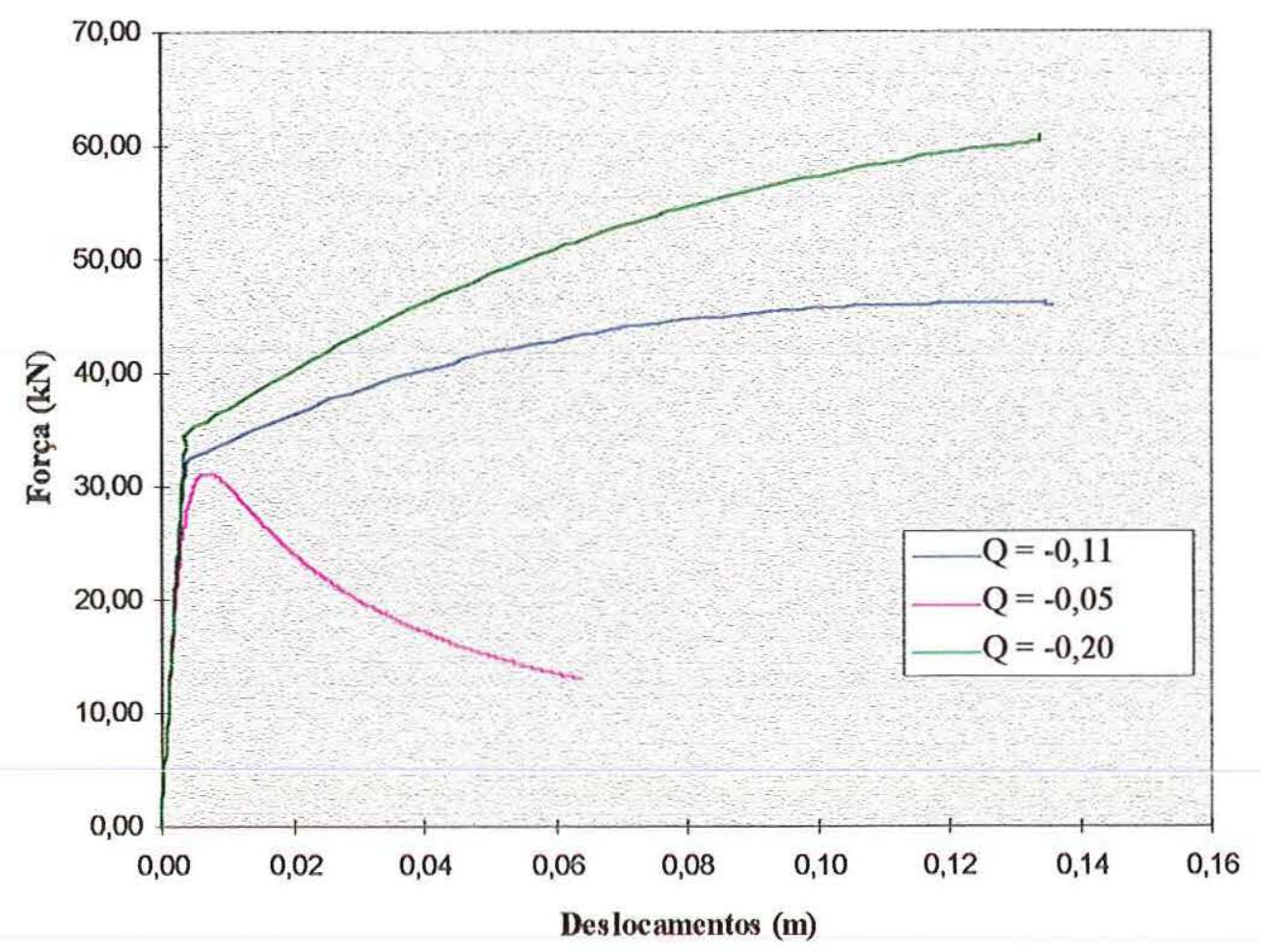

Figura 3.15 - Influência da constante Q na curva Força x Deslocamento.

No caso da figura 3.16, que ilustra uma curva momento termodinâmico x dano, a constante $G_{\text {cr }}$ possui valor nulo, ou seja, é assumido que o dano existe desde o início do carregamento da viga. Para o caso de $\mathrm{G}_{\mathrm{cr}}$ assumir um valor qualquer, sua influência pode ser visualizada na translação desta curva, porém com o mesmo formato, significando assim, que para um certo valor do momento termodinâmico inicia-se o processo de danificação, sendo este valor do momento termodinâmico denominado de $\mathrm{G}_{\mathrm{cr}}$. 


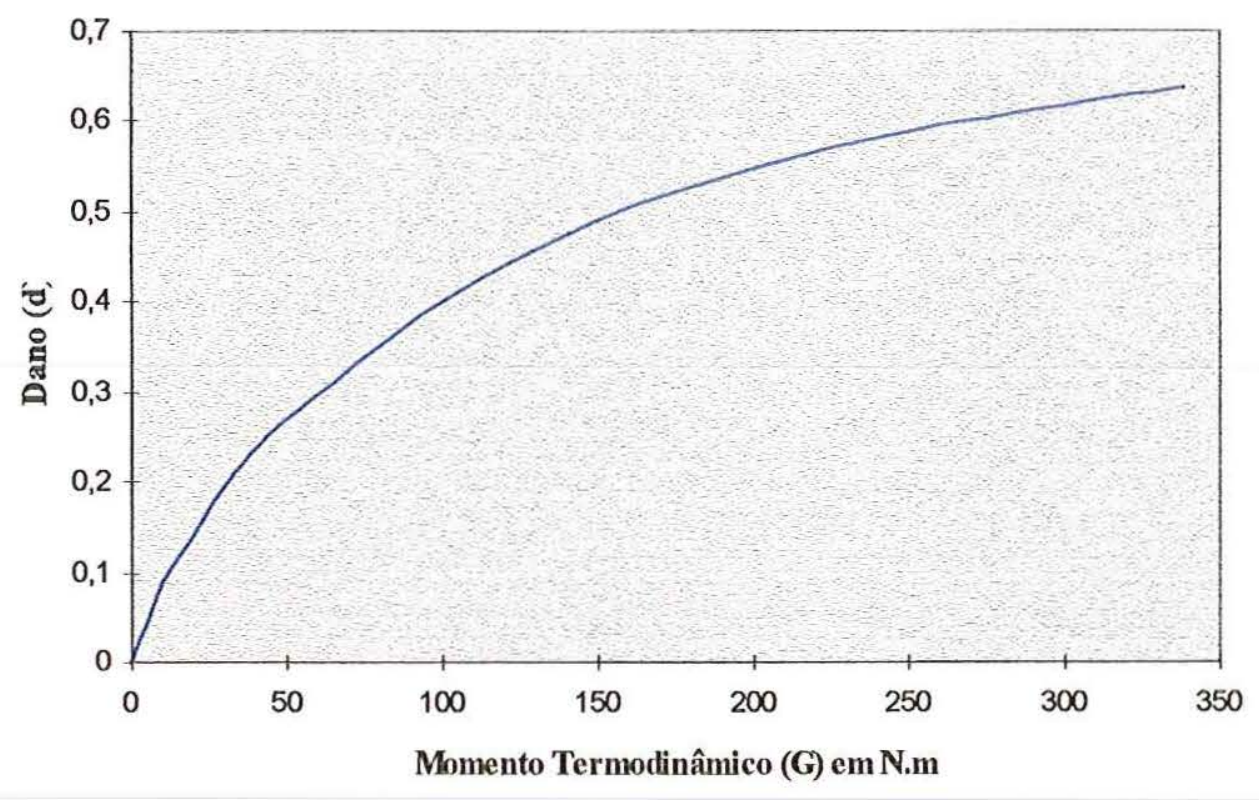

Figura 3.16 - Dano como função do seu momento termodinâmico associado. 


\section{EXEMPLOS DE APLICAÇÃO E ANÁLISE DE RESULTADOS}

\subsection{NTTRODUÇÃO}

No presente capítulo, faz-se uma avaliação do desempenho dos modelos estudados através de um estudo comparativo entre respostas numéricas obtidas com os modelos de ÁLVARES (1998), MAZARS (1984) e de LA BORDERIE, MAZARS \& PIJAUDIER-CABOT (1991) e valores experimentais de vigas biapoiadas e pórticos em concreto armado.

Inicialmente são estudadas vigas biapoiadas em concreto armado, apresentando-se os parâmetros utilizados em cada modelo e seus respectivos resultados numéricos. Em particular detalha-se o procedimento de homogeneização da seção transversal de concreto armado para a obtenção dos parâmetros utilizados pelo modelo constitutivo de ÁLVARES (1998). O confronto entre os resultados numéricos e experimentais, é ilustrado sob a forma de curvas carga aplicada por deslocamento vertical no meio do vão das vigas.

$\mathrm{Na}$ análise do pórtico em concreto armado, as respostas numéricas são confrontadas com a experimental através de curvas carga horizontal, aplicada no andar superior do pórtico, e respectivo deslocamento. 


\subsection{VIGAS EM CONCRETO ARMADO}

\subsubsection{Características das Vigas Ensaiadas}

As vigas em questão são biapoiadas com 2,40 m de vão, seção transversal retangular de $12 X 30 \mathrm{~cm}$, e com carregamento constituído por duas forças concentradas aplicadas nos terços do vão. Três vigas deste tipo são consideradas, diferenciando-se entre si pela quantidade e distribuição geométrica de armadura longitudinal inferior $(3 \phi 10 \mathrm{~mm}, 5 \phi 10 \mathrm{~mm}$ e $7 \phi 10 \mathrm{~mm})$. A armadura longitudinal superior é constituída por $2 \phi 5 \mathrm{~mm}$ em todos os casos e a armadura transversal por $\phi 5 \mathrm{~mm} \mathrm{c} / 12 \mathrm{~cm}$ com comprimento de $90 \mathrm{~cm}$. Maiores detalhes sobre a resposta experimental de cada tipo de viga, colhida a partir de provas realizadas com controle de carga encontram-se em ÁLVARES (1993). Na figura 4.1 são fornecidos os detalhes da geometria e da armadura.
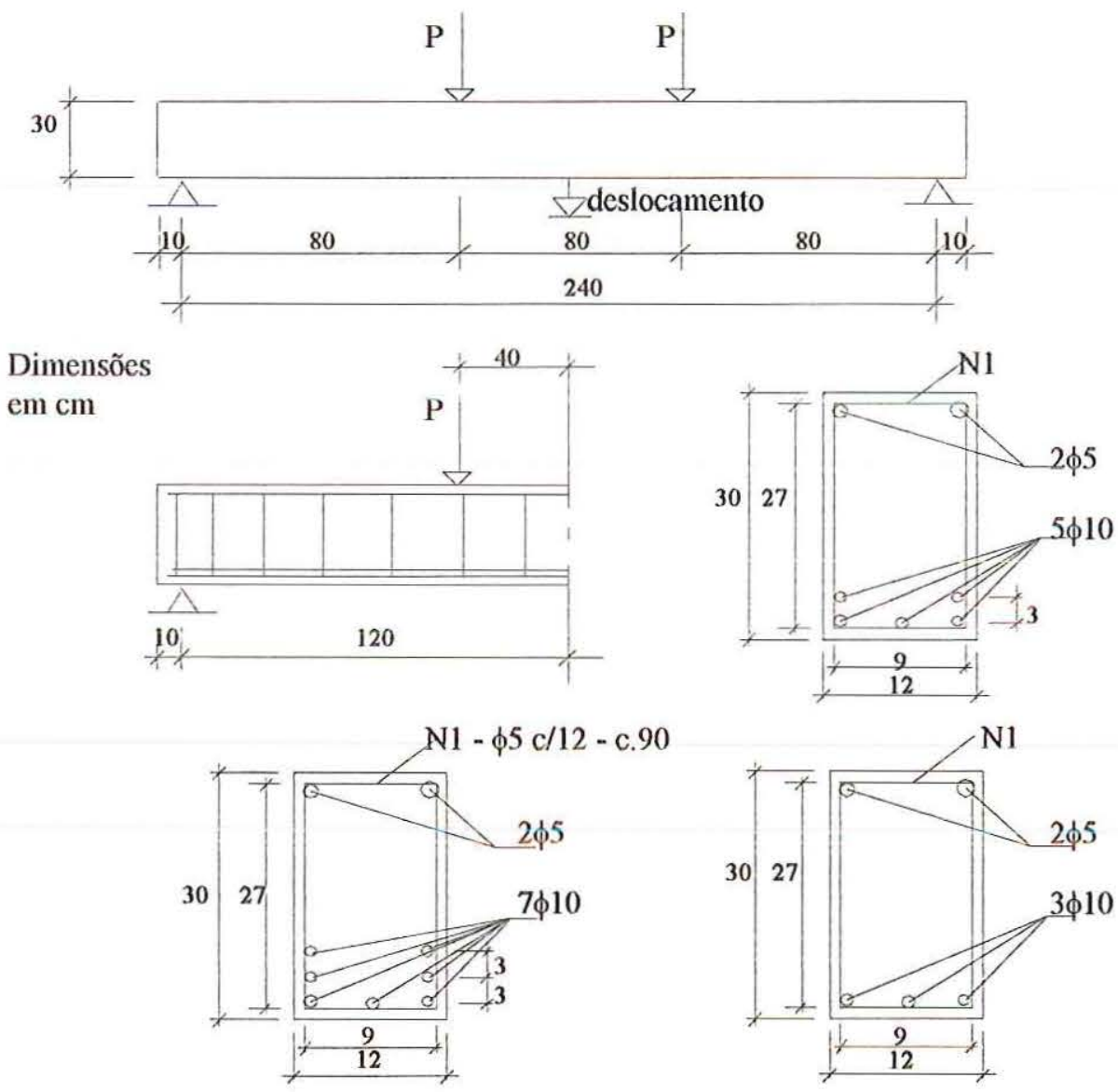

Figura 4.1 - Geometria e armação das vigas. 
$\mathrm{Na}$ tabela 4.1 estão descritas as propriedades dos materiais empregados nas vigas.

Tabela 4.1 - Propriedades dos materiais empregados.

\begin{tabular}{|lc|}
\hline \multicolumn{2}{|c|}{ Propriedades do Concreto } \\
\hline $\begin{array}{l}\text { Módulo de Young } \\
\text { Coeficiente de Poisson }\end{array}$ & $\mathrm{E}_{\mathrm{C}}=29200 \mathrm{Mpa}$ \\
$v=0,2$ (adotado) \\
\hline \multicolumn{2}{c}{$\mathrm{E}_{\mathrm{S}}=196000 \mathrm{Mpa}$} \\
\hline Módulo de Young & Propriedades do Aço \\
\hline
\end{tabular}

\subsubsection{Análise Numérica}

Adotaram-se para o concreto os modelos constitutivos de MAZARS (1984) para carregamento proporcional, de LA BORDERIE, MAZARS \& PIJAUDIERCABOT (1991) e de ÁLVARES (1998).

No caso do modelo de MAZARS (1984), os parâmetros foram determinados conforme testes experimentais descritos em ÁLVARES (1993), estando seus valores reunidos na tabela 4.2 :

Tabela 4.2 - Parâmetros do modelo constitutivo de MAZARS (1984) empregados na análise numérica das vigas.

\begin{tabular}{|c|c|}
\hline \multicolumn{2}{|c|}{ Parâmetros do modelo de MAZARS (1984) } \\
\hline $\mathrm{A}_{\mathrm{T}}=0,995$ (adotado) & $\mathrm{G}_{\mathrm{f}}=0,0016$ \\
\hline$A_{C}=0,85$ & $\mathrm{~B}_{\mathrm{C}}=1620$ \\
\hline$\varepsilon_{\mathrm{d} 0}=0,00007$ & \\
\hline
\end{tabular}

$\mathrm{Na}$ análise numérica só o concreto possui comportamento não-linear, para o aço admite-se uma relação constitutiva elástica linear. Com relação à interação entre 
os dois materiais, admitiu-se perfeita aderência entre o aço e o concreto, descartandose assim qualquer possibilidade de ocorrência de fenômenos decorrentes da perda de aderência na zona de interface.

$\mathrm{O}$ modelo foi implementado em código de cálculo em elementos finitos bidimensionais para a análise das vigas contidas em ÁLVARES (1993). Fazendo-se uso das simetrias de carregamento e de geometria, analisou-se, portanto, apenas metade da viga.
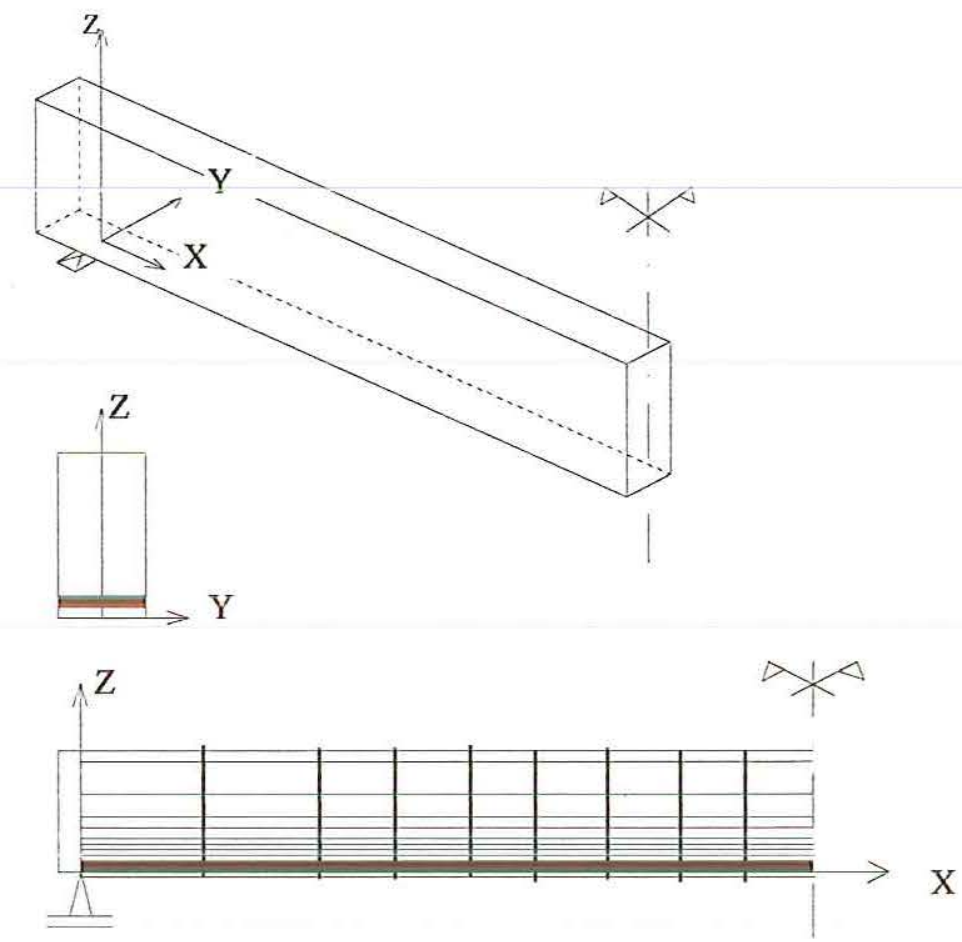

Figura 4.2 - Discretização em elementos finitos bidimensionais.

A rede adotada na discretização das vigas foi de 108 elementos finitos quadrangulares de 4 nós nos casos de média e alta taxa de armadura, sendo que para a viga com menor taxa foi adotada uma rede de 342 elementos finitos de 4 nós.

Na tabela 4.3 reúnem-se os valores adotados para os parâmetros do modelo constitutivo de LA BORDERIE, MAZARS \& PIJAUDIER-CABOT (1991). 
Tabela 4.3 - Parâmetros do modelo constitutivo de LA BORDERIE, MAZARS \& PIJAUDIER-CABOT (1991) empregados na análise numérica das vigas.

\begin{tabular}{|ll|}
\hline \multicolumn{2}{|c|}{ Parâmetros do modelo de LA BORDERIE, MAZARS } \\
& \& PIJAUDIER-CABOT (1991) \\
\hline $\mathrm{Y}_{01}=1,46 \mathrm{E}-04 \mathrm{MPa}$ & $\mathrm{B}_{1}=0,62$ \\
$\mathrm{Y}_{02}=0,15 \mathrm{E}-01 \mathrm{MPa}$ & $\mathrm{B}_{2}=1,50$ \\
$\mathrm{~A}_{1}=2,10 \mathrm{E}+03 \mathrm{MPa}^{-1}$ & $\beta_{1}=1,80 \mathrm{MPa}$ \\
$\mathrm{A}_{2}=7,00 \mathrm{E}+00 \mathrm{MPa}^{-1}$ & $\beta_{2}=-40,0 \mathrm{MPa}$ \\
$\sigma_{\mathrm{f}}=3,50 \mathrm{MPa}$ & \\
\hline
\end{tabular}

Uma versão unidimensional deste modelo foi implementada num programa em elementos finitos estratificados em camadas (EFICoS - Eléments Finis à Couches Superposées) para análise de vigas e estruturas aporticadas. Cada elemento é uma viga discretizada em vários estratos (figura 4.3).

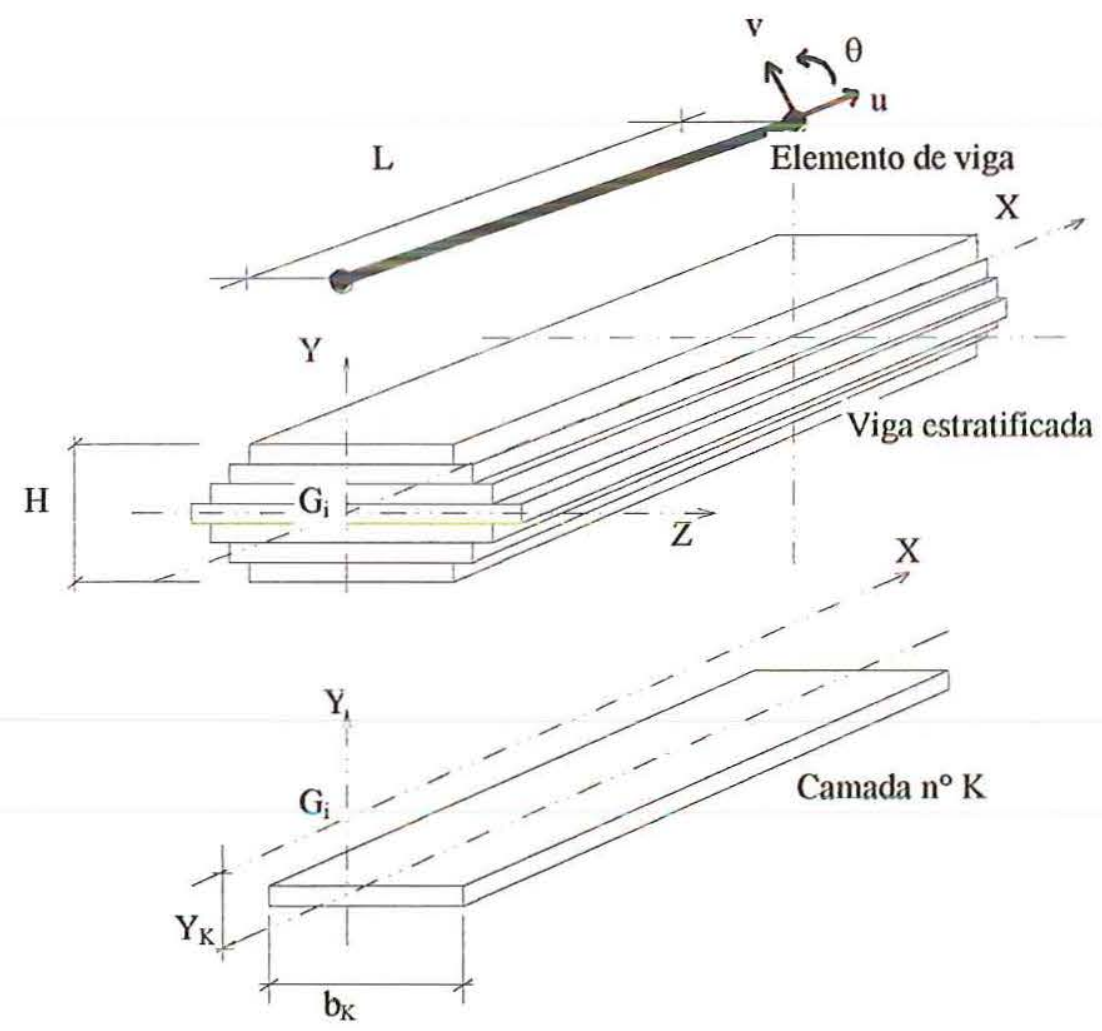

Figura 4.3 - Elemento finito empregado. 
Com esse modelo, as análises numéricas foram desenvolvidas empregando-se uma discretização com elementos finitos de barra, fazendo-se novamente uso das simetrias de carregamento e geometria, analisando-se, portanto, apenas metade da viga.

Para as barras de aço longitudinais, no caso de simulação de estruturas de concreto armado, é assumido um modelo elasto-plástico. Perfeita aderência entre aço e concreto é assumida.

Em todos os casos a rede adotada na discretização das vigas foi de 20 elementos finitos e 21 nós adotando-se ainda 15 camadas na discretização da seção transversal. No caso da viga com baixa taxa de armadura dentre as 15 camadas, foi definida 1 camada de aço. No caso da viga com média taxa de armadura uiilizaram-se 2 camadas de aço, e na viga com alta taxa de armadura foram utilizadas 3 camadas de aço.

No caso do modelo constitutivo de ÁLVARES (1998), os parâmetros utilizados foram os seguintes:

Tabela 4.4 - Parâmetros do modelo constitutivo de ÁLVARES (1998) empregados na análise numérica das vigas.

\begin{tabular}{|c|c|c|}
\hline \multicolumn{3}{|c|}{ Parâmetros do modelo de ÁLVARES (1998) } \\
\hline VIGA $3 \phi 10.0 \mathrm{~mm}$ & VIGA $5 \phi 10.0 \mathrm{~mm}$ & VIGA $7 \phi 10.0 \mathrm{~mm}$ \\
\hline $\mathrm{S}_{\mathrm{i}}=0,03735 \mathrm{~m}^{2}$ & $\mathrm{~S}_{\mathrm{i}}=0,03824 \mathrm{~m}^{2}$ & $\mathrm{~S}_{\mathrm{i}}=0,03900 \mathrm{~m}^{2}$ \\
\hline$(0,12 \times 0,311)$ & $(0,12 \times 0,318)$ & $(0,12 \times 0,326)$ \\
\hline$\phi_{\mathrm{pu}}=0,008$ & $\phi_{\mathrm{pu}}=0,01$ & $\phi_{\mathrm{pu}}=0,013$ \\
\hline $\mathrm{M}_{\mathrm{u}}=33,60 \mathrm{kN} \cdot \mathrm{m}$ & $\mathrm{M}_{\mathrm{u}}=48,00 \mathrm{kN} \cdot \mathrm{m}$ & $\mathrm{M}_{\mathrm{u}}=54,80 \mathrm{kN} \cdot \mathrm{m}$ \\
\hline$M_{p}=6,40 \mathrm{kN} \cdot \mathrm{m}$ & $\mathrm{M}_{\mathrm{p}}=8,00 \mathrm{kN} \cdot \mathrm{m}$ & $\mathrm{M}_{\mathrm{p}}=12,80 \mathrm{kN} \cdot \mathrm{m}$ \\
\hline $\mathrm{M}_{\mathrm{cr}}=0$ & $\mathrm{M}_{\mathrm{cr}}=0$ & $\mathrm{M}_{\mathrm{cr}}=0$ \\
\hline$c=35217,00$ & $c=40718,28$ & $c=37474,15$ \\
\hline$Q=-0,0175$ & $Q=-0,03335$ & $Q=-0,0403$ \\
\hline $\mathrm{M}_{\mathrm{y}}=6,465 \mathrm{kN} \cdot \mathrm{m}$ & $\mathrm{M}_{\mathrm{y}}=8,06 \mathrm{kN} \cdot \mathrm{m}$ & $\mathrm{M}_{\mathrm{y}}=13,00 \mathrm{kN} \cdot \mathrm{m}$ \\
\hline
\end{tabular}


Os valores de $M_{u}, M_{p}$ e $\phi_{p u}$ foram calculados através das respostas experimentais de cada viga. Para o parâmetro $\mathrm{M}_{\mathrm{cr}}$ foi adotado um valor nulo em todas as vigas, pois admitiu-se que o dano existe desde o início da aplicação de qualquer carga.

$\mathrm{Na}$ análise fez-se uma homogeneização da seção transversal composta de concreto e aço, transformando a área de aço numa área equivalente de concreto, assumindo que a toda seção transversal fosse composta apenas de concreto. Esta homogeneização está apresentada em LANGENDONCK (1962) baseada na Norma Brasileira de cálculo de peças de concreto armado. A expressão abaixo é sugerida:

$\mathrm{S}_{\mathrm{i}}=\mathrm{S}_{\mathrm{c}}+(\mathrm{n}-1) \mathrm{S}_{\mathrm{f}}$

onde:

$S_{\mathrm{i}}$ é a área da seção ideal (homogeneizada)

$\mathrm{S}_{\mathrm{c}}$ é a área de toda seção transversal (concreto + aço)

$\mathrm{S}_{\mathrm{f}}$ é área de aço existente na seção transversal (armadura longitudinal)

$\mathrm{n}$ é o coeficiente que relaciona o módulo de elasticidade do concreto $\left(\mathrm{E}_{\mathrm{c}}\right)$ e do aço $\left(E_{s}\right)$, ou seja

$\mathrm{n}=\frac{\mathrm{E}_{\mathrm{s}}}{\mathrm{E}_{\mathrm{c}}}$

Foram utilizados 4 nós e 3 elementos na discretização de metade da viga. Alguns testes foram realizados com uma rede mais refinada, porém os resultados encontrados foram os mesmos. O modelo de ÁLVARES (1998) foi implementado no programa EFICoS, porém foi utilizada apenas uma camada para discretizar a seção transversal toda de concreto, devido à homogeneização empregada.

Os confrontos dos resultados numéricos e experimentais estão ilustrados nas curvas carga aplicada por deslocamento vertical no meio do vão das vigas a seguir. 


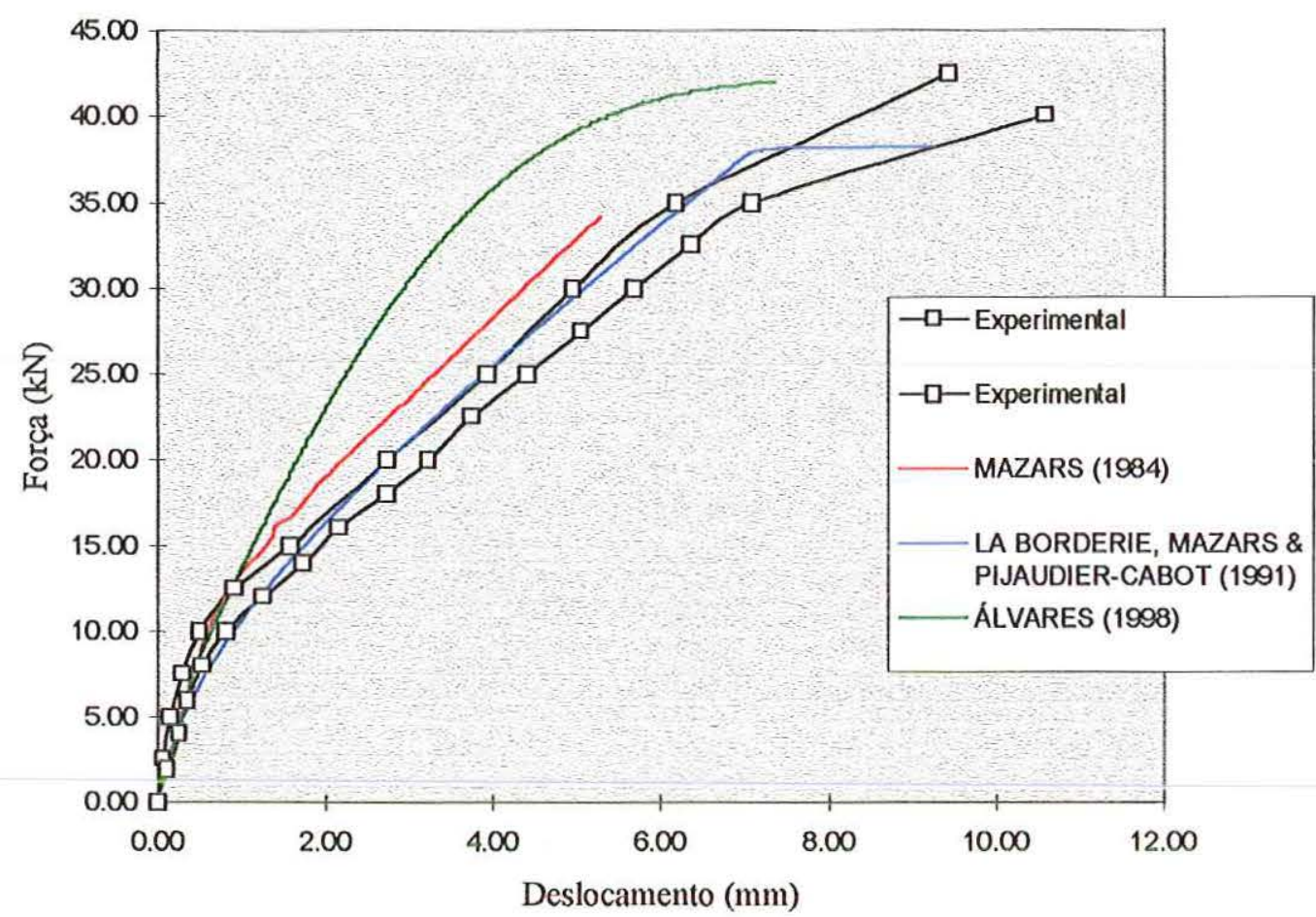

Figura 4.4 - Resultados numéricos - viga $3 \phi 10.0 \mathrm{~mm}$

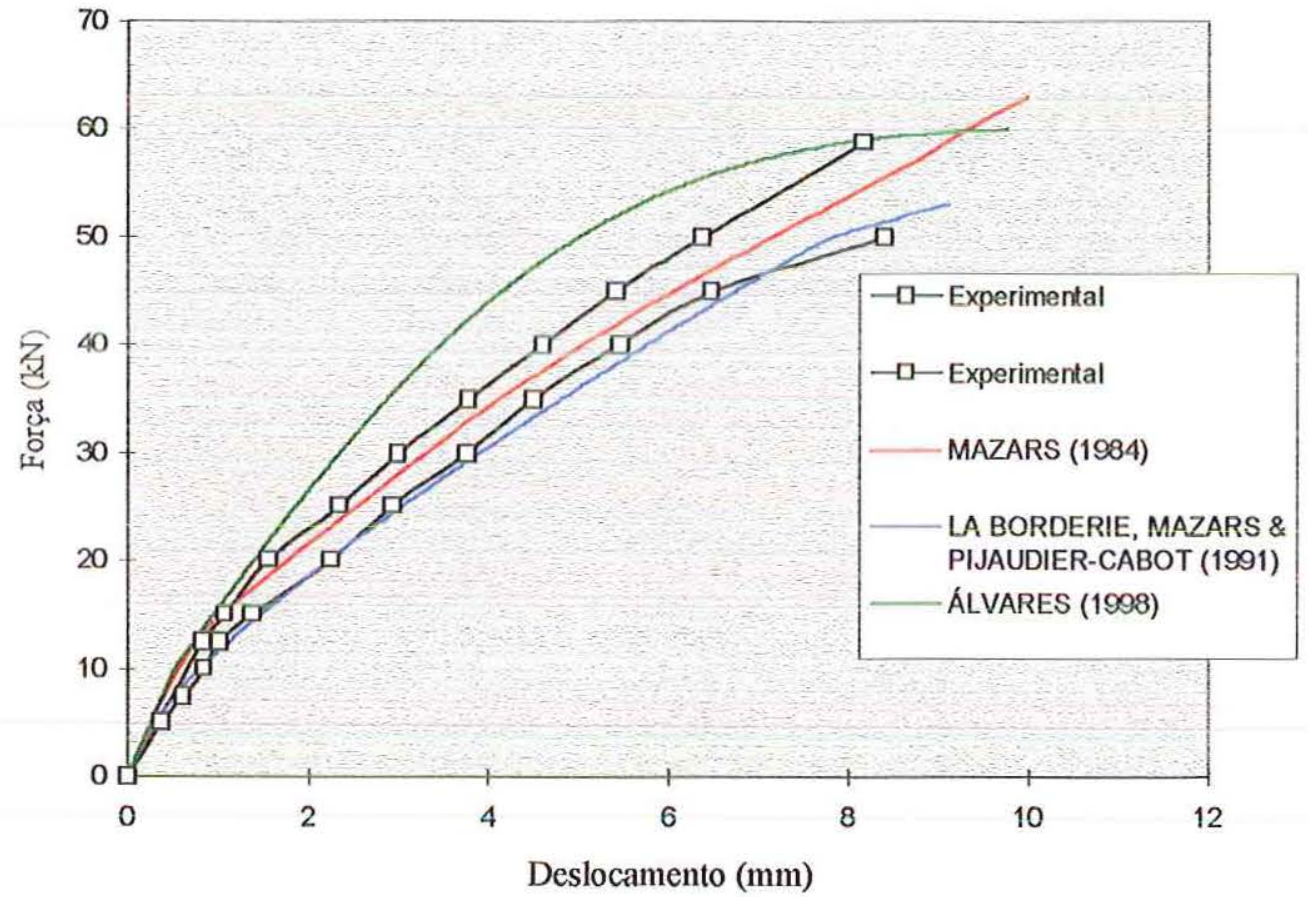

Figura 4.5 - Resultados numéricos - viga $5 \$ 10.0 \mathrm{~mm}$ 


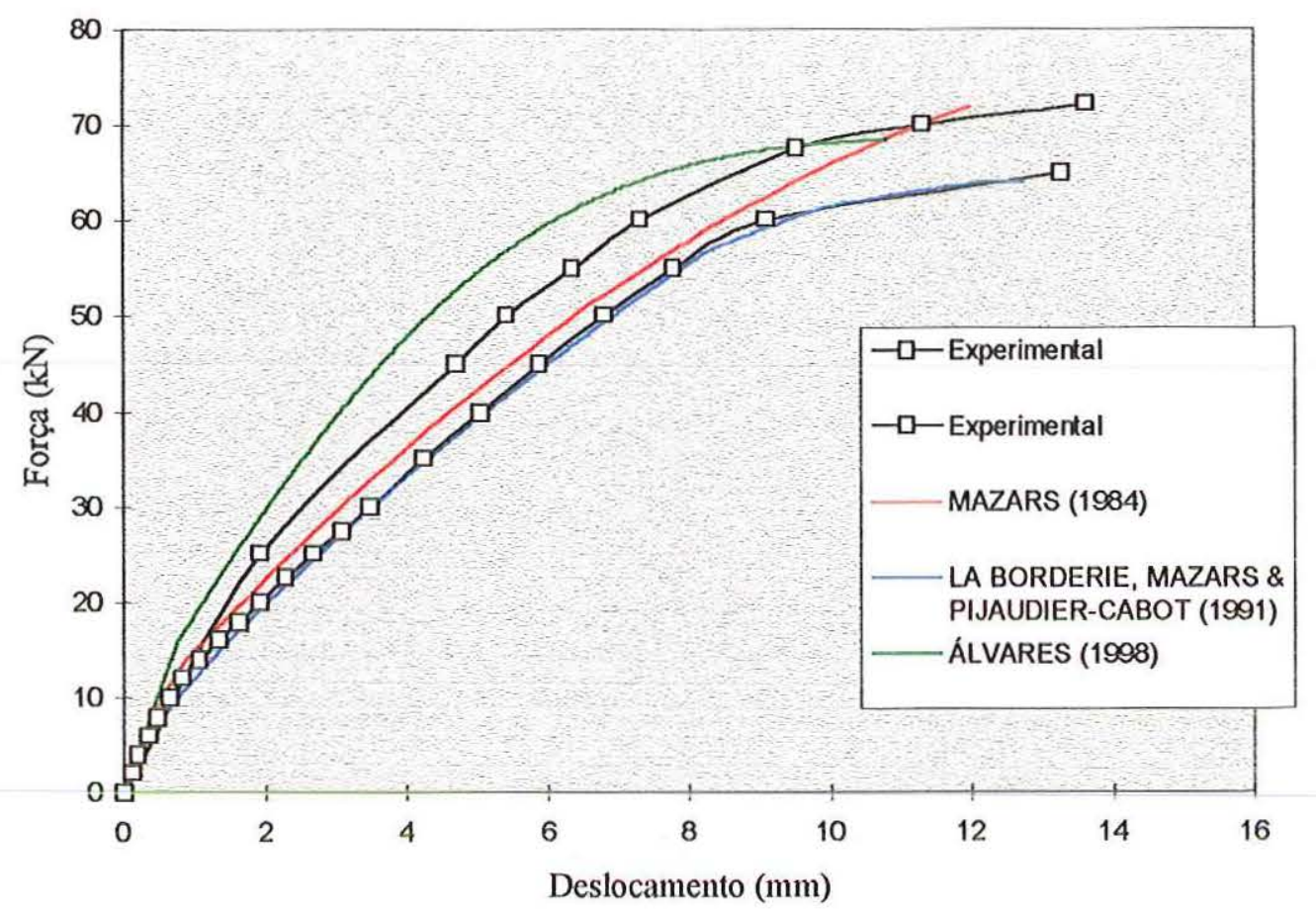

Figura 4.6 - Resultados numéricos - viga $7 \$ 10.0 \mathrm{~mm}$

Das figuras 4.4, 4.5, 4.6 pode-se interpretar que o modelo de LA BORDERIE, MAZARS \& PIJAUDIER-CABOT (1991) apresenta os melhores resultados em todas as vigas. O modelo de MAZARS (1984) apresenta resultados satisfatórios nas vigas de $5 \phi 10.0 \mathrm{~mm}$ e de $7 \phi 10.0 \mathrm{~mm}$, porém na viga de $3 \phi 10.0 \mathrm{~mm}$ sua resposta numérica resulta numa curva mais rígida, um pouco acima da nuvem de pontos experimentais. Já o modelo de ÁLVARES (1998) apresenta curvas mais rígidas, acima da nuvem de pontos experimentais para as três vigas.

Nota-se que no modelo de MAZARS (1984) a dissipação de energia é decorrente somente do processo de danificação pois deformações residuais e plastificação das armaduras não são consideradas. Ocorre que na viga de $3 \phi 10.0 \mathrm{~mm}$ o panorama de fissuras é mais localizado. Tendo menos armadura o concreto apresenta tal configuração de fissuras e as deformações residuais, por efeito do engrenamento dos agregados, se fazem mais significativas, resultando numa maior dissipação. Essa pode ser a razão para a menor precisão do modelo de Mazars no caso da viga com pouca taxa de armadura. Já o modelo de LA BORDERIE, MAZARS \& PIJAUDIER- 
CABOT (1991) apresenta bons resultados, pois leva em conta as deformações residuais e a eventual plastificação de armaduras.

No caso do modelo de ÁLVARES (1998), pela curva resultante nota-se que é possível recuperar a carga última que as vigas suportam, porém não se consegue descrever de forma satisfatória todo o comportamento não-linear. Imagina-se que este fato é devido à concepção do modelo admitir os efeitos de dano e plasticidade concentrados em rótulas, permanecendo as barras com comportamento elástico. No caso das vigas, provavelmente existe uma intensidade maior de energia dissipada pelos fenômenos que ocorrem, do que aquela reproduzida pelo modelo. O processo de homogeneização também é um fator a ser levado em conta na obtenção das respostas fornecidas pelo modelo.

\subsection{PÓRTICO EM CONCRETO ARMADO}

\subsubsection{Características do Pórtico Ensaiado}

O pórtico possui dois andares com um vão total de $5,70 \mathrm{~m}$ e uma altura total de 4,60 m. As seções transversais utilizadas para as vigas foram de $30 \times 40 \mathrm{~cm}$, e para as colunas foram de $40 \times 30 \mathrm{~cm}$. Todos os membros do pórtico possuem armadura longitudinal composta por 8 barras de $\phi 20.0 \mathrm{~mm}$ e armadura transversal de $\phi 10,0 \mathrm{~mm} \mathrm{c} / 12,5 \mathrm{~cm}$. Maiores detalhes encontram-se em VECCHIO \& EMARA (1992). Segue-se uma ilustração do pórtico em concreto armado assim como as seções transversais de vigas e colunas. 


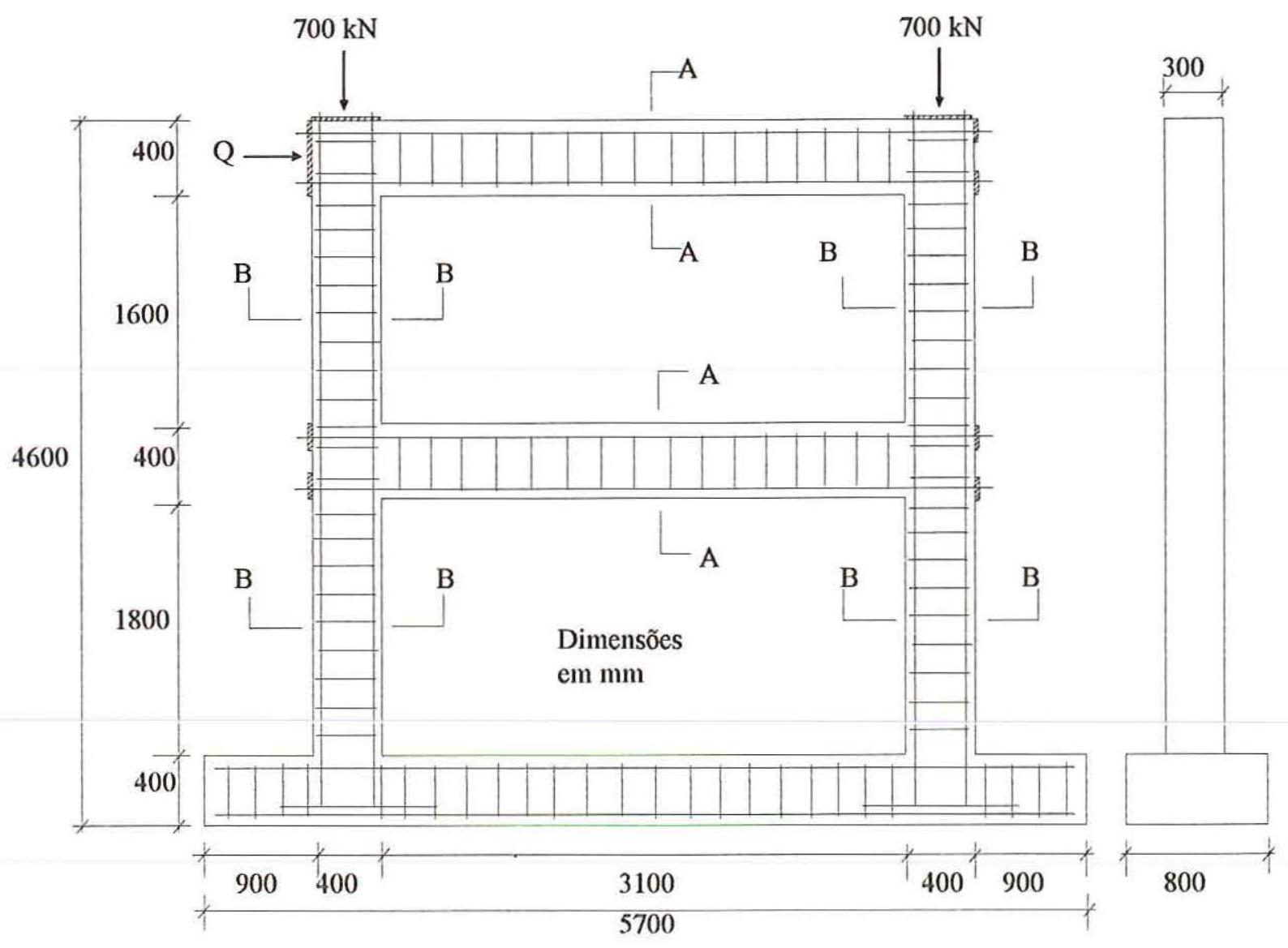

Figura 4.7 - Detalhes do pórtico em concreto armado.

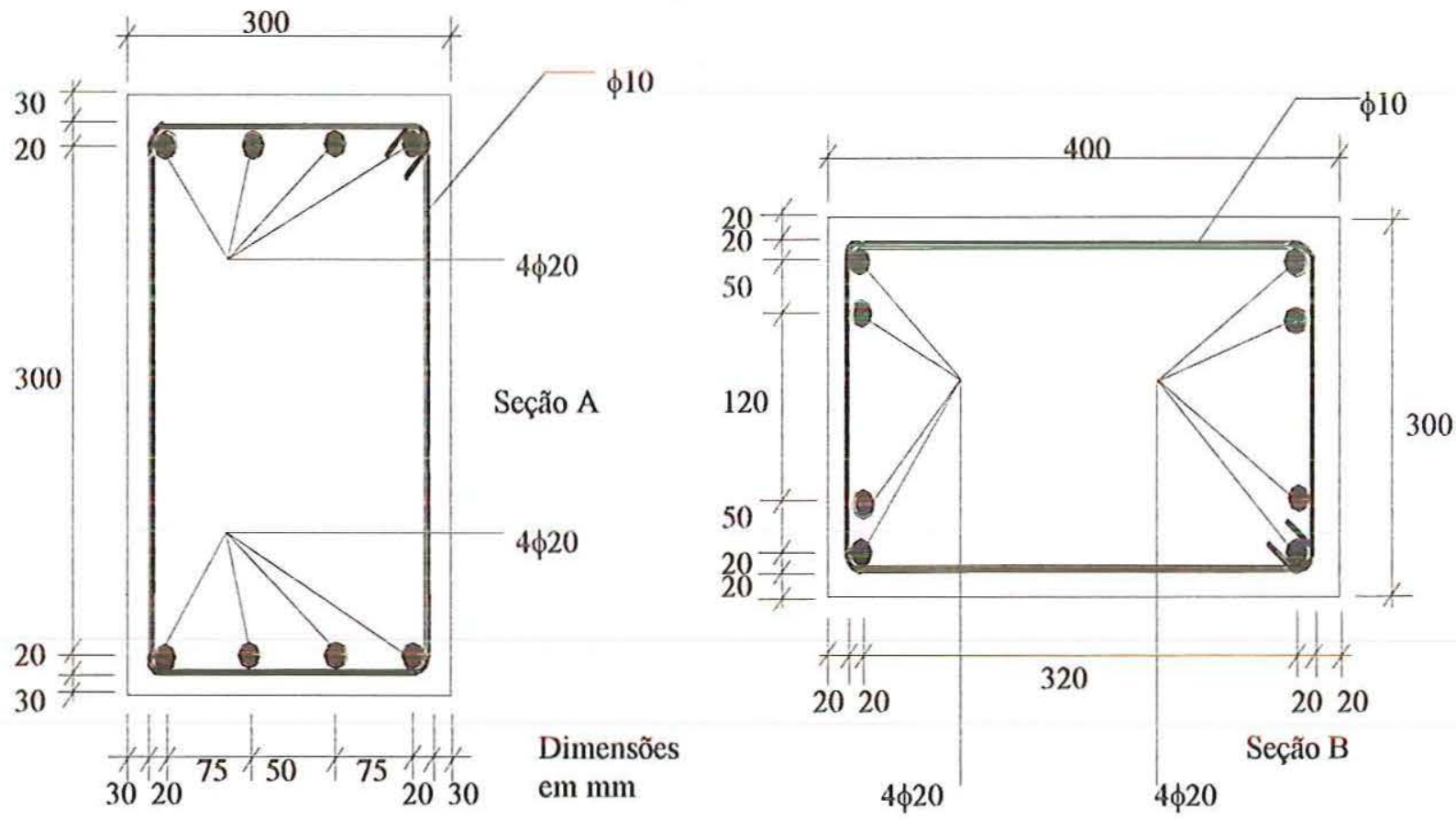

Figura 4.8 - Seções Transversais A e B. 
O ensaio experimental primeiro envolveu a aplicação de uma força axial total de $700 \mathrm{kN}$ para cada coluna mantendo esta força constante durante o ensaio. A força lateral foi então aplicada, incrementando esta, até a capacidade última do pórtico ser atingida.

A seguir estão descritas as propriedades dos materiais constituintes do pórtico analisado.

Tabela 4.5 - Propriedades dos materiais empregados na confeção do pórtico em concreto armado

\begin{tabular}{|l|c|}
\hline & \multicolumn{2}{c|}{ Propriedades do Concreto } \\
\hline Módulo de Young & $\mathrm{E}_{\mathrm{C}}=38200 \mathrm{Mpa}$ \\
\hline & \multicolumn{1}{c|}{ Propriedades do Aço } \\
\hline Módulo de Young & $\mathrm{E}_{\mathrm{S}}=192500 \mathrm{Mpa}$ \\
Tensão de Plastificação & $\mathrm{f}_{\mathrm{y}}=418 \mathrm{Mpa}$ \\
Tensão Última & $\mathrm{f}_{\mathrm{u}}=596 \mathrm{Mpa}$ \\
\hline
\end{tabular}

\subsubsection{Análise Numérica}

Para a análise numérica do pórtico adotou-se para o concreto os modelos constitutivos de LA BORDERIE, MAZARS \& PIJAUDIER-CABOT (1991) e de ÁLVARES (1998).

Inicialmente faz-se a descrição dos parâmetros utilizados pelo modelo LA BORDERIE, MAZARS \& PIJAUDIER-CABOT (1991). 
Tabela 4.6 - Parâmetros do modelo constitutivo de LA BORDERIE, MAZARS \& PIJAUDIER-CABOT (1991) empregados na análise numérica do pórtico.

\begin{tabular}{|ll|}
\hline \multicolumn{2}{|c|}{ Parâmetros do modelo de LA BORDERIE, MAZARS } \\
& \& PIJAUDIER-CABOT (1991) \\
\hline $\mathrm{Y}_{01}=3,35 \mathrm{E}-04 \mathrm{MPa}$ & $\mathrm{B}_{1}=1.10$ \\
$\mathrm{Y}_{02}=0,15 \mathrm{E}-01 \mathrm{MPa}$ & $\mathrm{B}_{2}=1,50$ \\
$\mathrm{~A}_{1}=3,00 \mathrm{E}+03 \mathrm{MPa}^{-1}$ & $\beta_{1}=1,00 \mathrm{MPa}$ \\
$\mathrm{A}_{2}=7,00 \mathrm{E}+00 \mathrm{MPa}^{-1}$ & $\beta_{2}=-40,0 \mathrm{MPa}$ \\
$\sigma_{\mathrm{f}}=3,50 \mathrm{MPa}$ & \\
\hline
\end{tabular}

A rede adotada na discretização da estrutura foi composta por 30 elementos e 30 nós, sendo empregados 10 elementos por coluna e 5 elementos por viga, além da estratificação das seções transversais em 10 camadas sendo utilizadas 2 camadas de aço dentre as 10 referidas conforme a geometria da seção da viga e da coluna (figura 4.8).

Para o modelo de ÁLVARES (1998) a tabela a seguir ilustra os valores dos parâmetros utilizados na simulação numérica da estrutura.

Tabela 4.7 - Parâmetros do modelo constitutivo de ÁLVARES (1998)

empregados na análise numérica das vigas.

\begin{tabular}{|l|l|}
\hline \multicolumn{2}{|c|}{ Parâmetros do modelo de ÁLVARES (1998) } \\
\hline \multicolumn{1}{|c|}{ VIGAS } & \multicolumn{1}{|c|}{ COLUNAS } \\
\hline$\phi_{\mathrm{pu}}=0,0167$ & $\phi_{\mathrm{pu}}=0,006$ \\
$\mathrm{M}_{\mathrm{u}}=189,00 \mathrm{kN} \cdot \mathrm{m}$ & $\mathrm{M}_{\mathrm{u}}=273,00 \mathrm{kN} \cdot \mathrm{m}$ \\
$\mathrm{M}_{\mathrm{p}}=161,00 \mathrm{kN} \cdot \mathrm{m}$ & $\mathrm{M}_{\mathrm{p}}=253,00 \mathrm{kN} \cdot \mathrm{m}$ \\
$\mathrm{M}_{\mathrm{cr}}=0,00814 \mathrm{kN} \cdot \mathrm{m}$ & $\mathrm{M}_{\mathrm{cr}}=0,02773 \mathrm{kN} \cdot \mathrm{m}$ \\
$\mathrm{c}=50700000,00$ & $\mathrm{c}=154000000,00$ \\
$\mathrm{Q}=-1005,37$ & $\mathrm{Q}=-1169,70$ \\
$\mathrm{M}_{\mathrm{y}}=218,00 \mathrm{kN} \cdot \mathrm{m}$ & $\mathrm{M}_{\mathrm{y}}=384,00 \mathrm{kN} \cdot \mathrm{m}$ \\
\hline
\end{tabular}


Em CIPOLLINA, A.; LÓPEZ-INOJOSA, A.; FLÓREZ-LÓPEZ, J. (1995), foram obtidas as propriedades dos membros através de teorias de concreto armado. A inércia e a área da seção transversal foram obtidas através da transformação da área de aço numa seção equivalente de concreto. É sugerido pelos autores um módulo de elasticidade de um material homogeneizado sendo igual a $26,33 \times 10^{+06} \mathrm{MPa}$.

$\mathrm{Na}$ discretização da estrutura foram utilizados 6 elementos e 6 nós correspondendo um elemento para cada viga e coluna. Devida à homogeneização da seção transversal não houve a necessidade de discretizar a mesma em camadas, considerando-a como uma seção única de um material fictício.

A seguir apresenta-se o confronto entre as respostas numéricas e experimental ilustrada em forma de curvas carga horizontal aplicada e deslocamento horizontal no andar superior do pórtico.

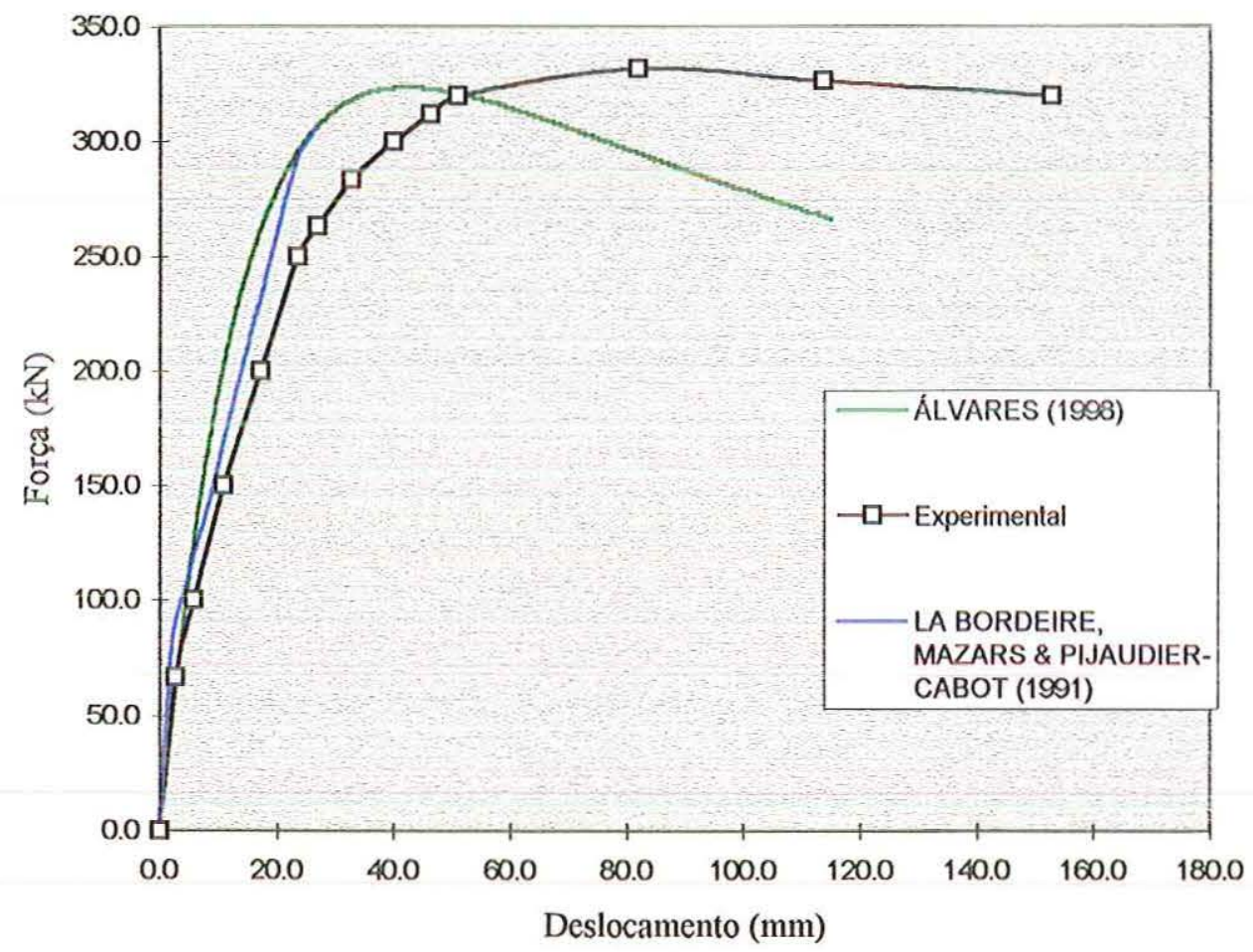

Figura 4.9 - Resultados numéricos do pórtico em concreto armado 
Os resultados apresentados pelo modelo de ÁLVARES (1998) são satisfatórios levando-se em conta o pequeno esforço na obtenção dos parâmetros por se tratar de um modelo bastante simplificado, além do baixo número de iterações apresentado pelo programa durante a resolução numérica do problema, evidenciando assim um pequeno esforço computacional.

Em VECCHIO \& EMARA (1992) é relatado que o pórtico experimentou a primeira fissura na carga de $52,25 \mathrm{kN}$ numa viga do pórtico situada no primeiro andar. Na simulação numérica, as variáveis de dano atingiram valores positivos para esta mesma viga (elemento 6, nós 2 e 5 , figura 4.10) na carga de $38,68 \mathrm{kN}$. Os valores de dano nos outros membros do pórtico estavam nulos nesta fase de carregamento. No teste experimental, fissuras na base das colunas ocorreram na carga de $93,00 \mathrm{kN}$. A primeira plastificação no teste experimentai ocorreu na carga de 264 $\mathrm{kN}$ na viga do primeiro andar. Deformações plásticas surgiram na simulação pela primeira vez no mesmo elemento (elemento 6, nó 2 , figura 4.10) na carga de $249 \mathrm{kN}$. A plastificação na base das colunas ocorreu em 323 kN e na simulação em 306 kN. A carga última observada durante o experimento foi de $332 \mathrm{kN}$, entretanto na simulação ocorreu a carga última foi de $323,70 \mathrm{kN}$. A discretização do pórtico utilizada na simulação numérica está ilustrada na figura a seguir:

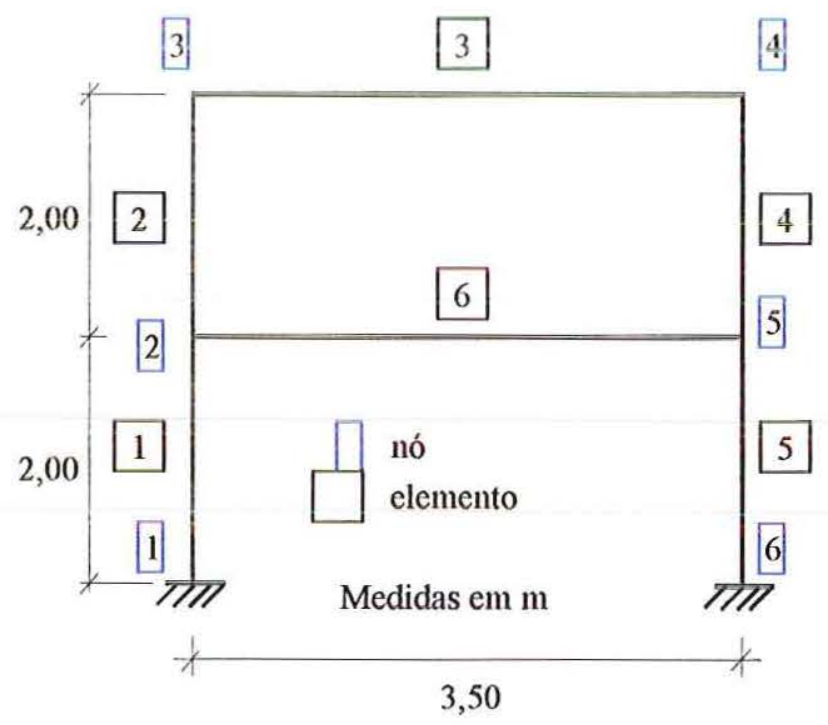

Figura 4.10 - Discretização adotada na simulação numérica com o modelo de ÁLVARES (1998) 
O mecanismo de falha do pórtico em concreto armado obtido na simulação numérica pelo modelo de ÁLVARES (1998) está indicado na figura abaixo:
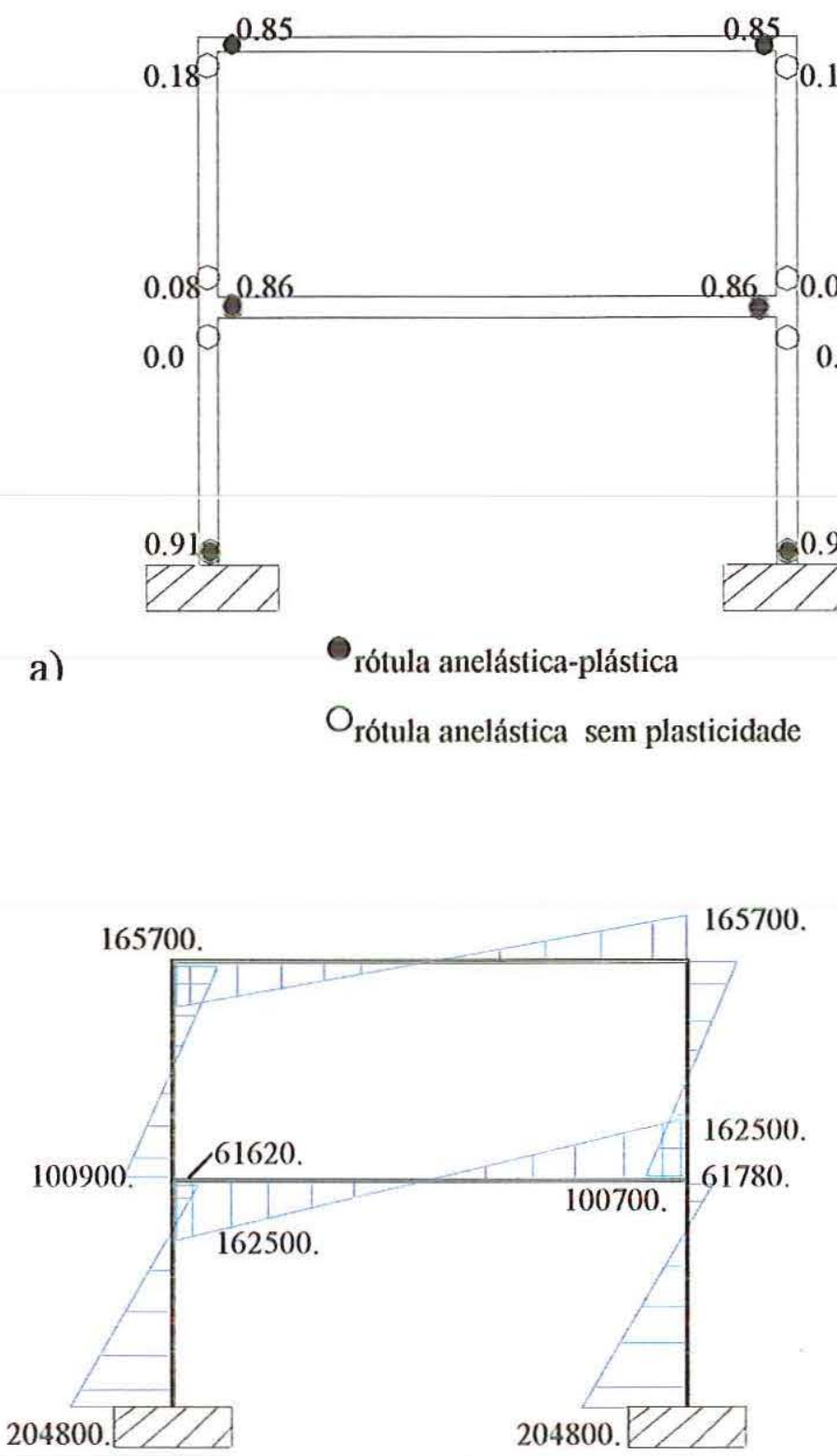

b)

Figura 4.11 - Estado do pórtico na carga última

a) Rótulas plásticas e de dano. b) Diagrama de momentos fletores em kN.mm

Para o caso do modelo de LA BORDERIE, MAZARS \& PIJAUDIERCABOT (1991), o valor da carga numérica de ocorrência da primeira fissuração foi 
de $64,07 \mathrm{kN}$. Durante o desenvolver da curva carga $\mathrm{x}$ deslocamento este modelo melhor se aproximou dos resultados experimentais, porém ainda apresentando um comportamento mais rígido que a curva experimental. A carga última não foi capturada pelo modelo sendo atingido um valor de carga de $307 \mathrm{kN}$. Vários testes foram feitos, entre eles o refinamento do incremento de deslocamento, mas pensa-se que isso é devido a fatores paramétricos do modelo, evidenciando assim uma sensibilidade do modelo com relação a variação dos seus parâmetros. Os dois modelos utilizaram nas análises numéricas um controle de deslocamento para evidenciar a resposta experimental do pórtico no comportamento pós-pico (ramo 'softening'). No modelo de LA BORDERIE, MAZARS \& PIJAUDIER-CABOT (1991) houve muitas iterações, dando uma amostra do esforço computacional bastante elevado se comparado ao modelo de ÁLVARES (1998).

Em resumo, o modelo proposto por ÁLVARES (1998) apresenta um comportamento semelhante à curva experimental até a região próxima de influência do processo de início de dano, porém captura a carga última do pórtico de forma bastante satisfatória. Já o modelo LA BORDERIE, MAZARS \& PIJAUDIERCABOT (1991) apresenta o mesmo comportamento citado anteriormente para o outro modelo, e ainda melhor acompanha a curva carga $\mathrm{x}$ deslocamento no trecho que segue a primeira fissuração, porém não consegue capturar a carga última do pórtico.

Para o caso deste pórtico em concreto armado, que apresenta carregamentos apenas nodais, o modelo de ÁLVARES (1998) se comportou de forma satisfatória, pois nesse pórtico evidenciou-se uma concentração maior de fenômenos dissipativos nos nós, tais como plasticidade e dano, diferentemente no que se passou nas vigas do exemplo anterior, parecendo bastante razoável a hipótese assumida por este modelo de concentração destes fenômenos em rótulas, porém existe a ocorrência de fenômenos nas barras, logo o modelo de LA BORDERIE, MAZARS \& PIJAUDIERCABOT (1991) melhor se adaptou ao exemplo pois o mesmo leva em conta dano e deformações anelásticas nas barras.

O que deve-se ressaltar é que o esforço computacional envolvido na análise numérica do pórtico em concreto armado por parte do modelo de ÁLVARES (1998) foi muito menor que o modelo de LA BORDERIE, MAZARS \& PIJAUDIER- 
CABOT (1991). Entretanto a dificuldade na obtenção dos parâmetros deste modelo, é compensada pela boa qualidade dos resultados evidenciados no exemplo em questão. 


\section{CONSIDERAÇÕES FINAIS, CONCLUSÕES E PERSPECTIVAS}

Neste trabalho abordam-se modelos constitutivos para o concreto fundamentados na Mecânica do Dano, através do estudo de aspectos relativos à sua formulação teórica e aplicação na simulação numérica do comportamento de estruturas. Destacam-se, nas aplicações, os chamados métodos simplificados de análise estrutural.

Inicialmente foram comentadas, de forma resumida, diversas formulações empregadas na simulação do comportamento não-linear do concreto e alguns aspectos do seu comportamento mecânico, discutindo-se individualmente as deformações permanentes, a resposta unilateral e a anisotropia do material. Em seguida relataram-se algumas evidências experimentais de dano no concreto com base em trabalhos contidos na bibliografia consultada, justificando-se assim a formulação de modelos constitutivos para o concreto fundamentados na Mecânica do Dano Contínuo.

Para um melhor entendimento do trabalho e limitando-se o nível de entendimento naquilo que interessa, foram apresentados o método do estado local e um formalismo da Mecânica do Dano atendendo aos princípios da termodinâmica em processos irreversíveis.

No capítulo 3, apresentaram-se os modelos constitutivos para o concreto utilizados durante o desenvolvimento deste trabalho.

Inicialmente foi descrito o modelo de dano escalar, proposto por MAZARS (1984), para o concreto submetido a carregamento proporcional crescente. Este modelo relaciona o processo de evolução da microfissuração (dano) com a presença 
de deformações por alongamento. Foram expostas as hipóteses básicas assumidas pelo modelo, o critério de início e propagação de dano, a lei de evolução da variável escalar representativa do processo de deterioração, além da influência da variação de cada parâmetro no desenvolvimento da curva tensão-deformação.

Neste mesmo capítulo, uma extensão do modelo de MAZARS (1984) para o caso de comportamento unilateral do concreto foi descrita. Foi incluído também um estudo feito por PAPA \& PROENÇA (1992) mostrando a possibilidade de perda de unicidade de solução na simulação da resposta unilateral do concreto com este modelo, justificando assim o estudo de modelos mais completos. Em seguida, o modelo proposto por LA BORDERIE, MAZARS \& PIJAUDIER-CABOT (1991) foi exposto, destacando-se as hipóteses básicas assumidas pelo mesmo, as leis de evolução das variáveis representativas de dano, e um estudo da influência de cada parâmetro na resposta do modelo. Na sua formulação é levado em conta o aspecto unilateral através da definição de duas variáveis, representativas do dano em tração e do dano em compressão. A ativação de um ou outro processo de danificação é feita através de um controle sobre o sinal das tensões principais. Consideram-se também deformações anelásticas.

Ainda no capítulo 3, o modelo proposto por FLÓREZ-LÓPEZ (1993) foi abordado. Este modelo admite que toda a energia dissipada se concentra em 'rótulas', enquanto que o comportamento da barra permanece elástico. Também foi exposto o ensaio numérico realizado por FLÓREZ-LÓPEZ (1993) para a identificação das leis de evolução das funções de dano e de plasticidade utilizadas pelo modelo.

Finalmente, o modelo proposto por ÁLVARES (1998) foi apresentado. Este modelo é uma extensão do modelo de Flórez-López introduzindo um número maior de graus de liberdade e gerando, portanto, uma nova matriz de rigidez para o elemento. Um estudo de variação paramétrica do modelo de ÁLVARES (1998) foi exposto.

Os resultados obtidos com os modelos foram resumidos em dois exemplos no capítulo 4, onde foram confrontadas as respostas numéricas fornecidas pelos modelos com as respostas experimentais colhidas na bibliografia consultada. 
No caso do exemplo das vigas, os resultados fornecidos pelo modelo de LA BORDERIE, MAZARS \& PIJAUDIER-CABOT (1991) tiveram destaque colhendo bastante bem todo o comportamento das três vigas ensaiadas. Este modelo incorpora as deformações permanentes, concluindo-se que esse fenômeno é de importância nas vigas pouco armadas. O modelo de MAZARS (1984), por não incorporar deformações permanentes nas suas hipóteses básicas, gerou resultados bons principalmente nas vigas muito armada e normalmente armada. Na viga sub-armada evidenciou-se uma certa limitação para o emprego do modelo, talvez devido à importância das deformações permanentes; mesmo assim sua resposta pode ser considerada satisfatória. Já o modelo de ÁLVARES (1998) por concentrar os processos dissipativos de dano e de plasticidade em rótulas, não permitiu colher boas respostas, porém a forma da suas curvas para as três vigas foram similares às curvas experimentais. É importante observar que no caso do carregamento considerado, gera-se uma zona central, de comprimento correspondente a um terço do vão, onde o momento fletor é constante. O panorama real de fissuração é totalmente distribuído nessa zona e, portanto, com a hipótese de rótulas não é possível capturar esses fenômenos com boa precisão. Destaca-se também que em todos os casos o comportamento da curva na região de pico permitiu reproduzir a carga máxima.

No exemplo do pórtico em concreto armado, o modelo de ÁLVARES (1998) apresentou boa resposta até a região de início do processo de fissuraçao e capturou, de forma bastante satisfatória, o comportamento na região de pico da curva carga $\mathrm{x}$ deslocamento, levando-se em conta o pouco trabalho na obtenção dos parâmetros utilizados para a simulação numérica da estrutura, além do pouco esforço computacional empregado. Com o modelo de LA BORDERIE, MAZARS \& PIJAUDIER-CABOT (1991), mostrou-se um melhor comportamento da curva carga $\mathrm{x}$ deslocamento, porém não foi possível capturar o comportamento nas regiões de pico e pós-pico, evidenciando assim uma grande sensibilidade do modelo com relação à variação dos parâmetros, além de um esforço computacional grande empregado na simulação numérica da estrutura. 


\section{Conclusões Gerais e Perspectivas}

Quanto às etapas do trabalho, deve-se destacar o estudo dos modelos abordados formando um texto básico sobre a modelagem numérica de modelos fundamentados na Mecânica do Dano. Sendo analisada também a termodinâmica e o método do estado local.

Com relação ao campo numérico, pode-se destacar a utilização do modelo proposto por ÁLVARES (1998), um modelo que leva em consideração fenômenos importantes que ocorrem no concreto tais como a plasticidade e o dano, destacandose o emprego de elementos finitos de barra e o seu esforço computacional reduzido, dando uma estimativa de resuitados que um engenheiro poderia obter na análise de estruturas com um baixo custo computacional. Outro destaque é a potencialidade apresentada pelo modelo proposto por LA BORDERIE, MAZARS \& PIJAUDIERCABOT (1991), porém para o caso do pórtico verificou-se sua grande sensibilidade paramétrica. Já o modelo de MAZARS (1984) apresentou resultados satisfatórios considerando-se as hipóteses simplificadoras adotadas pelo mesmo.

Como considerações gerais entende-se que o modelo de MAZARS (1984) pode ser estendido para sua aplicação em situações mais próximas da realidade, fazendo-se para isso, por exemplo, a incorporação de procedimentos tais como a plastificação das armaduras, localização de deformações permanentes e a consideração da interação entre o concreto e a armadura.

Para o modelo proposto por LA BORDERIE, MAZARS \& PIJAUDIERCABOT (1991) sugere-se um estudo da sensibilidade paramétrica do modelo, pois durante a formulação de qualquer modelo entende-se que não só a etapa de estudo dos fenômenos ocorridos na microestrutura do material e sua associação com variáveis que representem tais fenômenos devam ser levadas em conta; também um estudo numérico e matemático do comportamento através de uma análise de sensibilidade do modelo deve ser feito.

Outra sugestão, seria o emprego de procedimentos que visem uma aplicą̧ão mais prática na obtenção dos parâmetros do modelo de ÁLVARES (1998), como por 
exemplo uma associação dos momentos necessários calculados com a Norma para concreto armado, tornando-se assim um modelo de grande aplicabilidade no cálculo da carga de ruína de pórticos em concreto armado. Esses argumentos citados acima e outros de igual importância, constituem, sem sombra de dúvidas, um amplo campo de pesquisas a ser explorado. 


\section{REFERÊNCIAS BIBLIOGRÁFICAS}

ÁLVARES, M. S. (1993). Estudo de um modelo de dano para o concreto: formulação, identificação paramétrica e aplicação com emprego do método dos elementos finitos. Dissertação de Mestrado - Escola de Engenharia de São Carlos, Universidade de São Paulo.

ÁLVARES, M. S. (1998). Estudo de um modelo de dano para o concreto: formulação, identificação paramétrica e aplicação com emprego do método dos elementos finitos. Tese de Doutorado, em andamento - Escola de Engenharia de São Carlos, Universidade de São Paulo.

ARGYRIS, J. H. et al. (1974). Recent developments in the finite element analysis of prestressed concrete reactor vessels. Int. J. Nuclear Eng. And Design, v. 28.

AMERICAN SOCIETY OF CIVIL ENGINEERS - ASCE (1982). State of the art report on finite element analysis of reinforced concrete. New York.

BATHE, K. J. (1982). Finite element procedures in engineering analysis. Prentice Hall, Englewood Cliffs.

BAZANT, Z. P.; KIM, S. S. (1978). Plastic fracturing theory for concrete. In: ASCE CONVENTION, Chicago, Oct.

BENDITO, A.; THOMSON, E.; FLÓREZ-LÓPEZ (1997). Fatiga oliglocíclica en elementos estructurales de concreto armado. XXVIII Jornadas Sul-americana de Engenharia Estrutural, São Carlos, São Paulo, pp. 2079-2087.

BERTHAUD, Y. (1991). Mesures et modelisations de l'endommagement des materiaux. Laboratoire de Mecanique et Technologie, Cachan, France. 
BERTHAUD, Y.; LABORDERIE, C.; RAMTANI, S. (1990). Damage modeling and cracking closure effect. Damage Mechanics in Engineering Materials, v. 24, pp. 263-273, Nov.

BUYUKOZTURK, O.; NILSON, A. H.; SLATE, F. O. (1972). Deformation and fracture of particulate composite. J. Eng. Mech., ASCE, v. 98, n. EM3, Jun.

CEDOLIN, L. (1982). Leggi constitutive e criteri di rottura per il calcestruzzo. Genova, Atti dell'Istituto do Meccanica Teorica ed Applicata dell'Universita degli Studi di Udine.

CEDOLIN, L.; CRUTZEN, Y. R. J.; POLI, S. D. (1977). Triaxial stress-strain relationship for concrete. ASCE, J. of Eng. Mech. Div., v. 103, n. EM3, Jun.

CHABOCHE, J. L. (1988). Continuum damage mechanics: part I - general concepts. Journal of Applied Mechanics, vol. 55, pp. 59-64.

CHEN, A C. T.; CHEN, W. F (1975). Constitutive relations for concrete. J. Eng. Mech. Div., ASCE, v. 101, n. EM4, Aug.

CHEN, W. F.; SALEEB, A. F. (1982). Constitutive equations for engineering materials. John Wiley \& Sons, v. 1.

CIPOLLINA, A; FLÓREZ-LÓPEZ, J. (1995). Modelos simplificados de daño en pórticos de concreto armado. Revista Internacional de Métodos Numéricos para Cálculo y Diseno en Ingenieria, v. 11, n.1, pp. 3-22

CIPOLLINA, A.; LÓPEZ-INOJOSA, A.; FLÓREZ-LÓPEZ, J. (1995). A simplified damage mechanics approach to non-linear analysis of frames. Computers and Structures, v. 54, n.6, pp. 1113-1126. 
DIAZ, S. I.; HILSDORF H. R. (1971). Fracture Mechanisms of concrete under static, sustained and repeated compressive loads. Civil Engineering Studies, Structural Research Series n. 382, University of Illinois, Urbana, Aug.

DOUGILL, J. W. (1976). On stable progressively fracturing solids. Z. Angew Math. Phys. (ZAMP), v. 27, n. 4.

DRAGON, A. (1976). On phenomenological description of rock-like materials with account of kinetics of brittle fracture. Archives of Mechanics, v. 28, pp. 13-30.

DRAGON, A.; MROZ, Z. (1979). A continuum model for plastic-brittle behaviour of rock and concrete. Int. J. Eng. Science, v. 17, pp. 121-137.

DRIEMEIER, L. (1995). Considerações sobre a fadiga em metais e o comportamento do concreto sob solicitação cíclica. São Carlos. Dissertação (Mestrado) - Escola de Engenharia de São Carlos, Universidade de São Paulo.

FLÓREZ-LÓPEZ, J. (1993). Modelos de daño concentrado para la simulation numerica del colapso de pórticos planos. Revista Internacional de Métodos Numéricos para Cálculo y Diseno en Ingenieria, v. 9, n.2, pp. 123-129.

FLÓREZ-LÓPEZ, J. (1993). Calcul simplifié de portiques endommageables. Revue Européenne des élements finis, vol. 2, n. 1, pp. 47-74.

FUNG, Y. C. (1965). Foundations of solid mechanics. Prentice-Hall.

GAMBAROVA, P. G.; FLORIS, E. (1986). Microplane model for concrete subjected to plane stress. Nuclear Eng. and Design, v. 97.

GERMAIN, P. (1973). Cours de mécanique des milieux continus. Tome I, Universidade de Paris. 
HAN, D. J.; CHEN, W. F. (1986). Strain space plasticity formulation for hardening softening material with elastoplastic coupling. Int. J. Solids \& Struct., v. 22, n. 8.

HAN, R. P. S.; MOU, Y. (1993). Void induced damage in ductile materials. In: $14^{\text {th }}$ CANCAM, Kingston, Ontario.

HILSDORF, H. K. (1969). Drying and shrinkage of concrete and reinforced concrete structures. Ernst and Sohn.

HSU, T. C. et al. (1963). Micro-cracking of plain concrete and the shape of the stress-strain curve. A. C. I. Journal, v. 60.

INGLESSIS, P.; GÓMEZ, G.; QUINTERO, G.; FLÓREZ-LÓPEZ, J. (1997). Modelos simplificados de daño para el análisis de estructuras de acero. XXVIII Jornadas Sul-americana de Engenharia Estrutural, São Carlos, São Paulo, pp. 2149-2157.

JAEGER, J. C.;COOK, N. G. W. (1979). Fundamentals of rock mechanics. Third Edition, Chapman and Hall, London.

JANSON, J.; HULT, J. (1977). Fracture mechanics and damage mechanics a combined approach. Journal de Méchanique Appliquée, v. 1, n. 1, pp. 69-84.

KACHANOV, L. M. (1958). Time of the rupture process of non-linear solid mechanics. Otd. Tech. Nauk., v. 8, pp. 28-31.

KACHANOV, L. M. (1984). On brittle fracture of a thin plastic interlayer in creep conditions. In: DVORAK, G.; SHIELD, R., ed. Mechanics of Material Behavior. Amsterdam, Elsevier. 
KACHANOV, L. M. (1986). Introduction to continuum damage mechanics. Martinus Nijhoff Publishers.

LA BORDERIE, C. (1991). Phenomenes unilateraux dans un materiau endommageable: modelisation et application a l'analyse de structures en beton. These de Doctorat de l'universite Paris.

LA BORDERIE, C.; MAZARS, J.; PIJAUDIER-CABOT, G (1991). Response of plain and reinforced concrete structures iunder cyclic loadings. Cachan, France, Laboratoire de Mécanique et Technologie, Rapport Interne, n. 123.

LA BORDERIE, C.; MAZARS, J.; PIJAUDIER-CABOT, G. (1992). Computational modelling of concrete and reinforced concrete based on damage mechanics. In: Computational Plasticity, eds: Owen, D. R. J., Onãte, E., Hinton, E., Barcelona.

LADEVĖZE, P.; LEMAITRE, J. (1984). Damage effective stress in quasi-unilateral conditions, IUTAM Congress, Lyngby, Denmark.

LEMAITRE, J. (1984). How to use damage mechanics. Nucl. Eng. Des., v. 80, pp. 233.

LEMAITRE, J. (1987). Formulation and identification of damage kinetic constitutive equations. Continuum Damage Mechanics: Theory and Applications. C. I. S. M. Courses and Lectures n. 295, eds: Krajcinovic, D. and Lemaitre, J.

LEMAITRE, J.; CHABOCHE, J. L. (1974). A non-linear model of creep-fatigue damage cumulation and interation. In: IUTAM Symp. of Mechanics of Viscoelastic Media and Bodies, Gothenburg. Proc. Springer.

LEMAITRE, J.; CHABOCHE, J. L. (1985). Mécanique des matériaux solids. Paris, Dunod-Bordas. 
LEMAITRE, J.; CHABOCHE, J. L. (1990). Mechanics of solid materials. Cambridge University Press.

LUCCIONI, B. M. (1993). Formulación de un modelo constitutivo para materiales ortotropos. Tese de Doutorado - Universidad Nacional de Tucumán.

LUCCIONI, B. M. ; RAMALlO, J. C.; DANESI, R. (1997). Prediccion del comportamiento de estructuradas reparadas bajo carga. XXVIII Jornadas Sulamericana de Engenharia Estrutural, São Carlos, São Paulo, pp. 1487-1496.

MAJI, A.; SHAH, S. P. (1988). Experimental observation of cracking and damage. Proc. of the France-US Workshop on Strain Localization and Size Effect due to Cracking and Damage, eds: Mazars, J. and Bazant, Z. P., Cachan, France.

MALVERN, L. E. (1969). Introduction to the mechanics of a continuous medium. Prentice-Hall.

MARIGO, J. J. (1985). Modelling of brittle and fatigue damage for elastic material by growth of microvoid. Eng. Fract. Mech., v. 21, pp. 861.

MAZARS, J. (1984). Application de la mécanique de l'endommagement au comportement non lineaire et à la rupture du béton de structure. Thése de Doctorat d'État, Université Paris 6.

MAZARS, J.; BERTHAUD, Y.; RAMTANI, S. (1990). The unilateral behavior of damage concrete. Engineering Fracture Mechanics, v. 35, n. 4/5, pp. 629-635.

MURAKAMI, S. (1981). Effect on cavity distribution in constitutive equations of creep and creep damage. In: EUROMECH Colloque on Damage Mechanics, Cachan, France. 
MURAKAMI, S. (1987). Anisotropic aspects of material damage and application of continuum damage mechanics. Continuum Damage Mechanics: Theory and Applications. C. I. S. M. Courses and Lectures n. 295, eds: Krajcinovic, D. and Lemaitre, J.

OLLER, S.; LUCCIONI, B. M.; BARBAT, A. H. (1996). Un método de evaluación del daño sísmico en estructuras de hormigón armado. Revista Internacional de Métodos Numéricos para Cálculo y Diseño en Ingeniería, vol. 12,2, pp. 215-238.

OLLER, S. et al. (1988a). Un modelo constitutivo de dano plástico para materiales friccionales; parte I: variabiles fundamentales, funciones de fluencia y potencial. Ver. Int. de Met. Num. Para Calc. Y Diseno en Ingenieria, v. 4, n. 4.

OLLER, S. et al. (1988b). Un modelo constitutivo de dano plástico para materiales friccionales, parte II: generalización para processos com degradacion de rigidez. Ejempios. Ver. Int. de Met. Num. Para Calc. Y Diseno en Ingenieria, v. 4, n. 4.

ORTIZ, M. (1985). A constitutive theory for the inelastic behavior of concrete. Mechanics of Materials, vol. 4, pp. 67-93.

OWEN, D. R. J.; FAWKES, A. J. (1983). Engineering fracture mechanics: numerical methods and applications. Pineridge Press Ltd., Swansea, UK.

PAPA, E. (1990). Sulla meccanica del danneggiamento com particolare riferimento alle marature. Tesi de Dottorato, politecnico di Milano.

PAPA, E. (1995). Damage models for mansory structures. In; Engineering mechanics Div,/ASCE, Boulder, Colorado. 
PAPA, E.; PROENÇA, S. P. B. (1992). On numerical instability of a unilateral damage model for concrete. In: Third Int. Conf. On Comp. Plast. - COMPLAS III, Barcelona, Espanha.

PARK, R.; PAULAY, T. (1975). Reinforced concrete structures. Wiley-Interscience Publication, John Wiley \& Sons.

PEREGO, M. (1989). Danneggiamento dei materiali lapidei: leggi constitutive, analisis per elementi finiti ed applicazioni. Tesi di Laurea, politecnico di Milano, Anno Accademico.

PROENÇA, S. P. B. (1988). Sobre modelos matemáticos do comportamento nâolinear do concreto: análise crítica e contribuições. Tese de Doutorado, EESC/USP

PROENÇA, S. P. B. (1991). Meccanica del danneggiamento di materiali e strutture: applicazioni al calcestruzzo. Publicação resultante de pesquisas realizadas no Politecnico di Milano, Itália.

PROENÇA, S. P. B. (1992). Simulação numérica do comportamento de elementos estruturais em concreto e argamassa armada pelo emprego de um modelo de dano. Revista Internacional de Métodos Numéricos para Cálculo y Diseno en Ingenieria, v. 8.4, pp. 351-360.

PROENÇA, S. P. B. (1997). Sobre atividades de pesquisa em mecânica de materiais e análise não-linear de estruturas. Texto de Livre Docência, EESC/USP.

PROENÇA, S. P. B.; ÁLVARES, M. S. (1992). On numerical performance of a damage model applied to analysis of concrete structural members. In: International Congress on Numerical Methods in Engineering and Applied Sciences, Concenpcion, Chile. 
PROENÇA, S. P. B.; ÁLVARES, M. S. (1994). About numerical precision aspects on the use of a continuum damage model to concrete. XV CILAMCE, Belo Horizonte.

PUGLISI, M.; FLÓREZ-LÓPEZ, J. (1994). Lumped damage models for oligocyclic fatigue in RC frames. $3^{\text {rd }}$ International Conference on Computer-Aided Assessment and Control Localized Damage 94.

RABOTNOV, Y. N. (1969). Creep problems in structural members. Amsterdam, North-Holland.

RAMTANI, S. (1990). Contribution à la modélisation du comportement muitiaxial du béton endommagé avec description du caractère unilatéral. Thèse de Doctorat de l’Université Paris 6.

RESENDE, L. (1984). Constitutive modelling and finite element analysis in geomechanics. PhD Thesis, university of Cape Town.

SAENS, L. P. (1965). Equation for stress-strain curve of concrete in uniaxial and biaxial compression of concrete. A. C. I. Journal, v. 61.

SIMO, J. C.; JU, J. W. (1987). Strain and stress based continuum damage models j. formulation. Int. J. Solids \& Structures, v. 23, pp. 821-840.

SPENCER, A. J. M. (1990). Continuum mechanics. Longman Scientific \& Technical.

SPOONER, D. C.; DOUGLL, J. W. (1975). A quantitative assesment of damage sustained in concrete during compressive loading. Magazine of Concrete Research, v. 27, n. 92. 
SPOONER, D. C. et al. (1976). Damage and energy dissipation in cement pastes in compression. Magazine of Concrete Research, v. 28, n. 24.

STUBBS, N.; KRAJCINOVIC, D. (1985). Damage mechanics and continuum modelling. Proceedings of Engineering Mechanics Div./ASCE, Detroit, Michigan.

TAI, W. H. (1990). Plastic damage and ductile fracture in mild steels. Eng. Fract. Mech., v. 37, pp. 853.

VAN LANGENDONCK, T. (1962). Cálculo de concreto armado. Associação Brasileira de Cimento Portland, Comentários à Norma Brasileira NB-1, itens 1 a 13.

VAN MIER, G. M. (1984). Strain-softening of concrete under multiaxial loading conditions. PhD Thesis, Eindhoven Tech. Univ..

VAN MIER, G. M. (1985). Influence of damage orientation distribution on the multiaxial stress-strain behavior of concrete. Cement and Concrete Research, v. 15 , pp. 849-862.

VECCHIO, F. J.; EMARA, M. B. (1992). Shear deformations in reinforced concrete frames. ACI Structural Journal, vol.89, n. 1, pp. 46-56.

XIAOQING, Y. et al. (1989). Review of constitutive models for concrete. Report to Comission of the European Communities Joint Research Centre, ISPRA.

ZIENKIEWICZ, O C.; TAYLOR, R. L. (1989). The finite element method. McGrawHill, 4th Ed.. 


\section{APÊNDICE}

RELAÇÕES DE INTERESSE

\section{FLUXO ATRAVÉS DE UMA SUPERFICIE}

Considere-se uma superficie imaginária fixada no espaço com meio contínuo fluindo através dela. A superficie é identificada no espaço pelo versor normal ñ. $\mathrm{O}$ volume do material fluindo através de uma área infinitesimal da superfície dô $\Omega$ no intervalo de tempo dt é igual ao volume do cilindro com base do $\Omega$ e altura $\underline{y} \mathrm{dt}$ paralela ao vetor velocidade $\underline{v}$. Ver figura 1 . A altura do cilindro é $v_{n} \mathrm{dt}=\underline{v} . \underline{n d t}$. Portanto, o volume no tempo dt é $v_{n} \mathrm{dt} \mathrm{d} \partial \Omega=\underline{v} . \underline{n} \mathrm{dtd} \partial \Omega$ e o fluxo de volume ou volume por unidade de tempo fluindo através de $\mathrm{d} \hat{\partial} \Omega$ é $v_{n} \mathrm{~d} \hat{o} \Omega=\underline{v} . \underline{n} \mathrm{~d} \partial \Omega$.

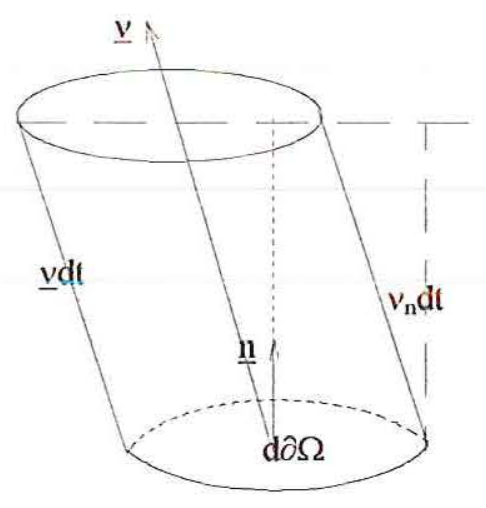

Figura 1 - Fluxo através de d $\partial \Omega$. 
O fluxo total de volume através de uma superfície finita do $\Omega$ é dado pela integral sobre a superficie

$\mathrm{V}=\int_{\partial \Omega} \underline{v} \cdot \underline{n} \mathrm{~d} \partial \Omega$

O fluxo de massa por unidade de área através de dô $\Omega$ é obtido pela multiplicação do fluxo de volume pela densidade local e o fluxo total de massa sobre $\partial \Omega$ resulta:

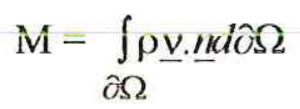

Analogamente, a quantidade ou taxa de calor (condução) que passa pela superficie $\partial \Omega$ por unidade de tempo é dada por:

$\mathrm{Q}=\int_{\partial \Omega} \underline{h} \cdot \underline{n} d \partial \Omega$

onde $\underline{h}$ é o vetor fluxo de calor através da unidade de superficie.

2 CONSERVAÇÃO DE MASSA E EQUAÇÃO DA CONTINUIDADE

Considere-se um volume arbitrário $\Omega$, limitado por uma superficie de um elemento de área $\partial \Omega$, identificado no espaço por um versor normal $\underline{n}$, e um vetor de fluxo $\underline{v}$ a ele associado, como mostra a figura abaixo. 


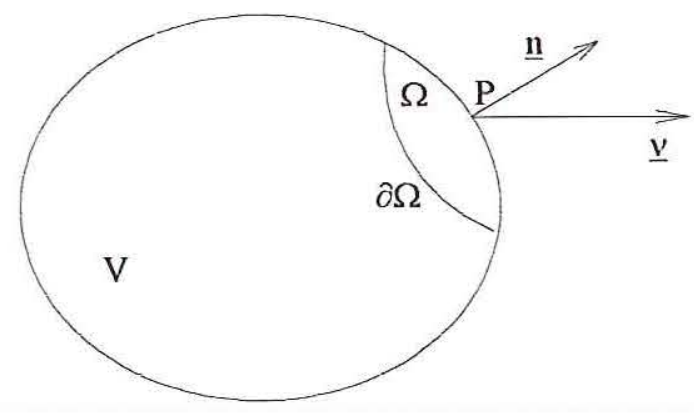

Figura 2 - Volume $\Omega$ no espaço.

Se o meio contínuo de densidade $\rho$ ocupa o volume $\Omega$ no instante t, a massa total em $\Omega$ é

$$
m=\int_{\Omega} \rho d \Omega
$$

A densidade $\rho$ varia, em geral, com a posição e o tempo

$$
\rho=\rho(x, y, z, t)
$$

A existência de uma função densidade contínua associada a um volume representativo dando a massa total como mostra a equação (4) é postulada como parte da definição de um meio contínuo. A variação no tempo da massa total no volume $\Omega$ é:

$$
\frac{\partial m}{\partial t}=\int_{\Omega} \frac{\partial \rho}{\partial t} d \Omega
$$

Se não há massa sendo criada ou destruída no volume $\Omega$, o princípio da conservação de massa afirma que a taxa de massa total do volume $\Omega$ deve ser igual à taxa de massa fluindo através da superficie $\partial \Omega$. 
O fluxo total de massa sobre $\partial \Omega$ é definida pela equação integral (2), sendo o sinal negativo indicando fluxo de massa entrante. Aplicando o teorema da divergência (teorema de Gauss) resulta:

$\mathrm{M}=-\int_{\partial \Omega} \rho \underline{\underline{v}} \cdot \underline{n} d \partial \Omega=-\int_{\Omega} \operatorname{div}(\rho \underline{\underline{v}}) \mathrm{d} \Omega$

Segundo a afirmação do princípio da conservação de massa, reunindo as equações (6) e (7), obtemos o seguinte:

$\int_{\Omega}\left[\frac{\partial \rho}{\partial t}+\operatorname{div}(\rho v)\right] d \Omega=0$

Uma vez que a equação (8) se anula para uma escolha arbitrária do volume $\Omega$, o integrando deve se anular em cada ponto de uma região em que nenhuma massa é criada ou destruída, assumindo que o integrando é uma função contínua. A equação resultante, uma consequência da conservação de massa, é conhecida como equação da continuidade:

$\frac{\partial \rho}{\partial t}+\operatorname{div}(\rho v)=0$

Levando-se em consideração que $\operatorname{div}(\rho \underline{v})=\rho \operatorname{div} \underline{\mathbf{v}}+\operatorname{grad} \rho . \underline{v}$, a equação da continuidade pode ser escrita da seguinte forma:

$$
\frac{\partial \rho}{\partial t}+\rho \operatorname{div} \underline{v}+\operatorname{grad} \rho \cdot \underline{v}=0
$$

Considerando-se $\underline{v}$ como a velocidade da partícula que ocupa a posição $(\mathrm{x}, \mathrm{y}, \mathrm{z})$ na configuração atual, a expressão anterior passa a 
$\rho^{\prime}+\rho d i v \underline{v}=0$

sendo a derivada material de $\rho$

$\rho^{\prime}=\frac{\partial \rho}{\partial t}+\operatorname{grad} \rho \cdot \underline{v}$

No caso particular de material incompressível, a densidade na vizinhança de cada partícula material permanece constante enquanto ela se move, portanto

$\frac{\partial \rho}{\partial t}+\operatorname{grad} \rho \cdot \underline{v}=0$

e a equação da continuidade toma a seguinte forma:

$\operatorname{div} \underline{v}=0$ 